\title{
THE ONTOLOGY OF MUSICAL OBJECTS IN CONTEMPORARY INSTRUMENTAL COMPOSITION
}

\author{
BY \\ JASON WILLIAM POST
}

A Thesis submitted in partial fulfillment of the requirements for the degree of Master of Music in the New Zealand School of Music, 2015

Wellington, New Zealand 


\section{Abstract}

The musical object occupies a strange place in music criticism. The new musicology schools influenced by post-structuralist continental thought have shied away from the object's autonomous existence, exemplified by Christopher Small's view of music as a cultural activity: "musicking." Other theorists, such as Dennis Smalley, have created taxonomies of musical sound. Smalley's spectromorphology defines sonic typologies that he claims to be based on an experiential understanding of sound, while simultaneously undertaking the technical project of a systematic cataloguing of sounds. Both views inhabit quite opposite positions in relation to the sound object - either a total rejection of its reality or a positivistic attempt at a catalogue of sound types. Both of these approaches suffer from distancing the sonic object through their respective discourse: by reducing the importance of the object for the sake of viewing music as a network of cultural relations, or by reducing it to an idealized and rationalized object, seeing it as just the product of a bundle of auditory qualities unified by perception. These views introduce a distance from auditory experience, which is at its core an object-oriented experience. In other words, neither meets the musical object on its own level, and because of this, they deny or caricature the musical object's ontology.

Graham Harman's philosophical study of Object-oriented Ontology is a radicalization of Heideggerian phenomenology. Through a new reading of Heidegger's tool-analysis, Harman argues that objects - whether real, living, non-living, ideal or abstract - are the primary location of ontological investigation, and that objects exist both discretely and as a part of a wider network of possible relationships. By viewing the object this way, and by recognizing the multifaceted and multidimensional features of the musical object, we may be able to account for features of music that the trends above are unable to recognize or assess, such as the twentieth century aesthetic practices of György Ligeti, Salvatore Sciarrino, and the Spectral school of composition. It is possible to read these composer's aesthetics as object-oriented because they are so strongly focused on examining sonic objects themselves -whether it is a physical event or modeling a natural process - instead of examining objects only through their affective potential towards human beings. This 
practice suggests that these qualities and processes are themselves areas for possible contemplation. Historically, this move away from an emphasis on the human-world binary goes against the nineteenth century aesthetic of Romanticism, which relies on an object's affective potential. Also, an object-oriented position rejects formalism, because of its reduction of music to an intellectual activity. An object-oriented approach to music traverses the line between these two positions, acknowledging the subtle and shifting relationships between the affective and the analytic or, to locate this within Harman's approach, between the sensual and real. The thesis will explore the implications of an object oriented approach to music, trace the history of its development in relation to music - chiefly that of the twentieth and twenty-first centuries - as well as make object oriented analyses of selected works, including my own compositions. 


\section{Acknowledgements}

My thanks go to everyone who helped me during my compositional and academic research.

My supervisors, Michael Norris and Dugal McKinnon: their expertise, patience, and support have been invaluable in not only this thesis, but throughout my time at the New Zealand School of Music. Their rigor and enthusiasm in both composition and musicology have continually stimulated and expanded my academic interests.

The New Zealand School of Music, for the generous scholarship that enabled me to undertake this project, and David Cosper and Michael Norris for taking me on as a teaching assistant. The experience teaching over the past year has been an enjoyable introduction to the responsibilities of an academic life. I was also fortunate to receive the Jenny McLeod Award for Orchestral Composition, which enabled me to write for the NZSM orchestra.

The NZSM Orchestra for a wonderful first performance of my work. The New Zealand String Quartet for their generosity in workshopping student compositions - a gesture I have repeatedly benefited from. Also, Asher Norris, who agreed to perform my work for organ at short notice.

Andrew Cole, Karlo Margetic, Blake Johnson, Richard Robertshawe, Reuben Jelleyman, Dorothy Ker, John Psathas, Ken Young, and the SMP Ensemble, for their enthusiasm and support for the thesis and portfolio.

And Lucy Alston - for everything. 


\section{Contents}

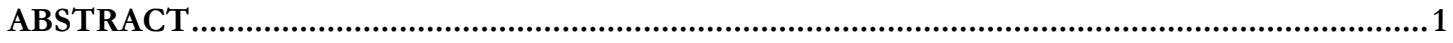

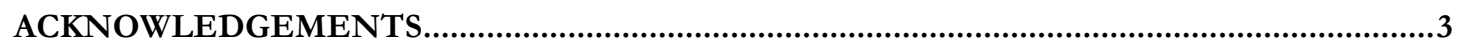

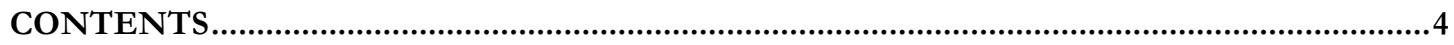

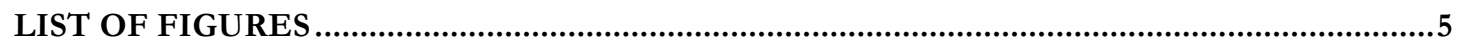

INTRODUCTION: PRESENCE, ABSENCE, AND OBJECT-HOOD ...................................6

1. THE MUSICAL OBJECT: ABSTRACTION AND ONTOLOGY ........................................ 13

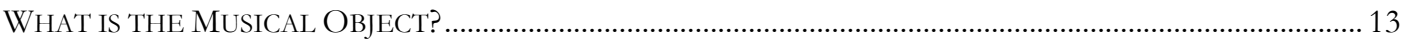

THE QUADRUPLE OBJECT .................................................................................................................................. 17

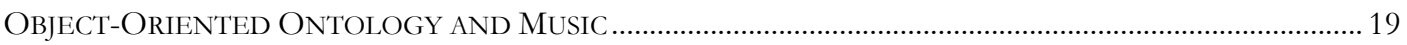

2. INTERACTIONS IN THE FOURFOLD OF A MUSICALLY ORIENTED OBJECT

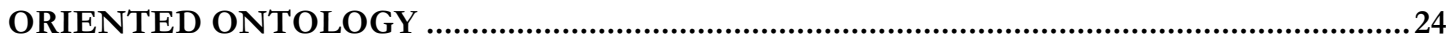

A DEEPER LOOK INTO THE FOURFOLD ……….......................................................................................... 25

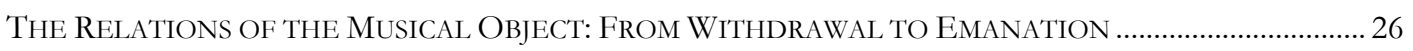

The Shadow of the Fourfold: Allure And the Aesthetic Power of Objects .......................... 33

3. CORRELATIONISM AND CARICATURE: AN EXAMINATION OF MUSICAL OBJECTS IN THE COMMON PRACTICE, EARLY ATONAL, AND INTEGRAL SERIALIST PERIODS

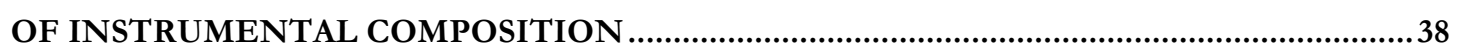

CARICATURE AND NATURE IN THE COMMON PRACTICE ……................................................................... 40

STRANGE WORLDS IN SCHOENBERG’' EARLy ATONAL PERIOD .................................................................. 44

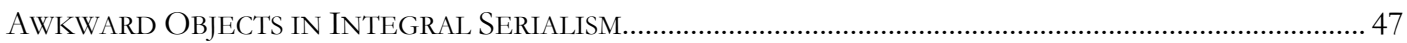

4. TIMBRE, TEXTURE AND OBJECT ORIENTED MUSIC, AND AN EXAMINATION OF

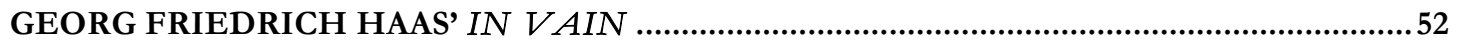

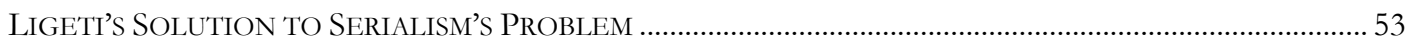

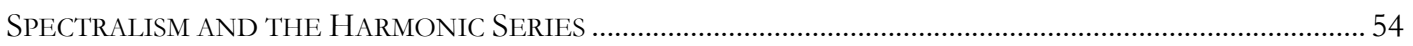

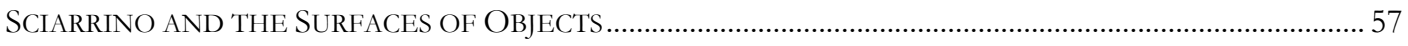

NATURE, Process, AND the HARMONIC SERIES: OBJECTS AND ORgANIZATION IN GEORG FrIEDRICH

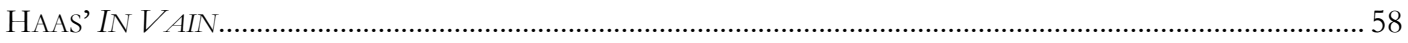

CONCLUSION: COMPOSITION AS CARPENTRY, AND RECONCILING COMPOSER AND

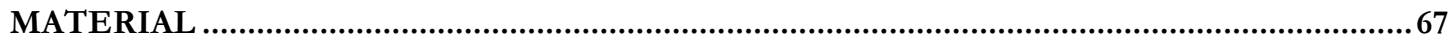

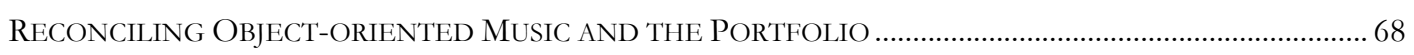

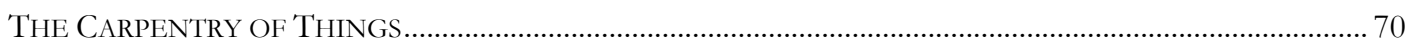

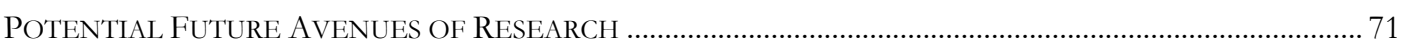

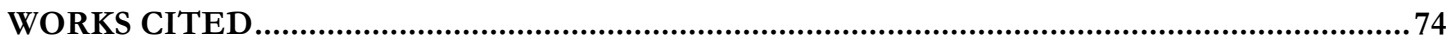




\section{List of Figures}

FIGURE 1: HARMAN'S 'FOURFOLD'

FIGURE 2: THE BROKEN LINKS OF THE FOURFOLD

FIGURE 3: TYPES OF CARICATURE RELATIONSHIPS IN BACH'S FOURTH INVENTION

FIGURE 4: MELCHIOR DE HONDECOETER: CONCERT OF BIRDS 43

FIGURE 5: STOCKHAUSEN'S SERIAL SQUARE. 49

FIGURE 6: SERIES PRIME FORM IN KLAVIERSTÜCKE VIII. 50

FIGURE 7: THE HARMONIC SERIES MATERIAL USED IN IN $V A I N$ 63 FIGURE 8: THE CHROMATIC SCALE, ALSO KNOWN AS THE LAMENTO MOTIF 64 


\title{
Introduction: Presence, Absence, and Object-hood
}

\author{
"Wordless music, in its sonorous incarnation, when compared to language, is "opaque," as nothing is shown \\ through the music. The music presents itself; it is a dense embodied presence.' \\ Don Idhe (155)
}

'To say that the world is filled with objects is to say that it is filled with countless tiny vacuums, like those bubbles that the Pythagoreans thought had been inhaled by the universe itself. What guerrilla metaphysics seeks is the vacuous actuality of things.' Graham Harman (Guerrilla 82)

To hear is to perceive, and yet what we hear is always evanescent. The kind of auditory presence that Don Idhe describes is more explicitly time-based than the visual presence of an art object. The visible object never disappears, and yet one can choose to look away. The audible object fades as soon as it is present, but it is far more difficult to ignore. To understand the object-hood of sound - and therefore music - is to understand its presence as a temporary force on hearing. What remains for listeners beyond that may be an afterglow, memory, or idea. The sound withdraws from perception, only to continue its existence in the mind. These two aspects of sound can be understood in terms of the real and the sensual. Martin Heidegger describes this phenomenon in relation to tools. When we use a hammer, it is ontologically the closest thing to us and becomes an extension of us through becoming invisible to the mind (ready-at-hand or Vorbanden). Yet if the hammer breaks, we are left with a tool revealed to us in all its surface and accidental qualities (present-at-hand or Zubanden). This theory can be understood as the foundation for all of Heidegger's thought - that objects exist in two realities: they are either present or absent to conscious perception.

However, Graham Harman argues that Heidegger has this dichotomy reversed. When a hammer is being used, it is far more present to the mind in terms of human access, but when it breaks, the object becomes withdrawn, and enacts a reality in which the hammer user has limited access. In Harman's words: 
The tool isn't used, it is. What saves the bridge from being a mere pile of iron and asphalt is not the fact that people find it convenient, but the fact that any pile of anything exerts some sort of reality in the cosmos, altering the landscape of being in some distinct way. If this reality happens to be useful for people, so much the better. But natural mountain passes and other obstacle have no less equipmentality than an artificial tunnel. (Harman Speculative 98)

Graham Harman's position on Heidegger's tool analysis gave rise to his theory of objectoriented ontology (OOO). OOO is a relatively new field that began with Harman's doctoral thesis Tool-being: Heidegger and the Metaphysics of Objects, submitted in 1999. Harman's theories stem from the phenomenological school of thought, generalized to such a degree that many of the issues in phenomenology are posited by Harman to exist within everything, not just human beings - from animals and particles, to inanimate objects. The consequence of this extension of phenomenology is that objects proliferate in the extreme: there are only objects, and even relationships between objects become objects themselves. This brings phenomenology back into the territory of metaphysics because, as Harman argues, there is an implicit anti-realism at the heart of post-Kantian philosophy, including conventional phenomenology. Both Husserl and Heidegger vacillate as to the possibility of knowing the world beyond experience, and the phenomenologists who inherited their thought have continued this pattern, often by ignoring the issue of the real world altogether, as in Emmanuel Levinas and Maurice Merleau-Ponty (Harman Quadruple 44). Harman continues:

\begin{abstract}
It is the "what difference does it make?" approach to philosophy, too often accompanied by contorted facial expressions, and too often aimed at those who have labored subtly and patiently for years at issues that critics take only a few seconds to dismiss. In fact, the question of whether the world is real or not for phenomenology makes a buge difference, since it bears directly on the internal structure of phenomena themselves. (Guerrilla 41)
\end{abstract}

This metaphysical discussion may initially seem to have little bearing on music, which is a cultural and artistic activity bound with human perception. Nevertheless, this debate is relevant because musicology itself is deeply invested in this kind of anti-realism. Much, if not most, contemporary musicology is deeply influenced by the cultural theorists of the linguistic turn, ${ }^{1}$ which shares the anti-realist sentiments of post-Kantian continental philosophy. This distrust of twentieth-century continental theory is what unifies the speculative realists, a broad movement in which object-oriented ontology is but one

\footnotetext{
${ }^{1}$ New Musicology takes significant influence from the New Criticism school of literary theory, such as 'The Intentional Fallacy' by Wimsatt and Beardsley, the formalist ideas of Cleanth Brooks, 'The Death of the Author' by Roland Barthes, and Jacques Derrida's deconstructionism, specifically 'Structure, Sign, and Play.'
} 
school. The idea they broadly oppose - called the principle of correlation by Quentin Meillassoux - is that one cannot think about the world without considering the structure of thought itself. Musicology is entwined with this hermeneutic circle, which is the principle of correlation as applied to texts or artworks: the idea that one cannot understand a work without considering its cultural context and creation, and vice versa. In the extreme view of hermeneutics, nothing exists without a human to witness and interpret it. This idea has fueled the research of musicologists Tina DeNora, Nicolas Cook and Lydia Goehr, whose work attempts to understand music in social, cultural and historical terms. Phenomenological approaches in music such as Schaeffer's l'objet sonre, and Don Idhes's musical phenomenology equally rely on hermeneutics. Despite Schaeffer's interest in the object, he sees it as a tool to learn more about the self rather than the object. In Schaeffer's words:

\begin{abstract}
The age of mechanism, denounced wrongly by Pharisees of spiritualism, is the age of the most inordinate human sensibility. It is not solely a question of machines for making, but of machines for feeling which give to modern man tireless touch, ears and eyes, machines that he can expect to give to him to see, to hear, to touch what his eyes could never have shown him, his ears could never have made him hear, to touch what his hands could never have let him touch. As this enormous puzzle, which knowledge of the exterior world is, composes itself, strengthens itself, verifies itself and finally 'sets' into shape, man recognises himself in it: he finds in it the reflection of his own chemistry, his own mechanisms (92).
\end{abstract}

Given the significant constraints of the correlationist view, it is not entirely clear how musicology can develop further, as it seems condemned to repeat the hermeneutic circle, much like a snake eating its own tail. Object-oriented ontology is radical because it flattens the hermeneutic hierarchy, and acknowledges the limitations of a human understanding of the world.

Music, like all artistic practices, is a cultural activity in which objects are always filtered though our own knowledge and senses. However, the development offered by an objectoriented musicology is that the work is not considered only as a product of a culture, or a theoretical system of organization, but rather as a force upon the world. This allows us to think about the object-hood of musical works in their relationship to the world and other objects. This shifts the emphasis of musicology from a strictly subject-object correlation, in which the human subject determines and dominates the object, to include the wider possibilities of object-object relationships in which objects and subjects are on the same ontological level. This is not a way out of the hermeneutic circle as such, but rather a 
recognition that objects themselves are engaged in their own kind of hermeneutics, and that human beings are part of a larger system in which objects determine us as much as we do them.

In order to outline an object-oriented musicology, enquiry must begin with a phenomenological discussion in order to make clear the nature of the intervention such a musicology represents. The approach taken in this thesis is not so much to weigh the values of different methodologies, but rather to focus on how we can use different means of investigating music to produce a wider picture. The truly interesting part however is the underside of this task: a speculation on the nature of what we cannot access through these various means of experience. Kant called this object the Noumenon (86), Adorno called it the non-identical (119), and Heidegger calls it that which is ready-to-hand, or quhanden (Being 72). This underside of the object is what the field of 'object-oriented ontology' is concerned with. To explore this, an object-oriented musicology is required, as there is currently limited research in this area. However, Chuck Johnson has written a speculative article about the object-hood of experimental electronic music in the context of Timothy Morton's contribution to object-oriented ontology. Johnson writes:

\footnotetext{
What is a [David] Tudor piece if not an interconnected "mesh", to borrow Morton's term - a mesh of configurable objects in sensual relationships with one another? Remove one object or add a new one and the piece is not the same - it may even implode, or explode.... And these sonic entities - can we not view them as Morton's "strange strangers," so called visitors with whom we have an ethical imperative to engage on their own terms? (76)
}

Johnson clearly illustrates the object-hood of Tudor's work. My argument in this thesis is that this approach can easily be applied to a number of different musical works. In particular, this thesis will attempt to engage with object-oriented ontology in a way that illustrates its relation to contemporary instrumental composition, rather than to discuss object-oriented ontology's relationship to electronic music, or fully explore its place in the wider phenomenological tradition of musicological thought. This narrow focus is required, as a fully explored theory of an object-oriented musicology is beyond the scope of this thesis.

From a compositional perspective, object-oriented ontology can serve as an aesthetic guide. Rather than allowing theory or material concerns to inform compositional decisions, an object-oriented compositional approach would engage with the philosophical concerns just described in such a way that musical works might explore the musical 
objects not in the deterministic context of theoretical frameworks, but in their own private worlds - that is, as objects. Such a compositional approach might be informed by the object itself, letting perception - as determined by the object - dictate composition. For example, a musical phrase may be explored in a way that reveals different qualities to that phrase, rather than requiring it to be resolved within an established convention or harmonic framework. Such a work could result in something like Gerard Grisey's Vortex Temporum, in which a musical phrase is repeated in various forms and with subtle shifts in orchestration. While the approach to motivic development shared by many composers of the common practice - such as, to use the most obvious example, Beethoven - can certainly be understood as concerned with musical materials, contemporary composers such as Grisey extend this approach, demonstrating concern with musical materials in and of themselves. The implications of $\mathrm{OOO}$ for a compositional approach are further explored in the conclusion of the thesis alongside an object-oriented view of the author's creative work. As explored throughout the thesis, traits of an object-oriented music may include:

The object is shallow - at least perceptually. An object-oriented music would be concerned about the perceptual object itself as pure presence, while perception never exhausts the object's qualities

Recognition of the withdrawn nature of things. Objects are explored as relational entities, though their qualities remain inexhaustible. For example, the major scale was never truly exhausted by the common practice, as shown through the non-tonal scalar practices of Igor Stravinsky and György Kurtág.

* No reliance on one particular system of pitch organization. These organizations are overly concerned with the determinations of the subject, such as through the codification of emotion or scientific determinations, which are equally subjective

* Rejects the Romantic conception of teleology as a representation of human experience. Teleology itself is acceptable, but it needs to be reconciled with the object's own features and not be subservient to formal organization

Rather than discuss these ideas in full here, these ideas will be explored and explained in chapters two and three. However, what should be emerging at this point is a sense of just 
how radically an object-oriented approach challenges a conventional, correlationist understanding of music.

As the fields of speculative realism and object-oriented ontology have gained more traction within mainstream academia, numerous critiques have surfaced questioning fundamental concepts put forward by Harman and others, mostly concerning the OOO conception of metaphysics. The most notably damning of these is Peter Wolfendale's long essay "The Noumenon's New Clothes (part one)," which questions Harman's 'philosophy grab bag', as picking and choosing ideas from disparate sources to create a metaphilosophy. Wolfendale goes on to question Harman's understanding of Heidegger's conception of the 'as-structure', the foundation of the tool analysis Harman extrapolates his philosophy from. However, despite this critique and the possible philosophical shortcomings of OOO, it remains a very powerful and relativistic set of tools in the analysis and critique of musical works and the scholarship surrounding music. Of particular value as applied to music is the analytic power of Harman's fourfold of object relationships. However, the theory's strength lies not only in how it may produce new ideas concerning music, but also in the way in which it aggregates disparate theories of music and recognizes the value and limitations of any given approach. The strength of $\mathrm{OOO}$ is therefore in its ability to find relationships and tensions between different analytical techniques, and different perceptual theories.

OOO will bind this thesis together as an aesthetic and philosophical discussion. Structurally, this volume includes a portfolio of three major works and a written thesis. The three works are:

1. Noumena for orchestra

2. Rift for string quartet

3. Ether for organ and live electronics

Scores of these works can be found in the portfolio that accompanies this thesis; an explanation of how the live electronics operate in Ether is also included, as the electronics are the most substantial aspect of the work. 
The written thesis is concerned with reconciling object-oriented ontology with both musicology and compositional practice. The first chapter outlines existing musicological approaches to the musical object, and introduces Graham Harman's idea of the fourfold of objects, a particularly useful tool in the discussion of how musical objects interact. The second chapter outlines these specific interactions in detail with musical examples, followed by a brief discussion of 'allure', the term Harman uses to describe what happens when these interactions break down. Chapter three examines, via a select number of works, how the history of Western art music can be understood in object-oriented terms, beginning with Bach and ending with Stockhausen. Of course, these examples can only begin to explore the possible ramifications of an object-oriented approach. The fourth chapter demonstrates how recent compositional trends can already be understood to represent an object-oriented music, namely that of Gygöry Ligeti, the Spectralists of the 1970's, and Salvatore Sciarrino. This chapter closes with a discussion of Georg Friedrich Haas's In Vain for twenty-four musicians, which is offered as a strong example of objectoriented music. The final chapter outlines possible directions for future research and considers how the composition portfolio can be understood in the context of the written part of the thesis. This concluding discussion serves to connect the two aspects of the work undertaken for this thesis. 


\section{The Musical Object: Abstraction and Ontology}

The musical object occupies a strange place in music criticism. The so-called new musicology - drawing on post-structural tradition - has shied away from describing the object as autonomous, with perhaps the most well-known example being Christopher Small's "musicking": the view of music not as a thing but as a cultural activity (Small 14). Other theorists, such as Dennis Smalley, take a more structuralist line in seeking to create a total taxonomy of musical sound. Smalley's spectromorphology is a litany of sonic typologies that claims to be based on an experiential understanding of sound, while simultaneously undertaking a technical project of cataloguing sound. Both views inhabit quite opposite positions in relation to the musical object - either a total rejection of its realism or a positivistic attempt at a catalogue of all sound. Both of these approaches reject the idea of the musical object in some way, either by reducing its importance, or by reducing it to an idealized and rationalized description in lieu of its immediate physical reality. These views are both removed from auditory experience, which is at its core object-oriented: we hear a sound as an object because of the cognitive tendency to 'objectify' experience. George Lakoff and Mark Johnson describe this cognitive bias as an ontological metaphor, saying "[it is] not merely understood intellectually, but [it is] used automatically, unconsciously, and without noticeable effort as part of our normal functioning" (Lakoff 13-14). In other words, neither of these mentioned approaches to the sonic object meets the object on its own level, and because of this, they deny the musical object an ontological existence beyond its ability to represent (i.e. to "stand in" semiotically for something else). The musical object is really both of these opposing views and neither at the same time. The musical object is an 'object-being', a thing that exists as an event, and which also exists beyond its relations to our perception.

\section{What is the Musical Object?}

Music is undoubtedly a human and cultural activity. There does need to be a human participant in the reception of sound for it to become musical; how one listens is therefore of extreme importance, as the phenomenal experience of sound is the foundation of the aestheticised musical object (Fisher 170). For this reason, phenomenology initially appears 
to be the most appropriate tool in the investigation of what the musical object is. However, such an approach can result in a degree of anti-realism because of importance placed on human perception rather than the physical attributes of the sound itself, which in turn denies the sonic object an ontological existence beyond its reality as a perception (Meillassoux 28). Another option might be to accept the post-structural tendencies of current musicology and efface the object in favour of relativism. Yet the central difficulty in this approach is locating any musical object at all: Is Beethoven's manuscript of his Fifth Symphony the original? The original performance? The sum of its performances in the last 200 years? It quickly becomes impossible to even discuss the idea of Beethoven's Fifth with all of these potential confusions. These questions are very common in both music criticism and in general ontological philosophy. I want to suggest here that such questions fail to recognize the multifaceted and multidimensional properties of the sonic object, which exceed both our experience and our range of relations to the object.

As Edmund Husserl points out, perception is an objectifying act that results in what he calls the intentional object (Harman Quadruple 20-23). When listening to the soundscape of a city, one may hear the wheezing of a bus, the distant meanderings of a busker playing a guitar, or in the case of Wellington (NZ), the howling of a northerly wind. These sounds are primarily functional for us, helping us to navigate space and perhaps, evolutionally speaking, warn us of potential dangers. This experience is most likely not an aesthetic one for the average listener, though there exists no physical barrier to doing so. The Kaluli people of New Guinea do engage with their environment in this way, incorporating the sounds of surrounding birdsong, rivers and waterfalls and even the wind into their musical compositions (Fisher 169). In Western society, what we experience as music is defined and circumscribed by the framing mechanism of culture itself. The difference between musical and non-musical sound becomes the beginnings of a larger taxonomy of sound. These boundaries have changed dramatically throughout history, exemplified by the eleventhcentury shift from monophonic Gregorian chants to polyphonic chants, such as Leonin's Dulce lignum, which incorporate parallel fourths and thirds: a radical change in the acceptance of new musical content (Taruskin). As the shifts in the framing mechanism of 'what can be accepted as music' dictated compositional praxis throughout Western history, subjective taxonomies of sound types were created, modified and abandoned. These new theories of sound do not change the content of Dulce lignum, but reveal features that may have been hidden to us previously, such as frequency content, or a geometric significance. 
While culture thus dictates what is considered aesthetic, this calls into question why certain sounds should be excluded from aesthetic experience: the coughing at an orchestral concert, the cheers of a crowd at a stadium gig, or the artifacts of a damaged CD. Many of these sounds have been accepted and incorporated into composition, but they have also been deemed as noise lying outside the musical work. This distinction between the musical object and that which lies outside is one of the most problematic hurdles in the definition of the musical object.

In Adam Harper's Infinite Music, Harper describes musical objects as abstractions of possible performance 'events' (using the term broadly to encompass any instance of musicality, whether a single pitch in a melodic line or a composer's entire creative output). These objects are totally continuous with each other, making up the totality of potential music space, which he describes as being analogous to white noise (83-94). Music then becomes a framed zone within 'noise' space; Harper describes an object as a quantisation within the continuum of music space. And while one may not be able to truly experience the same object twice in the exact same way, the object itself remains consistent as a concept. When one recalls Bach's famous Well Tempered Clavier Prelude I, it is not just the surface detail that comes to mind, but an abstracted general outline of the piece as well: the instrumentation, the direction, the dynamics, the rhythmic pulse that carries throughout: these things help us to recognize a work as an object. In Harper's schema, musical objects also exist at different scales: a single pitch is a musical object just as the whole symphonic repertoire of Mahler is a musical object. It is the level of abstraction that is the important distinction for Harper. ' $\mathrm{F}$ above Middle $\mathrm{C}$ ' is an abstraction, but ' $\mathrm{F}$ above middle $\mathrm{C}$ on an alto-flute played at pianissimo, as a counterpoint to a mezzo-soprano in bb. 9 of Berio's Altra Voce during its premiere on the 20 $0^{\text {th }}$ of August, 1999' is also an abstraction, albeit more constrained. One can think in various levels of abstraction to focus on a particular scale of object relationships. This rhizomatic way of conceiving musical objects allows for a creative and free association of objects, allowing us to think in nested networks of ideas. ${ }^{2}$ Harper demonstrates this with the example Jazz - Jazz music of Mile Davis - Miles Davis performance on February $12^{\text {th }} 1964$ at the Philharmonic Hall

\footnotetext{
2 The Rhizome is an important concept in Deleuze and Guattari's $A$ Thousand Plateaus. The influence of this in Infinite Music is evident in Harper's listing of Deleuze and Guattari in the bibliography of his book, although they are never referenced within the text itself (220). Deleuze and Guattari set an important precedent in the reintroduction of metaphysics to continental philosophy. However, their contribution lies outside the scope of this thesis.
} 
of Lincoln Centre] (99). While the last object in this network is very specific, the object of 'jazz' is open to a wide variety of potential expressions. This way of thinking is a way of framing objects within the totality of music-space, but there needs also to be consideration of what lies outside this frame, and, in terms of the object, what the frame fails to capture. While Harper's system may initially seem simple in its conception of how to think in musical objects, it allows for great complexity in its practical application. Also, by acknowledging the framing of the musical object, Harper gestures towards the side of the musical object that - to use the Heideggerian term - withdraws from us.

As outlined in the introduction, one of Martin Heidegger's greatest contributions to phenomenology is the recognition of the hidden features of objects to which we do not always have access (Harman Heidegger 60-63). When one uses a hammer, the tool becomes ontologically close to that person, as the hammer enacts a human intention. If the hammer breaks, the object can no longer fulfill this purpose, and instead, for the human being, the hammer withdraws, and loses its previous purpose, and exists simply as a useless object that must be once again put together to be of use. Harman argues that Heidegger hints at another mode of being for the hammer, which Harman calls tool-being (Tool-being 67). For Harman, an object that is Vorbanden is totally inaccessible, existing in a private world in which it enacts its reality. For Harman, an object that is withdrawn is totally inaccessible, existing in a private world in which it enacts its reality:

Its gravity is so strong that no information can escape, hence we never see the black hole or have direct access to anything about it... we can discover more about black holes by looking at their effects on other objects, but they are not reducible to these effects (Prince 184).

Tool-being is the ontological equivalent to Heidegger's Being, except that it extends through all objects, whether human, animal, non-living, or abstract.

Ultimately, Heidegger discusses objects as existing in 'real' and 'sensual' realms. This is also true for Husserl, who claims there are real qualities to objects ('eidetic variation'), as well as the sensual object itself, and its various sensual qualities (Harman Quadruple 27-30). In contrast, for Heidegger there is a real object beyond its sensual profile (Vorbanden), and there are sensual qualities that are encrusted on the surface of an object (Zubanden). Out of the four objects described by Husserl and Heidegger, there is only one overlap - the object's sensual qualities, which are necessary to any phenomenological discussion as they 
are the foundation for all experience (Harman Quadruple 50). In terms of music, while our ability to hear a sound is always necessarily predicated on its sensual qualities, we can also gain insight into the work through the score or through Fourier analysis, both of which can be thought of as measurable, or real, qualities. Thus, while there are many ways to approach a musical object, no one method will reveal all of its nature at once; a sound is inexhaustible as an object from its creation to its inevitable dissipation. As an entity, the sound exists in both its own private mode of being while also being partially accessible through its sensual and real qualities.

In Harman's radical reading of the tool analysis, Heidegger accidentally creates a metaphysical statement. While Heidegger limits his theory of objects to surface features and total withdrawal, Harman prescribes a more extensive model for a fully formed metaphysical conception of objects. By comparing the different conceptions of an object in Husserl and Heidegger, he proposes a combination of their ideas in a metaphysical concept called the 'four-fold', in which the object consists of four aspects: the real withdrawn object; the sensual and intentional object; the object's real measurable qualities; and the object's sensual and perceivable qualities. How these different objects privately exist and relate to one another is the foundation of Object-oriented Ontology. As I hope to prove through this thesis, the four-fold can be of immense use when incorporated into current dialogue on musical objects and aesthetics, and can be integrated into compositional and musicological thought.

\section{The Quadruple Object}

Graham Harman's object-oriented metaphysics can be described as a de-centering of the subject-object relationship prevalent in post-Kantian philosophy, in favour of the possibilities of object-object relationships. In concrete terms, an object-object relationship is one that does not necessarily involve a human subject, and which, despite this, is just as valid for philosophical inquiry as the dominant, and anthropocentric, strains of twentiethcentury Continental philosophy: phenomenology, semiotics, and critical theory. The qualities perceived through these object-object relations are never exhaustive - Harman gives the example of fire having access to the flammability of cotton, though it does not have access to the whiteness, softness or production of that cotton (Prince 77). Borrowing the term from Heidegger, the object can be said to be always withdrawing, in the sense 
that other objects can never capture but can only translate a select few of their qualities in a process Harman calls 'vicarious causation' (Harman Vicarious 200). Harman also describes the activity as one object 'caricaturing' another, in that objects only access, and therefore exaggerate, a select few of another's qualities at the expensive of its total reality. ${ }^{3}$ Just as the phenomenology of Husserl and Heidegger demonstrated the extent to which subject-object relations are limited, Harman's object-object relations never allow for full access to all aspects of the object.

As described above, Harman's metaphysical system is based on four aspects of the object: the real object - the object in its infinite and hidden reality; the sensual object - the object we encounter in experience; real qualities - the qualities we have access to through intellectual scrutiny and analysis; and sensual qualities - the different qualities (what Harman calls the 'mist of accidental features') that we can perceive of the sensual object. He then links these features together to create his metaphysical framework (Prince 203). The four primary links between the objects, or 'tensions' (the central four in Figure 1), are termed (from one to four) essence, space, eidos and time.

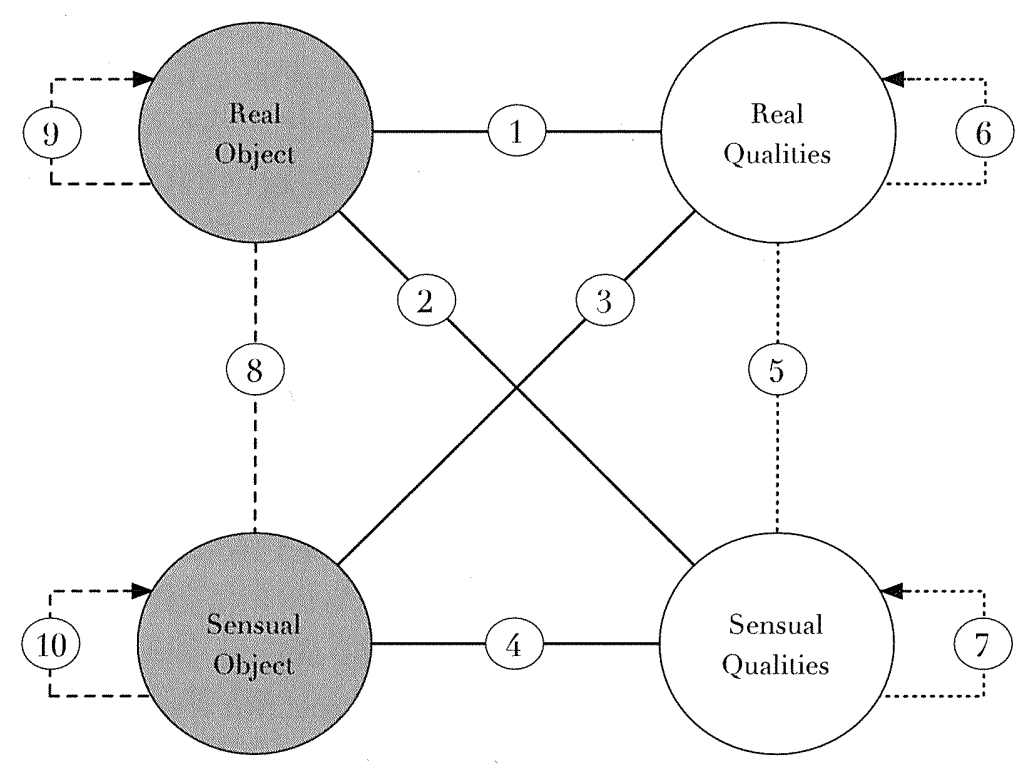

Figure 1: Harman's 'fourfold'.

(Quadruple 78)

\footnotetext{
${ }^{3}$ Timothy Morton has another expression for this phenomenon: the strange stranger: Timothy Morton, 'Thinking Ecology: The Mesh, The Strange Stranger, and the Beautiful Soul', in Collapse Vol 4: Geo/Philosophy, ed. Robin Mackay, Urbanomic, 2010: 265-293 
While these four tensions are not the only possible types of interaction between the object's parts, they form the basis for a new metaphysics in that contrary to the traditional understanding of space-time as a kind of surface, existing prior to objects and providing the background for their relations, object-oriented ontology posits that space and time are two of the possible products of object relations, though this again is not purely relational as it creates an object through vicarious causation. ${ }^{4}$ Eidos can be thought of as the stripping away of features to get at the eidetic surface of a thing; this is always an intellectual, not a sensual, exercise. Essence is what makes the object what it is, similar to the way in which Leibniz's monads have their own particular identity, though with the added feature in Harman that the object is destructible (Prince 205).

Outside of these main four, the remaining links are: 5. 'sincerity' - the way in which real objects interact with each other (though in music this is always mediated through sensual qualities); 6. 'withdrawal' - which is not mediated through the sensual realm and therefore simply does not occur; 7. 'contiguity' - the mediation of objects through vicarious causation; 8. 'duplicity' - a connection between the different real and sensual qualities of an object made through experience only; 9. 'contraction' - the tension between measured qualities of an object (for example, the relationship between the notation and a FFT analysis of the piece); and 10. 'emanation' - the connection of different sensual qualities, what can be understood as the basic foundation of phenomenology. A full discussion about how these relationships behave in musical contexts will take place in chapter two.

\section{Object-Oriented Ontology and Music}

Harman's model is strikingly similar to Harper's, insofar as hierarchical order is a distant memory. However, there is an important difference: Harman makes a clear distinction between sensual and real qualities, while Harper does not. In Harper's system, ' $\mathrm{F}$ above middle $\mathrm{C}$ ' as an object exists at the same level as the object ' $\mathrm{F}$ above middle $\mathrm{C}$ played on an alto flute'. For Harman, in contrast, ' $\mathrm{F}$ above middle $\mathrm{C}$ ' would be a 'real' object, in that it is abstract and withdrawn, and cannot become a sensual object until it is articulated through an object such as a flute or an engine. In other words, according to Harman's

\footnotetext{
${ }^{4}$ The implications of such a theory are too grand to discuss in this thesis, however more information can be found here: Graham Harman, 'Time, Space, Essence, and Eidos: A New Theory of Causation', Cosmos and History: The Journal of Natural and Social Philosophy, vol. 6, no. 1, 2010: 1-17
} 
system the object ' $\mathrm{F}$ above middle $\mathrm{C}$ ' is partially withdrawn from human access, while for Harper it exists definitely as that object. However, Harman's distinction between real and sensual objects should not be understood as hierarchical; rather, they simply afford different degrees of human access through either perception or logical rationalization. As a metaphysical model, Harman's theory allows one to locate musical objects at any level of experience, whether it is a single pitch isolated within a melody, a texture, a movement of a symphony, an entire musical work, or even the broad concept of equal temperament or another harmonic system. No single level of a work is more important than any other level; simultaneously, the framing concept gestures towards uncovered and subterranean levels that are not accessible. In this model, music is just one feature of sound in general: there is always a potential for musical perception, but that perception does not exhaust the sound itself. For example, a timpani hit might be a musical punctuation for a human being, while if an ant were walking on the timpani's surface the hit might feel like an earthquake. However, the main benefit of this system when used in a musical context is the ability to track music as an object-oriented phenomena, and to thus account for some aspects of music that post-structuralism and empiricist positions are unable to assess.

At this point it is worth revisiting and extending upon an earlier discussion. Cultural theorists such as Tina DeNora and Nicolas Cook give detailed insight into how music functions as a cultural activity and how it is used as an emotional or social tool in everyday life. However, these discussions tend to lack information about the music itself; the discussion of how music is constructed is usually relegated to the empiricist project of music theory. Both cultural and music theorists thus marginalize the object in some way, either by what Harman calls undermining or overmining the object. To undermine an object means to think of an object only as symptom of an underlying force, such as a chord being thought of in the context of a harmonic field. To overmine an object, in contrast, is to see an object only as a relational point in a network, for instance, to understand music as a tool to reinforcement the self through memories and repeated listening throughout a lifetime (DeNora 141). Object-oriented ontology navigates the space between these two approaches, and is therefore able to incorporate various approaches in the recognition of the musical object's different qualities and relational possibilities. Similar projects, though not explicitly connected to OOO, have been undertaken in English literature and cultural studies through Bill Brown's 'Thing Theory' and Jane Bennett's idea of 'vibrant matter'. In both these theories the object holds a position as privileged as the subject's, in that it has 
real power in the world and is able to effect change. The benefit of using object-oriented ontology rather than one of these systems, however, is in its recognition of the inherent limits of understanding an object as a network of relations; the object always exceeds such relations because some of the object's qualities are withdrawn, inferring a kind of private world to which we do not have access. ${ }^{5}$ The problem with any kind of network theory is therefore that we can only understand it through vicarious causation. This is particularly exciting for music because it recognizes that musical objects are complex and irreducible to any one theoretical model, which then promotes a heterogeneous approach to musical analysis and composition.

Object-oriented ontology is suitable for musical analysis because music is itself based on perceived material relationships, either through real or sensual qualities. In general, musical forms go through a process of revealing and withdrawing within a given piece: musical ideas are presented, developed and potentially resolved in some way. A simple example of this process is the popular 'rule of three' principal, in which a musical idea is repeated twice before having to develop. This process often reveals new qualities of the same object: pitch collections become contextualized in scales and relationships between chords become clearer. This idea is the foundation of musical form: the material must go through some kind of transformational or developmental process, which results in some kind of musical interest or intrigue - even if this is the constant repetition of one idea. This basic principle demonstrates why the object-oriented approach is evidently congenial to compositional practice.

While there exists no formal object-oriented movement in musical history, there has been a broad trend in post-Romantic aesthetics that can be thought of as object-oriented. These approaches have become increasingly prominent since the impressionistic experiments of Debussy and Ravel in the early twentieth century. While on a surface level it may seem like composers such as Messiaen and Debussy share the familiar Romantic interests in nature, religious experience and the universe at large, I want to suggest here that rather than representing a continuation of the Romantic mode, the music of such composers does not consider these objects in their affective capacity towards the human, but instead turns its attention to the objects in themselves. Instead of writing music about, for instance, the

\footnotetext{
${ }^{5}$ This is not to suggest that there do not exist important parallels between Brown and Harman's theories, such as the influence of Heidegger, and the flattened ontological status of subject and object. However, Brown theory lies outside the scope of the thesis.
} 
affective power of the solar system on human activity - such as Holst's The Planets - these composers often write music using processes that caricature (used in Harman's sense) natural phenomena. Messiaen, for example, models the first movement of Quartet for the End of Time on the looping but somewhat static character of the natural world, as opposed to the humanly affective and reflective tone of Vivaldi's Seasons. While the centrality of the material is clearly evident in the former's work, the move towards a focus on objects after the decline of Romanticism was a gradual process. The impressionism of Debussy and Ravel suggests a scene or object, de-centers Western tonality, and stretches tonal ideas of modulation and key movement; however, impressionist work is still based on an affective relationship between the world and the subject. Any work in which the subject is made central is predicated on an anthropocentric understanding of the world.

Another fundamental principle of the object-oriented approach is what Ian Bogost calls carpentry, which he uses as a term for philosophically charged creative work (Bogost 85111). In music, research-led composition is an obvious parallel to this idea. Carpentry is not just making art, it is making art that asks philosophical questions, or that does philosophical work. Speaking generally, Oliver Messiaen's focus on the natural world and his spirituality demonstrates his interest in objects beyond the human. Messiaen is a carpenter in this sense as his Quartet for the End of Time imagines a music made without those materials that are readily used to produce temporal tension: a sense of metric expectation, non-symmetrical scales that have inbuilt tendencies to resolve melodic and harmonic tension, and systems of familiar formal organization. Experimentation is not quite the goal here, as the sounding object is often foreseeable for the composer and even the audience. The interest comes when an aesthetically rich experience presents itself in the piece, which seems to rise above and separate from the object. This is what Harman calls allure - the act of distancing the sensual object in favour of a focus on its qualities: a simulation of seeing the thing itself, acting in its 'object-being' (Harman Guerrilla 143).

Object-oriented ontology can therefore be a particularly useful tool in the discussion of music because it treads a line between the theoretical - the hidden features of sound - and the phenomenological and relational - the sensual features of sound. Attention to such hidden features is useful because it allows us to discuss what lies between the framing mechanism that is culturally defined, and the scientific and theoretical features of a musical work. The discussion of sensual features is equally important, because it involves talking 
about the relational features of sound, and how the framing mechanism changes the way people listen to music from person to person: what sounds novel to a person exposed to a certain set of culturally-defined experiences might sound clichéd to someone with a different background and set of experiences. For composers, the distinction between the real and sensual object also allows an understanding of how objects withdraw and reveal their qualities to each other: the way a dominant seventh chord relates to its resolving major tonic chord is as sensually important as its theoretical logic. However, this may not be true for other kinds of relations: the woody timbre of a high-register bassoon melody contrasts with the cold metallic nature of the trombone in the same register; while this contrast has a strong sensual presence, the hidden spectral content is rarely investigated by composers. Object-oriented ontology is useful because it always frames the musical object in its dual realities - the hidden and the sensual - which acknowledges both the infinite regress of the object, and the multidimensional relational possibilities of objects.

While this chapter has necessarily covered a large amount of material in a relatively brief fashion, the discussion of the terms and concepts outlined here will be the foundation for the further investigations made in this thesis. A more involved exploration of the Quadruple Object metaphysical system will be explored in the second chapter, while a full discussion about carpentry can be found in the conclusion. In chapters three and four, we will see how the description of the sonic object discussed here fits into the historical context of composition, including its relationship to modernism, Ligeti's critique of serialism and the move to a process-as-form style of composition in the twentieth century. 


\section{Interactions in the Fourfold of a Musically Oriented Object Oriented Ontology}

This chapter will outline how object-oriented ontology can be applied to music, and how the necessary changes made to it in this context result in a musically oriented objectoriented ontology. This purpose necessitates the description of how each term in objectoriented ontology relates to music. In order to make clear the sometimes complicated nature of these relations, I will employ musical examples, not only to emphasize the practical application of this theory, but also to demonstrate the extent to which musical theory and musicology are already object-oriented.

As briefly explained in the previous chapter, Harman's theory of vicarious causation is the idea that one object is able to translate only a few qualities of any object with which it comes into contact (Vicarious 20). Harman uses an ancient Islamic example from the occasionalist tradition: when fire burns cotton, the fire only comes into contact with the cotton's flammability; the fire cannot translate the cotton's colour, smell or texture (even though we, as humans, witness these changes). In other words, the fire has no access to other aspects of the cotton, even if the fire destroys the cotton completely. The fire caricatures the cotton because it reduces it to something it can interact with. The cotton, for fire, can only be fuel. This example shows that for Harman, causation is asymmetrical. For Harman, an action does not give an equal reaction: an action gives a reaction only to the extent to which another object is able to react. In other words, an object only reacts to another object within the limits of its own ability to translate the other object (Harman Prince 203). Fire cannot interact with the colour of cotton; it only interacts with its flammability. ${ }^{6}$ This idea of indirect causation - that things never really fully connect themselves - has never died in philosophy. While the Islamic traditions and Descartes believed that God was the only medium that things related through, the philosophy of Kant and Hume both dictates that it is human experience that holds this position. This aspect of Harman's theory will become important in this chapter in the discussion of how musical objects relate and react to each other.

\footnotetext{
${ }^{6}$ Harman's repeated use of the fire-cotton example - in addition to its simplicity - is my reason for employing it here. For a fuller exploration of the implications of this idea, see Harman 2012, $188 \mathrm{ff}$.
} 
Another important point to remember is that while we are using a philosophy based on the democratization or flattening of relations - whether object-object, subject-object or subject-subject - we are working in a field that is inherently concerned with subject-object relations. Music, like all artistic practices, is a cultural and phenomenological (sensory) activity and so therefore any relationship between musical objects is always filtered though our own knowledge and senses. Therefore, if discussing the relationship between the real object $(\mathrm{RO})$ and the sensual object (SO), we are always analyzing this relationship through the real qualities $(\mathrm{RQ})$ or sensual qualities $(\mathrm{SQ})$ that the relationship emanates. Ultimately this means any relation we perceive is a caricature of that relationship, which in turn means that this exercise is inherently limited. The knowledge of this limitation can be useful in the analysis of music, as it allows space for speculation on the nature of these relationships and the particular set of qualities thereby revealed. With this in mind, it may seem like this chapter must return to familiar territory: concern with the world as the mind interprets it is the traditional exercise of phenomenology. To some extent this is true, however the benefit of an object-oriented approach lies in its extension of certain aspects of phenomenology, combined with a relational approach: Harman's theory that there are four distinct aspects of each object, for example, is a contrast to other kinds of phenomenology that recognize only a subset of these. As Harman points out, Heidegger only recognizes two of the fourfold (the real object and its sensual qualities), while Husserl recognizes three (real qualities, sensual qualities and the sensual object) (Harman Quadruple 47-50).

\section{A Deeper Look into the Fourfold}

As can be seen in Fig. 1, Harman's fourfold describes ten possible relations between objects (Quadruple 78). In order, these are:

1. Essence

2. Space

3. Edios

4. Time

5. Sincerity

6. Withdrawal

7. Contiguity

8. Duplicity 


\section{Contraction}

\section{Emanation}

These relationships are also grouped into categories of connections: the first four are called 'tensions', numbers five to seven are 'junctions', and the final three are 'radiations' (Quadruple 114-115). The purpose of these categories is to describe the nature of these relationships: tensions are object-quality relationships, junctions are object-object relationships, and radiations are quality-quality relationships. It is important to remember that this system is the foundation of Harman's metaphysics, and that how this system behaves as an aesthetic philosophy will be returned to and discussed later in the chapter. The following section of the chapter, however, will focus on how these ten terms can be adapted to a musical context, and what they may mean in terms of both empirical and phenomenological analysis. While some of the terms are quite easily applicable to music, others require greater analytical work. Because of this, the structure of what follows will move from the most withdrawn relationship (RO-RO) towards the most open (SQ-SQ). The more withdrawn the relationship, the more difficult it is to talk about, but such discussion necessarily informs our understanding of the most revealed objects.

\section{The Relations of the Musical Object: From Withdrawal to Emanation}

The first relationship to be considered is totally withdrawn: the connection between two real objects (6. RO-RO, a junction). Harman calls this specific relationship a dijjunction, as no real object can ever relate to another unless through the sensual realm. Harman describes this as like two objects existing in their own private worlds, each unable to influence or be influenced by the other. In musical terms, this makes very little sense because music is a sensual force upon human beings, and therefore this relationship is the most difficult to talk about. As we have no access to the real object, we can only speculate about its existence, and infer from what we can sense through either its real or sensual qualities. This problem is best described as a vacuum, and for this reason the only musical relationship that can be discussed in these terms is silence. Yet, as famously shown through his short piece for piano, John Cage proves there is no such thing as musical or acoustic silence. We can understand it as a concept, and speculate about it, but it is impossible to experience. In these terms, 4'33'" is not simply a meditation on 'what is' but has an ontological emptiness implicit in its purpose - in an attempt to encounter silence, 
we open our auditory horizon to even more sound, which is in the process of becoming musical through the framing of the sounds as a piece. Negating music does not result in silence, but instead opens our ears to the sensual (including the aesthetic) qualities of objects to which we do not regularly attend. Because silence therefore exists only outside of our experience, we can thus conclude that silence and withdrawn consciousness are real objects.

The next relationship is more open to human understanding, and is therefore more quantifiable. The relationship between the real object and real qualities (1. RO-RQ, tension) are what gives an object its features. Without this relationship, each object would be exactly the same as the next. Harman describes this relationship as essence, and ascribes its conceptual birth to Leibniz and his theory of monads (Prince 205). Because we can access certain real qualities of the object, we can speculate more on the real object. An example of this relationship is found in Stockhausen's Klavierstücke series. These notoriously difficult pieces - both conceptually and performatively - are concerned with a highly rigourous formalism; integers are mapped to compositional parameters, resulting in further asymmetry between the real qualities and the sensual object. Stockhausen's pieces in this series create complex object and while Stockhausen himself would likely disagree, these objects are unknowable even to the composer. By mapping serial and group networks to interval size, note length and register, a huge number of objects emerge at ontological scales both larger and smaller than the level Stockhausen works at. This complex network of relations is withdrawn to the composer, the listener and the theorist, and therefore the objects that inhabit this network have rich lives as nodes in a kind of serial network. The new objects at the larger level have Stockhausen's mapped integers as incredibly complex real qualities. The withdrawn nature of this relationship leaves a lot of room for speculation into the inner life of serial music. Further discussion of the Klavierstücke pieces takes place in chapter three.

My focus now turns to the first real-sensual relationship: that between the real object and the sensual object (5. RO-SO, junction). Harman labels this relationship 'sincerity', and a conjunction. It is through their connection to the sensual realm that real objects relate to each other; this is also the location of vicarious causation, as discussed in the first chapter. In musical terms, we always experience sound through its surface or sensual qualities. Because of this, we must remind ourselves that RO-SO is for us always and already RO- 
SO-SQ. As discussed above, one kind of real object in music is simply an absence of sound (acoustic silence); the RO-SO relationship can be shown to be the sensual version of this (musical silence). Because of this, an RO-SO relationship can be described as the listener experiencing an absence of presence. While this may sound like an oxymoron, the listener becomes aware of something that is not there through its effect on the sensual realm. A productive example might be the experience of watching television on mute. One is aware of the absence of sound because one knows television is an audio-visual experience, and yet only the visual is being experienced. One knows the sound is there, and is accessible through the use of the remote. This experience is in essence what the RO-SO relationship is like, with the added restriction that we cannot unmute that which we do not have access to. A piece of music that illustrates this idea is Helmut Lachenmann's Gran Torso for string quartet. Lachenmann often focuses his attention on the corporeality of instrumental sound production, using the timbral excess of music as his main materials. Gran Torso is a piece that does exactly this, using bow noise, the sounds of strings being rubbed, and the scratch of bowing the wood of the instrument. Some of these sounds would be at home beneath the harmony of a Beethoven string quartet, or in the tone of a student in the process of developing good technique. Because of this, Lachenmann's music can almost be thought of as a surface tracing - giving a general outline without any of the harmonic detail. The music has a complete absence of conventional harmony, instead drawing attention to accidental sounds, and suggesting the lack of what might be traditionally conceived as music. This effect can be likened to what Adam Harper calls 'hauntological' music (Harper 148). ${ }^{7}$ In Lachenmann's case, the specter is the corporeal, and those sounds that are conventionally considered excessive in instrumental music. While Harper relates hauntology to the music of Scottish electronic duo Boards of Canada, it is equally well applied to Lachenmann's music. Gran Torso uses those corporeal sounds - deemed as noise in the signal of music - to hint at sensual objects beyond the auditory horizon.

The last real object relationship to be considered is the second of the four main tensions, between the real object and its sensual qualities (2. RO-SQ, tension). This relationship is perhaps one of the richest in terms of philosophical inquiry. The RO-SQ relationship is described by Harman simply as space - the space between the infinite regress of the real object and its multitude of shifting surface qualities (Quadruple 48). The main philosophical

\footnotetext{
${ }^{7}$ This is a term first coined by Jacques Derrida to refer to the spectre of the past that haunts the present
} 28 
influence for this relationship is Heidegger's tool analysis: it is the difference between the tool-being - the private world of the object - and its readiness-to-hand - the caricatured functionality we perceive of the object, and how we might utilize its particular properties (Harman Guerrilla 217). There is a substantial ontological space between these two aspects, and it is the outermost tension possible in Harman's fourfold. In musical terms, this relationship is between the many sensual qualities of a musical object and the real, withdrawn object beneath its surface. Later in this chapter we will discuss what happens when this relationship breaks down, creating that moment when the surface qualities break from their object and produce what Harman calls allure. In musical terms, caricatures are everywhere. The inversion and retrograde of a 12-tone row are caricatures of the prime form, scalar transpositions of a theme in Beethoven, and the sound that results from a low pass filter applied to a digital recording of the wind. While each is clearly an object in its own right, the way they are articulated through various means of materials dictates a journey towards becoming new objects. Because of this, orchestration is one of the most efficient means in creating caricature in instrumental music. Different textural and registeral combinations can act as a spotlight on the harmonic series and the potential harmonic space of the orchestra. Unusual combinations can make a relatively conventional melody in a major key sound create the darkest moments in a Lutoslawski symphony. There are so many examples of the RO-SQ relationship in music, but one that illustrates the point well is Vortex Temporum by Gérard Grisey. In this work, the orchestration (SQ) acts as a flashlight across a broadly changing timbral structure (RO), whose harmonic series is always in flux from natural to inharmonic (Hasegawa 349-371). The notes the ensemble plays never keep up with these changes; rather they are surface memories or adumbrations of an object out of reach. This piece also highlights the influence of electronic music in contemporary instrumental composition. It is yet another example of how caricature is used in music, as the main object in the first movement of the piece could be described as analogous to an electronic delay effect. There is looping of a phrase and a slowly developing low feedback hum, which builds and then rapidly dies away, before the process starts all over again. Because physical instruments articulate this process, the caricature is reminiscent of pixilation or rough approximation, of what a technological process would sound like, and this gap between the hidden process and the audible result is what makes this piece so intriguing. When the gap between the real and the sensual becomes this wide, we are looking not only at a new object (this is obvious), but also at allure, which we will return to later in this chapter. 
I want now to leave behind the real object in order to focus on other relationships, the first being the relationship between the sensual object and real qualities (3. SO-RQ, tension). This relationship - called eidos by Harman - is one of the main tensions, and owes its philosophical origin to Husserl. It is perhaps the most classically phenomenological of the tensions, as it is essentially the same as Husserl's idea of eidetic reduction: we gather knowledge about the world through subtraction of features to find an essential object underneath, rather than through an addition of features as Hume would suggest (Harman Prince 219). This process is primarily theoretical, not sensual, as we arrive at these conclusions by reasoning rather than observing. In music, this process may be informed by an RQ such as a conventional harmonic analysis of a score, or through an FFT analysis of an electroacoustic work. This relationship has an extremely withdrawn quality in music, as music is primarily experienced through sensual qualities for most listeners and practitioners. However, because all music has real qualities, any piece can serve as an example of the relationship's application to music. One may measure the wavelengths produced by a Javanese Gamelan gong, or work out the harmonic framework and progressions of a pop song. The example I want to explore here, however, is not a work but a theory: Neo-Riemannian theory and Kopp's extension to this theory (Cohn). Neo-Riemannian theory can be used to generalize much Hollywood, pop, and rock chord progressions down to a few simple rules, which are often analyzable to an extremely exact degree. Such use of this theoretical approach posits that many of the chord progressions of film, pop and rock works are made through common tones rather than a key-based system. This can also be seen as far back as Schubert, in his ability to move freely from $G$ major to Eb major in his string quintet: distant keys in the circle of fifths, but sharing a common tone $(G)$ in their tonic triads. In relation to Harman's concept of eidos, the sensual object can be understood as the intentional embodiment of the real world features of Neo-Riemannian theory; in other words, because chords share certain notes and ratios with each other, when one strips away the sensual features of an ensemble playing a particular chord progression, the chord progression can be understood as an intentional object outside of the context of that particular rendition.

The next relationship is between the two kinds of qualities: real and sensual (8. RQ-SQ, 'radiation'). Harman refers to this relationship as both radiation and 'duplicity' - the latter term employed because the impression is given of two objects: the real qualities infer the 
real object, while the sensual qualities infer the sensual object. It can therefore appear difficult to reconcile these two 'objects', which, of course, according to Harman's schema, are one and the same (Quadruple 110-115). As Harman explains, this is because the qualities seem superfluous to the real or sensual object, and that the qualities infer objects withdrawn from access. When thought of in relation to music, we can see that certain real qualities are recognizable upon listening: the particular intervallic qualities of the whole tone scale, or the changes in tempo that result from an arbitrary addition and subtraction of rhythmic values. Sensual qualities, on the other hand, are immediately accessible: for example, the accidental features that occur in different recordings of the same work highlight the small but significant possibilities for variation in the interpretation of a musical work. A piece that illustrates such a relation between theory and experience is Debussy's Voiles, from his first book of piano preludes. This piece's process becomes highly transparent if one knows some basic post-tonal theory, as the majority of the work is in the whole-tone scale. Without this knowledge, however, the piece can just be heard as a veil of impressionistic and dreamlike qualities. With no tendency tones, and therefore no semitone tension in the scale, the music floats and lingers without any real reason to disappear. This experience does not require theoretical knowledge to hear, and the theory does not require experience to prove how transparent it is - the whole tone $(0)\left(C_{h}\right.$ transposition) scale is quite clearly utilised in the score. These two modes of access to the piece have their own merits, yet neither can really account for the other. We can draw causation from the whole tone scale in the experience of the listener, but the theory remains withdrawn unless the listener is made aware of it. This relationship therefore highlights the limitation of both theory and experience that exists for all musical experience, in that we recognize the real and sensual qualities as limited methods for musical experience on their own.

The relationship between real qualities and other real qualities is one to which we have limited access (9. RQ-RQ, radiation). Harman remains quite vague as to what the relationship entails in his object-oriented philosophy. Applied to music, however, it makes more sense than might be expected. Musicians, composers, and music technology specialists are all interested in examining various real qualities of music, whether it is the score, the theory, a spectrum analysis or its evolving qualities in an oral tradition. A contraction between real qualities and other real qualities could be the relationship between the score and a spectrum analysis of the music itself. These two manifestations of 
the music may have complementary, contradictory or ambivalent relationships, but are unified by the music itself, which is withdrawn from the artifacts that emanate from it. For example, in Saariaho's Verblendungen, comparing the particular techniques used by the orchestra to the measured results of a spectrum analysis can tell us about the combination of overtones created by the orchestra, and how new sounds might be developed through particular orchestrations (Saariaho 93-133). Such research lies outside the scope of this thesis, but can lead to technologies such as computer-aided orchestration with an emphasis on extended instrumental techniques. This potential has yet to be explored fully by the music technology community, though there have been a number of computer-aided orchestration programs developed using conventional instrumental techniques, such as Orchidée (IRCAM, Carpentier and Bresson). The RQ-RQ relationship is therefore one of the most productive relationships for investigation from a theory-oriented standpoint.

In the purely sensual realm, there is the relationship between the sensual object and sensual qualities (4. SO-SQ, tension). Harman calls this tension 'time', as it outlines the difference between the sensual object that endures, and the various ways it manifests through sensual qualities (Quadruple 100). This relationship is easily correlated to music, as we hear objects in music through sensual qualities. Some pieces, however, illustrate the relationship better than others, such as Salvatore Sciarrino's first caprice from his Sei Capricci. This work focuses on two gestures, which are rearticulated and looped in quick succession. There are then micro-variations in each articulation of the gesture, some of which come from physical limitations of performing the work - such as playing natural harmonics that do not exist - and some which are written in the score, such as different melodic lines, with one or two notes difference to the original gesture. The repetitive nature of the musical idea and its extremely fast pacing makes it initially difficult to get a sense of the sensual object: there is a constant stream of new accidental features of which to take note. While we always access music through sensual qualities when listening, this work relies on this fact more than others, as the fleeting nature of the melodies becomes difficult for the ear to grasp - these gestures are the sensual object behind the sensual features.

The relationship between two sensual objects is similar to the relation between the real object and sensual object, though the former is restricted to the sensual realm (7. SO-SO, 'junction'). The relationship is one of vicarious causation. As a junction, the two objects 
exist in experience; the relationship occurs because of close contact between them. A musical work that exhibits this relationship well is Witold Lutoslawski's Chain III, for orchestra, in which Lutoslawski demonstrates his chain orchestration technique. In chain orchestration, textures are set up in the score in a chain-like manner; one texture is slowly developed and a new texture is born out of it, often perceptively distinct from the previous link. This process develops in a range of speeds: some chain-links are seconds long, others minutes. A similar, though freer process is Stockhausen's idea of moment form, in which formal considerations are only intended at the micro level, rather than macro-level structures such as binary or sonata form (Kramer 177-194). Chain III is concerned with the translation of different timbral objects, morphing into one another, and translating each other through indirect relationships. As each chain morphs into the next, new sensual qualities become revealed, while others withdraw. The SO-SO relationship is also important in my work Noumena, which accompanies this thesis, in which two musical objects interact in various ways but are never fully revealed. ${ }^{8}$

The last relationship to be considered is the connection between different sensual qualities (10. SQ-SQ, 'radiation'). This relationship can be thought of through Husserl's concept of 'epoché', the idea that we can bracket out moments of experience to analyse the sensual features of in isolation from any possible cause, effect or theory 9 (Fink 40). This is basic phenomenology, and along with his idea of eidos, constitutes Husserl's lasting contribution to the field. Don Idhe relates epoché to the experience of listening to an orchestral piece and focusing on individual instrumental lines in a static texture. As the listener changes their focus to different instruments, diverse relationships are formed in the brain between each line (77-78). Like many of the relationships discussed thus far, SQSQ is a prominent relationship in all musical experiences. Georg Friedrich Haas' In Vain, a chamber concerto for 24 instruments, a downwards chromatic gesture articulated by the whole ensemble in desynchronized lines, though all working through a rhythmic lattice with tuplets of various sizes. A more in-depth discussion of In Vain accompanies chapter four.

\section{The Shadow of the Fourfold: Allure and the Aesthetic Power of Objects}

\footnotetext{
8 As discussed in the introduction, the noumenon is the word Kant uses for objects outside of phenomena: in Harman's term, the real objects.
} 
The discussion of relationships above is a translation of object-oriented ontology to a musically oriented object-oriented ontology, and as such, describes the metaphysical state of musical objects. However, the underside of the fourfold requires a discussion of what happens when objects behave in unusual ways, or more explicitly, what happens when the relationships discussed above break down, and subsequently reconnect in unexpected ways. Harman calls this process fissure and fission, and limits his discussion of it to the four main tensions: essence, eidos, time and space. The terminologies for the corresponding breakages are, in order: causation, theory, confrontation and allure, as shown in Figure 2.

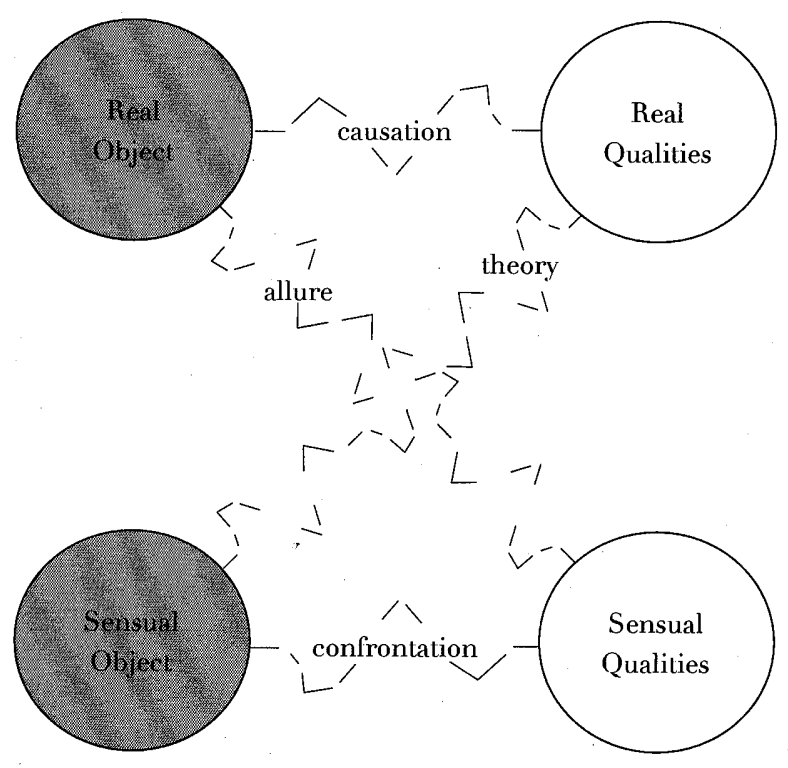

Figure 2: The Broken Links of the Fourfold (Quadruple 107)

These breakages are fundamental concepts in Harman's object-oriented aesthetics. As discussed by Harman in Guerilla Metaphysics, these breakages are evidence of the withdrawn nature of objects, that an object never exceeds its relation to other objects. Of particular use to the present discussion is the concept of allure. Harman discusses allure and its role in metaphor as a linguistic tool, an example of which is the phrase 'man is a wolf.' Man is not literally a wolf, but has wolf-like features; the two ideas interact in an asymmetrical way. The qualities of 'wolf' are lifted from the real object 'wolf' itself, and the other qualities unsuitable for such a transformation are left to the side, such as a wolf's keen sense of smell or its particular communication skill set. Because of this fact, the metaphor of 'man is a wolf' as a new object takes some qualities from 'man', and others from 'wolf', and not 34 
the totality of both. The qualities of wolf are temporarily lifted from wolf before it succumbs to a new object, the metaphor in question (Guerrilla 178). Harman sees this process as existing in every object; all new objects are formed in this way. For example, when one watches a baby or a newly born animal, we are drawn to their enigmatic and 'cute' features and this allure forms a new object for us: 'cuteness' as an object (Guerrilla 142). Harman sees allure as an important function of every artwork, in that the various qualities of an object become disconnected with the object itself. This happens in every art object: music, photography, painting, and writing all work based on the presence of allure. Interestingly, Harman argues that when this breakdown between the real object and its sensual qualities happens, there is a kind of simulation of direct access to the real object. The key word here is simulation; there is a kind of presence of the real object through its absence in allure. As Harman explains:

\begin{abstract}
Allure is the presence of objects to each other in absent form. It is the alpha factor of the universe, found in all objects from the ground up, but gradually built up into increasingly larger and more intricate shapes. While allure has no hope of ever getting us closer to the objects themselves, it can unleash objects that had been largely muffled in their relations with us, and can translate already recognized objects into more potent form. Allure is the fission of sensual objects, replacing them with real ones (Guerrilla 245-246).
\end{abstract}

To link this to the wider phenomenological tradition, we can compare Harman's allure to the way Heidegger talks about the artwork. For Heidegger, artworks work beyond the withdrawn and revealed duality of tools, instead revealing their inner working through the frame of examining an object through an aesthetic lens (Heidegger Origin 181). In giving the example of Vincent van Gogh's painting of peasant shoes, Heidegger shows that it is not the shoes' ability to perform a specific task that entrances us, but that the aesthetic lens of the artwork instead draws attention to the qualities and surface details of the shoes (146). This may seem like a banal point, but by drawing attention to the thing-ness of an object, we realize that allure does not highlight the functionality of objects for daily life, but instead their features, the sensual qualities that make them appealing. In a musically oriented object-oriented ontology, allure is the aesthetic effect of music: it is what makes those relationships discussed above so entrancing for us as listeners.

Allure is particularly applicable to music created with an emphasis on timbre as a musical parameter sharing equal status with melody or rhythm. This is especially relevant to my own compositional practice and creative concerns. As discussed in the first chapter, 
culture acts as a frame for what is considered music and what is considered noise. Just as the organum composers of the Middle Ages would never use the sixth or ninth interval, extreme timbral variation in Romantic music is generally avoided. While rhythm, melody and harmony are indeed features and notes of an object, timbre has always been considered the quality of a sound. Because composition concerned with timbral and textural continua is indeed focused on the quality of sounds, there is an immediate sense of allure, as if these qualities have become detached from the object itself, and have formed an entirely new object. For example, when we listen to the fast, repetitive gestures of Sciarrino's first violin caprice, the quality of the sound is immediately present, as the violin is being played in an unconventional way. It is this note of difference that immediately challenges the way we listen, at least within the frame of common practice music. Although it certainly relies on the effects of novelty, to my mind the effect is far greater. The work is totally supported by these phenomena - and would need to exist in a completely different form without them - whereas novelty is always a temporary and fleeting effect. Sciarrino fissures the violin from its cultural baggage, and fuses it with qualities not normally focused on in experience: its physical and limited textural existence. This physical limitation of the violin, struggling to speak under its unconventional use, becomes the new focus for us as listeners.

This precedent for allure as an important aspect of experimental works also has some consequences for music based on a particular process, as such works tend to have unintended or accidental features. The music of James Tenney is often the result of pithy instructions, or through notation that has a very narrow degree of freedom. His Koan for solo violin is an example of process music: a violinist plays a moderately paced tremolo between two notes, and the interval slowly changes by eighth tones (a microtone, not the rhythmic value). The process is glacial and relentless, and yet there is no immediate teleological drive to the music. The changing interval resists any stagnation through its sheer instability - the eighth tone is not an interval that many people recognize in the music they listen to, and as such can sound out of tune: it is this tension that carries the work. Koan is an example of allure in action, and while not specifically a timbrally based work, Koan uses a technique not entirely familiar to us as listeners: microtonality. The interval of an eighth tone does not exist in the chromatic equal tempered scale, but it does exist in the harmonic series, and one way or another, many people have heard it, even if it is just through tuning their guitar. This strangeness can be quite powerful if incorporated 
into a harmonic system, which Tenney does in Koan. By fissuring the twelve tone harmonic system, Tenney fuses qualities unfamiliar to the object, and through this, he incorporates the noise back into the signal: by integrating it into the system itself.

So far I have outlined Graham Harman's fourfold of objects and how it might be integrated into the study of music, towards the end of a musically oriented object-oriented ontology. By examining how we can discuss musical works through the fourfold, we have arrived at a means of incorporating multiple strands of theory into a more general discussion of music. The focus will now shift to how an object-oriented trend can be observed in recent music history. To limit our scope to contemporary instrumental composition, this involves tracing the evolution of Western art music, beginning with a critique of Romanticism and the failure of serialism as a viable successor. This will lead into a discussion in chapter four of the work of Ligeti, the Spectralist composers, and Sciarrino, and their solutions to the problems of serial music. As this thesis progresses, I want to make clear that music is by definition object-oriented at the perceptual level. In the next chapter, this will be demonstrated not only through looking at the cutting edge contemporary music of today, but also in Romanticism, which is packed with caricatures of nature and human drama. 


\section{Correlationism and Caricature: An Examination of Musical Objects in the Common Practice, Early Atonal, and Integral Serialist Periods of Instrumental Composition}

Objects exist in layers. From the microscopic to the massive, objects are simultaneously in their own private worlds, and related to each other in a vast network of relationships. Some objects transcend our experience of space and time, such as climate change or plutonium. Timothy Morton calls these hyper-objects: similar to Adam Harper's idea of a music space, Morton is concerned with what might be called 'geological space' plutonium, for example, has a radically different timeline to human beings, and as such our place in its network is limited. Such an object is abstract to us; we only experience the earth for a limited time, and yet the earth will still exist long after humanity becomes extinct. Hyper-objects are usually discussed in ecological terms, but I want to suggest here that the term can be productive when applied to music. Tonality can be discussed as a hyper-object, as the harmonic series is something that is not only expressed in the natural world, but a concept that permeates all Western musical styles and genres (Tymoczko 4). Because tonality is a hyper-object it has shaped the evolution of harmonic languages throughout the history of Western art music. Similarly, Curtis Roads points out that the experience of duration in a concert is contextualized through the micro, macro and supra time scales: the musical phrase is momentary compared to the totality of time left in the universe. Time can therefore also be thought of as a hyper-object, as time exists outside of the teleology of human life.

This chapter will discuss these two concepts - tonality and teleology - and the way in which they shaped the history of Western art music from the common practice to the integral serialists of the 1950s. As Graham Harman argues, if one approaches objects with the principle of correlation, object-object relationships are dismissed as simply a product of the human mind. This chapter will deal with how composers have approached this problem at three distinct periods in Western compositional history. First I will discuss the musical object in the common practice period, from Bach to Wagner. Then there will be an examination of how the object was approached in the early atonal period, especially in 38 
the context of the pre-serial works of Arnold Schoenberg. Finally, I will consider how Boulez and Stockhausen reevaluated their position to the object through their post-war integral serialist works. Such short analysis can only be indicative rather than total; in covering such a broad range of styles from the $17^{\text {th }}$ to the early twentieth-century I wish to avoid reductive reasoning. For this reason, the examples from these periods will be highly selective and can only be illustrative of the broader stylistic tendencies of the time. While the overall focus of this thesis is primarily in twenieth and twenty-first century art music, a broad overview of objects in the common-practice era will help elucidate the dramatic changes undertaken by composers in twentieth century music. A discussion of the late twentieth and early twenty-first centuries will accompany the analysis of Georg Friedrich Haas' In Vain in chapter four. The three periods discussed in this chapter are: the common-practice, early atonal and integral serialisr. Each gives distinctive insights into how composers have approached objects in music, and relates to the speculative realist idea of correlationism - that philosophy is limited by its focus on the subject-object correlate. In the music of the Romantics, the subject-object correlate is expressed through the idea that the representation of human expression and emotional depth is seen as the ultimate creative endeavor. The subject matter of Romantic music is often based on ideas of love, sex and death, and the orchestration techniques of the Romantics often involved a generous amount of expressive vibrato across all instruments, and an increased use of chromatic harmony to help tease out and expand the foundational I-IV-V-I progression of the classical period. This technique is often used in an attempt to simulate a romantic notion of consummation (McClary 81).

Another relevant concept is Harman's idea of caricature - that through vicarious causation, objects caricature each other through asymmetrical translation. Conventional musicologists may read 'caricature' as a stylistic approach to composition such as mimicry or imitation, but here caricature is meant as the transformation of one object through the form of another. The implication of this is that objects can never truly transform each other, only a select few of their qualities. While Harman uses the example of fire burning cotton, in this chapter we will discover how musical objects become caricatured in mostly harmonic contexts, as transposition and inversion can be thought of as forms of caricature. It is important to remember that the objects that result from this process are not ontologically inferior to the objects that spawned them, but they do exist at a different ontological scale. 
As discussed in the first chapter, Harman argues that philosophy suffers from the privileging of subject-object relationships, as it denies objects-object relationships without a subject involved to understand these, as if to suggest the world would not exist with a human subject there to witness it. Even if we set this aside, we can talk about the objecthood of music simply because that is how we perceive music as such. A chord or phrase is an object that we can discuss in the music of Bach, and entire pieces are objects with their own set of relations, such as Wagner's Siegfried, despite it being made up of smaller works, and relating to a higher level operatic cycle. We treat these ideas as objects when we listen, analyse, or remember. The relevancy for an object-oriented musicology is clear because this is already how we perceive music. There is an object whenever we conceive of something as a unity: that is the definition of an object, and as discussed in chapter two, objects are everywhere in music, at various ontological scales that connect in limited ways through networks of relationships. It is with this set of concepts in mind that I approach these historical eras in Western art music composition.

\section{Caricature and Nature in the Common-Practice}

Discussing objects in the Common-Practice era of composition is conceptually practical. Despite the flurry of styles that emerged in this time frame - from the Baroque to the Romantic - there is a theoretical homogeneity evident in the music, particularly in harmonic and programmatic terms. Dmitri Tymoczko's five components of tonality demonstrate that music of the common-practice fundamentally adheres to a few vital constraints:

1. Conjunct melodic motion: melodies tend to move by short distances

2. Acoustic consonance: consonance is preferred to dissonance

3. Harmonic consistency: different harmonies in the same work tend to be structurally similar to each other

4. Limited macroharmony: total number of pitch classes rarely exceeds 5-8

5. Centricity: one note is heard more often than others (Tymoczko 4)

One can think about these prescriptions as abstract components that construct the space of common-practice tonality, from the scalar practices of Bach to the chromaticism of 
Wagner. The music of both composers adheres to these constraints, and in this way inhabits the same conceptual constraint-space. As an object in this space, a C major triad may be expressed using Tymoczko notation ${ }^{9}$ as $\{C, E, G\},(E, G, C, C),(C 4, G 7, E 2)$, or even as an arpeggio or another rhythmic grouping. One could also perceive a chord progression as an object at another scale, such as IV-V-I: the most common harmonic progression in this period. The basic blocks of the object 'c major chord' is built up of three distinct objects themselves, which also all relate to an overtone series with $\mathrm{C}$ as the fundamental frequency. The significance of these relationships is that they demonstrate that tonality is an object-oriented language. Each of Tymoczko's components prescribes the limitations of objects in the tonal language, there are certain approaches to the lattice that are very rarely taken, and sometimes totally avoided, such as melodic movement with extreme and continuous gaps in register. However, this example is fitting beyond the common-practice, as Pierre Boulez utilizes this technique in the integral serialist work Structures 1 a . By using the components outlined by Tymoczko, the method of writing music in the tonal system becomes fairly systematic, if yet stylistically diverse. This is not to say composers in the common-practice were aware of all of these restrictions as such, but the trend seems to suggest the components are important in composing music in the tonal system, demonstrating the role the tonal system, as an object in itself, takes in forming and determining musical objects.

These components are maintained through variation also, as difference in tonal music normally functions as a process that essentially caricature melodic or harmonic ideas. The developmental techniques in tonal music of transposition and inversion have are relevant here, and different forms of these techniques have varying degrees of success in the translation of musical objects. Techniques such as scalar and chromatic transposition change the character of a melodic object while still maintaining the structural coherency of the object. This can help us to recognize the different caricatures (or versions) of an object in a particular piece of music, an important activity of any harmonic analysis of music from this period. Bach's two-part Invention no. 9 is a clear example of this process of object caricaturing. The work utilizes various kinds of transposition and inversion, allowing the scalar material in the first system to move from $\mathrm{F}$ minor, to $\mathrm{Bb}$ melodic minor ascending, through to G Lydian Augmented and then $\mathrm{F}$ harmonic minor. This

\footnotetext{
${ }^{9}$ Curly brackets are ordered, normal brackets are unordered, repeated pitches are pitches in different registers, numbers refer to register $(3=$ middle $\mathrm{C})$.
} 
focus on caricaturing objects to allow for smooth scalar movement can be understood as a hallmark of Bach's compositional technique.

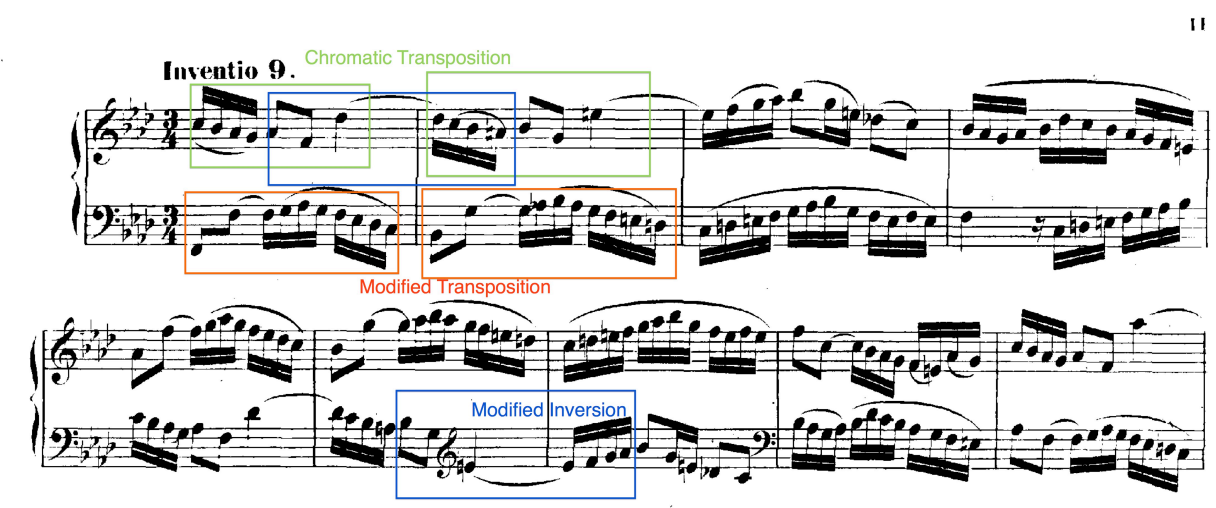

Figure 3: types of caricature relationships in Bach's ninth Invention Source: Complete Inventions; Bach-Gesellschaft Ausgabe; ed. Carl Ferdinand Becker; 1853

Musical objects are not the only objects being caricatured in common-practice music. There are extra-musical objects in music from Bach to that of Beethoven and Wagner, representing nature, love and death. Throughout visual art, literature and music, the move from the classical period to romanticism was generally concerned with the move from society and the wider world, to the individual. In musical terms, this resulted in programmatic and strongly representational forms and content. Beethoven's symphonies are clear examples of the trend, centered either on a heroic idea, a personal love of nature, or a connection to the sublime. These characteristics are an expression of an ideal representation of the world, or in fact an ideal representation of how one might interact with the world as something to which one aspires. Richard Leppert discusses how music shapes the human understanding of the natural world though the aestheticisation of time. By examining Synder's painting Concert of Birds, he shows how the cultural attitude towards music was one that represented man's mastery of nature:

The image puts nature into time; nature marches in step, in a pretty rhythm. It does so for the pleasures of those, both inside and external to the painting, who look, and who expect to see what they are seeing, and also what they are invited to sense: the triumph of organizing the world around the human pleasures of sensing and, through the particularities of sensing, and through the particularities of the appeals to sensing, the construction of modern subjectivity and selfhood (Leppert 354). 


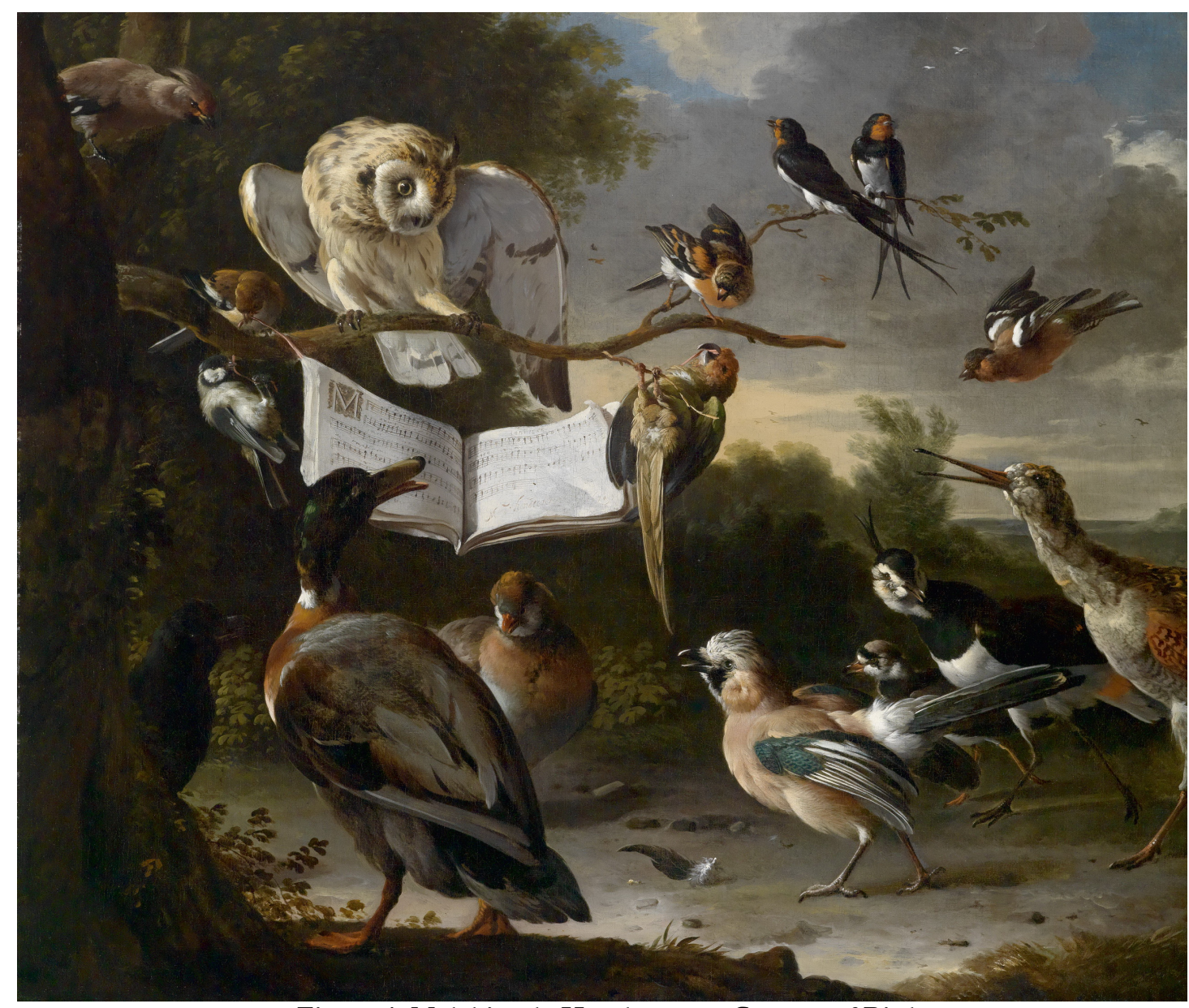

Figure 4: Melchior de Hondecoeter: Concert of Birds

1670. Oil on canvas. Private Collection.

This representation of nature and life is a constant presence in music of the commonpractice. The formal implications that shape music of this period are defined by the linearity of periods of tonal stability, harmonic tension and then the reinstatement of stability. This progression is largely representational of a life lived - teleology towards death, and arguably towards the stability of an afterlife. Even harmony itself became a representation of one's relationship to nature and the wider world: structured, aestheticized and hierarchical. As Jacques Attali writes:

\footnotetext{
Harmony is in a way the representation of an absolute relation between well-being and order in nature. In China as it is in Greece, harmony implies a system of measurement, in other words, a system for the scientific, quantified representation of nature $(60)$.
}

The transformation from the raw sound of nature to ordered materials puts nature and man into a hierarchy of economics: nature becomes a commodity, while humans are the merchants. In this way, musical harmony becomes an object caricaturing humanity's relationship to nature. Through this system, composers found a way to represent not only 
the world, but also the inner turmoil and emotional depths of fictional characters. Wagner's operas strongly evoke the subjective power of his characters, or, a in a very general sense, the erotic stimulation of uninhibited love (McClary 81). Wagner's Tristan und Isolde places both strong harmonic and programmatic objects on display: the use of the half-diminished seventh as a chromatic pivoting chord, and the story of Tristan itself, resulting literally in a sexual transformation through death - Isolde experiencing the erotic sublime after dying. The musical objects are used specifically for this purpose, and are therefore delimited by the correlationist attitude, which in this case caricatures objects through conceptual overmining.

While Wagner's Tristan resists Tymoczko's five components of tonality - at least in his $2^{\text {nd }}$, $4^{\text {th }}$ and $5^{\text {th }}$ rules - the work is still concerned with the general project of harmony: a representation hierarchy, with human beings at the top of the pyramid. There are few art forms so entrenched in the misery and ecstasy of human activity and drama than opera, and such a practice has an inherent representation of the world as secondary to, or even reliant on man. Opera of this time is strongly correlationist - focused explicitly on the subject-object relationship of man and world, a strongly anthropocentric view of the world. Such a representation has an implicit message of man being superior to the world, an assumption perhaps implicit in Western culture.

\section{Strange Worlds in Schoenberg's Early Atonal Period}

The work of both Harman and his contemporary Timothy Morton attribute an especially object-oriented compositional approach to Schoenberg's chamber opera Pierrot Lunaire. While initially this doesn't seem to be a particularly object-focused work - as the piece is focused on the trials and tribulations of the central character - there is a darkly caricaturing quality to the work, for we must remember that Pierrot is not a man at all, but a clown: a silhouette of human activity, a caricature of the mistakes we make, and stupidity we enact (or in Pierrot's case, we fail to enact) in everyday life. Opera in general has this very quality of caricature, and it is no coincidence that both opera and clowns owe their existence in the west to Greek theatre, being populated by dramatic and comedic archetypes, masks and scenic elements to trick audience perception (Parker 3). 
The narrative world Pierrot inhabits is full of strange objects that take on important roles: a sick moon, menacing butterflies, shining swords. Such objects take the focus away from the subject-object correlate and leads to speculation on how objects affect the world around us. As an attitude towards composition, Pierrot Lunaire does seem to have an object-oriented view of the world as a withdrawn network of relations. The objects in this piece are mysterious, as it is not clear how they function, but they do affect Pierrot's perception of events and his actions: the objects are withdrawn but act on Pierrot in unusual ways. Pierrot seems to show us the finitude and fallibility of human activity, our limited and lonely existence. As the hero and the fool, Pierrot clearly points towards a view of humanity as fractional to the world, not all-encompassing as an opera like Tristan und Isolde would suggest, where the world of the work dies when the character's subjectivity ceases to exist. Such a reading would advocate that Pierrot Luniare is an anti-humanist work, but Pierrot as a caricature of man is necessarily a negative one, as Pierrot is still shown to be a sympathetic, pitiful character. The music still has some attractive qualities, with quite soft and sensual melodic lines as apposed to dark brooding drones. Timothy Morton gives a very pithy blog post about the work, claiming:

\footnotetext{
The sparseness of the instrumentation emphasizes each musical object starkly. The music has that menacing yet ridiculous, menacingly ridiculous quality of really good clowns. Menacing intimacy. It's like sitting in a very small theater, right up close to the performers. (Pierrot Lunaire as Object-Oriented Music)
}

Other works made in the same era, such as Stravinsky's Petrushka and Berg's Wozzeck, have similar concerns. In the case of Petrushka, a puppet replaces the clown, while Berg's Wozzeck presents a protagonist that is an amoral, selfish analog of the masses. The work then suggests that people are destined to repeat the same mistakes and transgressions through every generation. Petrushka and Wozzeck both have central characters that are fundamentally flawed. While this is often the case in operas of the Romantics, these works offer a sense of parody - and in the case of Wozzeck - objectivity to the drama. This further distancing from the drama of human relationships is a case of caricaturing Romanticism itself, rather than actual human drama.

In the case of Pierrot Lunaire, Morton and Harman have shown great affection for the work as a bastion of object-oriented ideas in music, but it must be said they lack the specific musical knowledge required to go into detail about the harmonic and formal structures that produce such an effect. While I have suggested elsewhere in the thesis that this is not 
a requirement of understanding a work (all understanding is limited as objects are not totally accessible), theoretical knowledge does shed some light onto how this work achieves such an effect. The following discussion will focus on Schoenberg's harmonic idea and techniques of orchestration, which have an undercurrent of object-oriented tendencies. Pierrot Lunaire can be understood as a landmark in Schoenberg's career, having been written just after his Sechs kleine Klavierstücke (op. 19): a work of mostly instinctive atonal composition. Pierrot is similar, in that many of the scalar and harmonic choices are seemingly contradictory, move freely from pitch collection to pitch collection, and yet still retains the familiar techniques of tonal relationships. This can be related to Schoenberg's later serial works, in that they mostly retained the structures and variation ideas of the nineteenth century canon, but used the row at the center of the work instead of a shorter melody. Pierrot opens with the whole tone scale and its only other transposition in another register, completing the chromatic scale. There is no saturation of information however, as the floating, tensionless nature of the whole tone scale is preserved. Perhaps the clearest reference to the Romanticism as an object is in the continued use of a few easily identifiable rhythmic cells. This is quite clear in the song Valse de Chopin, which shares gestural shapes with the late Romantics, including some trill interjections from the bass clarinet. Such expressivity in Pierrot Lunaire takes one dark qualities, as the harmonies become more dissonant with each expressive interjection. These gestures are articulated on a staccato lattice from the piano, giving a very jolted backdrop to the freer sounding expressions of the bass clarinet. This caricaturing of Romantic and expression based aesthetics becomes an important aspect of the work. This use of orchestration as caricature is another technique Schoenberg implements. The use of a very high drone note is common occurrence throughout many of the songs; the most startling of which is in the song 'Madonna', where the bass clarinet plays a high (sounding) F. The clarinet in A performs the same task in the song 'Gebet an Pierrot', and the flute in the song 'Raub.' This is just another form of caricature as the kind of theme and variations we have seen in Bach. While composed in free atonality, Pierrot still shares many characteristics with the common-practice in terms of formal organization.

The early atonality of Schoenberg has an experimental nature. While he later settled on the 12-tone technique, the early piano works freely explore of the chromatic possibilities of the piano. At this early stage in his career, Schoenberg was far more concerned with an intuitive approach to atonality, often through the dominance of one or two intervallic 
values, using these techniques in works such as Drei Klavierstücke (op. 11) and Sechs kleine Klaverstücke. However, because these works were composed soon after the decline of Romanticism, the free atonal works still have vestiges of late Romantic tonality present. The tension between Schoenberg's intentional disassociation from Romanticism, and his subtle embrace of certain intervallic qualities integral to Romantic music, make these works particularly interesting for the study of musical objects. In this context, Romantic music is an object being assimilating into a wider musical space, caricatured through all twelve available notes on the piano. Through this exercise, Schoenberg pulls the frame of musicality wider, which allows for a more diverse set of objects to be accepted as musical. Fred Lerdahl discusses features in Sechs kleine Klaverstücke that relate to Ernö Lendvai's theory of axial tonality in Belá Bartók's music, in that the music seems to orientate itself around two pitches (79). In the case of the second movement, there is a clear reference to $\mathrm{G}$ and $\mathrm{B}$ throughout, which acts as a kind of tonal pull, not at all dissimilar to the way conventional tonal music orientates itself towards consonance. There is also a focus on major and minor third relationships between chords. As if taking a cue from Bach, Schoenberg's approach to his musical materials shows an object-oriented practice, as the intervallic explorations of these early works view musical objects with a degree of objectivity by viewing his materials as objects, as opposed to the continued exploration of representative qualities of Romantic harmony. The break from traditional methods of musicality is the defining moment in modernism because it makes a conscience effort to disconnect from those five components of tonality that Tymoczko prescribes. While these explorations into atonality would lead to the serialization of harmonic materials, which is even more clearly object-oriented, these pre-serial works give some insight into the development of Schoenberg's atonal language, and its position to the past feels more accepting.

\section{Awkward Objects in Integral Serialism}

The move from free atonality to the 12-tone technique has its own kind of paradox. On first look, impressionism and 12-tone music are aesthetic opposites: the Russian painter Wassily Kandinsky observed that Schoenberg's early atonal music had a freedom of association:

The independent progress through their own destinies, the independent life of the individual voices in your compositions, is exactly what I am trying to find in my paintings...I am certain that our modern harmony is not to be found in the 'geometric' way, but rather in the anti-geometric, antilogical way (Kropfinger 9). 
Schoenberg's turn to the extreme structure of the 12-tone technique seems to suggest he conceived of a way composers could fundamentally change their attitude towards composition. This move towards serialization continued with the works of Karlheinz Stockhausen and Pierre Boulez, with a rigorous and deep-set formalism in integral or total serialism. To Stockhausen and Boulez it seems, the answer to the proliferation of possibilities in twentieth century music was the absolute and precise control of each musical parameter. While this reaction is understandable as a modernist event, as a purging of the past, it may have just been that a new set of constraints were felt to be required as the infinite possibilities of music space proved overwhelming. Integral serialism is extremely object-oriented, and is perhaps the practice most aware of objects in music in any twentieth century. The focus on how each facet of a sound is crafted, how long each note should sound for, and the mathematic rigor of ensuring a purity of concept, all have the sonic object as the center the practice. However, there are limitations on how these objects operate, as composers of this music are concerned primarily with only one ontological level - the formal aspect, which results in the other ontological levels of a sound - such as pitch, rhythm, and timbre - being flattened onto a single plane, even as they resist it. The formal level becomes conceptually dominant.

Perhaps the most clearly objective aesthetic in twentieth century music is integral serialism, which is concerned with the serialization of all musical parameters. However, this saturation of theory (or in Harman's terms, the hidden, real qualities of the work) is difficult to distinguish through sensual experience, and can often be so obtuse that one needs to have the concept explained to appreciate the music even if its formal level remains withdrawn. This trend began with Schoenberg's serial works, which forms a major difference between the theoretical pre-compositional theory and the perceptual result, a major breakdown between the real and sensual objects. When Ligeti made his critique of serialism, it wasn't to do with the fact there was an organizing principle, it was to do with the imperceptibility of that kind of organization, which moves the importance in sound quality to the need of a self-organising, self-replicating system, which democratizes every parameter so that every interval, dynamic and rhythm has a place in every piece (Bernard 207). The problem is that this fails to take into account the sensual object for the listener. Integral serialist works not only require repeated listening, but also a familiarity with the aesthetic style, and while this could be said of many styles, the emphasis on pre- 
compositional planning and the super-structural nature of serialist thought placed great limitations on the perceptible object. In Ligeti's words:

\begin{abstract}
The individual character of the various serial arrangements fades as a result of the superposition of several horizontal series, in which, wherever possible, common notes occur at the same pitch. Such interweaving obscures the single serial threads (especially when all the parts are played on one instrument), and the resulting intervals have little or nothing to do with the original arrangement. Where such a procedure is coupled with the series of durations the composer can hardly even retain an influence over the intervals that are to result, let alone determine them. They follow automatically from the type of procedure. In this way the pitch series loses its last remnant of function, paralyzed by the emerging complex (Bernard 207).
\end{abstract}

Ligeti's critique is clear in object-oriented terms: the object becomes subservient to higher ontological levels - sounds (sensual experience) become as Ligeti puts it 'paralyzed by the emerging complex' (formal organization). In works like Structures $1 a$, the result is a pointillistic texture in chromatic space, difficult to perceive as the abstractly connected real and sensual qualities are split. As discussed in chapter one, phenomenological experience is overmined by the compositional schema, and is undermined by the emergence of objects at a lower level.

While I have already pointed towards the critique of integral serialism, it is still important that a work is analyzed to demonstrate these broad appraisals. Because of its logical rigor and transparency in analysis, Stockhausen's Klavierstück VIII is a good choice. Richard Toop sees it as the work most clearly aligned to its pre-compositional plan in the Klavierstück series. Toop outlines his analysis based on a single $6 \times 6$ serial square, which prescribes much of the formal elements in the Klavierstücke series 5 - 10 (93): 
The first line is the outline of an 'all-interval' series, while the remaining lines are created through operations (addition, subtraction, reversal) of the first line. This square is responsible for the tempo changes, dynamic shapes and formal sections of the work, while the actual series displayed below is a separate group of two six-note 'all-interval' series note that in the first half, the first and sixth note completes the interval possibilities betwseen them (Toop 99).

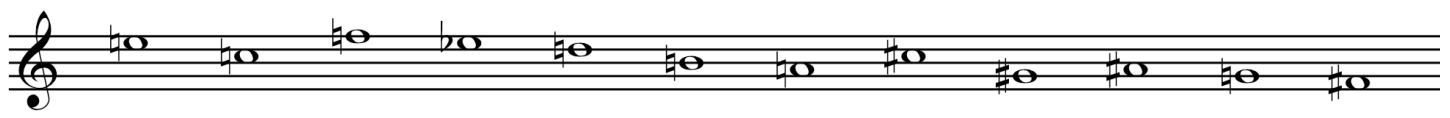

Figure 6: Series prime form in Klavierstücke VIII

The level of detail, and adherence to the square - in a formal context - is astoundingly precise. The kinds of dynamic envelopes are even specified through assigning each shape a number (Toop 97). This prescription of how musical objects behave in the serial space outlined by the square creates an extremely broad and unique set of musical objects, the implications of which goes beyond the square itself, into ontologically rich inner lives of the objects in question. One could conceive of a set of works dealing with just one object in the range of objects present throughout these pieces. Perhaps it is because of this excess of objects that many people find it so difficult to understand integral serialist composition at the sensual level. Without explicit repetition of some form, it is difficult to relate objects as perceived to the formal schema that produced them, even if that schema is precisely set. However, an interesting point Arnold Whittall makes in his discussion of Klavierstück VIII, is that there is sometimes a significant gap between the underlying structure and choices the composer made to enhance the musicality of his materials. As Whittall writes, 'such tension between surface and substructure seems only appropriate, given the highly fragmented nature of the keyboard writing' (183). While Whittall abandons this train of thought, it does give an interesting insight into the Stockhausen's method of treating such rough edges in serial planning; in object-oriented terms, it is as if he were attempting to reconcile the sensual sonic object the audience expects with the real qualities derived from rigid mathematical process. Such an observation does not condemn integral serialism, as there are many cases in Spectral or microtonal pieces where the work as perceived deviates from the original formal plan. However, such an action recognizes the intrinsic anthropocentricism in Western musical planning, an inherited feature from the commonpractice period which results in the need for audible objects. In other words, such deviation from the planning stages shows a desire for the music to be audibly understood. 
As Ligeti revealed, however, such a gesture in integral serialism often goes unnoticed due to the object's overwhelming paralysis in the face of overlying structures.

In Harman's language, it could be said that Serialism suffers from 'overmining' the sonic object because it limits the sonic object to an articulation of an omnipresent force in the work: the series, the serial square, and the assigning of numbers to different dynamic shapes and so forth (Quadruple 10-13). While the series itself is an object, this compositional method fails to recognize the objects it gives rise to on other scales as objects in their own right. Ligeti's solution to solve this problem is to work on a macrostructure as well as creating coherent individual lines throughout his work, which are all meticulously considered alongside the perceptible sonic result. This acknowledgement of the need to approach sonic objects at different scales is a central need of an objectoriented methodology, as the perceptual frame of the sensual object is a dynamic one in different musical contexts. As an aesthetic for composition, one must always recognize both aspects of ones materials, which is exactly how Ligeti thought about music in his critique of Serialism.

This chapter has served as a broad overview of how composers have treated the sonic object across the last two centuries, and has offered a kind of narrative from a subjectobject position on music with common-practice harmony, then moving to an objectobject position, observed in the strict integral serialist approach. Such a discussion has shown both the abundance of sonic objects in musical history, and the widening of the frame of musicality. We have discovered that the auditory horizon is not just about what one cannot hear, it is also about what one chooses to hear as music. This discussion has a secondary purpose, which is to prepare the reader for a more in-depth analysis in the final chapter, of twentieth century timbral composition and Georg Friedrich Haas' In V ain in particular. While we have already discussed timbral music in the last chapter, our discussion will be expanded to accommodate the discoveries made here, particularly the idea of caricature. Also, In Vain can be shown to be a particularly rich expression of a musically oriented object-oriented ontology. Haas' music is concerned with nature as an oppressive and dangerous force, which recognizes the limitation of human knowledge of the world. But also, the objects that inhabit the sound world are particularly interesting in the context of Harman's fourfold. 


\section{Timbre, Texture and Object Oriented Music, and an examination of Georg Friedrich Haas' In Vain}

Composition concerned with timbral and textural continua provides an interesting case study in the context of Graham Harman's fourfold system of objects. While the concepts of caricature and correlationism discussed in the last chapter have significance in all music, composition concerned with timbral and textural continua is generally more concerned with the surface level detail of sound than narrative, pitch-driven form or other kinds of extra-musical functionality. It therefore has an antithetical relationship to the correlationist attitude, which promotes an anthropocentric understanding of musical narrative and form. This chapter is concerned with late twentieth century composition's use of timbre and texture, and how this relates to the ideas of caricature and correlationism. In tracing this connection, the engagement with the object-hood of musical works that is particularly evident in composers of this generation becomes increasingly clear. The three case studies used to illustrate these ideas will be: György Ligeti's textural experiments of the 1960s; Gerard Grisey and Tristan Murail's Spectralism of the 1970s; and the hermetic sound worlds of Salvatore Sciarrino's music. The remainder of the chapter will be devoted to an object-oriented analysis of Georg Friedrich Haas' In V ain for 24 musicians. This analysis will function as an in-depth discussion of the ideas discussed in this thesis, and demonstrate how the work can be understood as object-oriented music. The use of philosophy as a practical and analytical tool is rarely a goal in the development of new ideas; however, Harman's fourfold approach of seeing objects as both isolated and relational is a novel one in contemporary musical analysis, which, as shown in chapter one, tends to either catalogue sounds to individual sound types or simply list musical objects in semiotic-like descriptions. The object-oriented approach will demonstrate the benefits of heterogeneity, as the ability to incorporate multiple theories strengthens the act of analysis. Yet ultimately, the purpose of this chapter is to define what an ideal object-oriented music would be. The examples below will be discussed through the lens of object-oriented ontology, to ascertain how certain features can be thought of as object-oriented. An object-oriented perspective can allow for a heterogeneous collaboration between theory and speculation, as it recognizes that all theories are non-totalizing: each theory can only caricature the work, and so different theories will allow the analyst to asses the work anew from different methodologies. 


\title{
Ligeti's Solution to Serialism's Problem
}

György Ligeti saw his textural music as a solution to the problems that arose in integral serialism. Composers working within integral serialism claimed that it was able to maintain conceptual consistency through very rigid formalist ideals, but this manifested as a highlevel mode of listening that was deeply abstracted from traditional methods of hearing musical structure. Each audible object became paralyzed by this high level structure, unable to function in any way but to articulate an abstracted organization. Schoenberg himself showed great dismay in how people misread the project of serialism to be centered on the row, rather than on the music itself.

\begin{abstract}
This isn't where the aesthetic qualities reveal themselves, or, if they do, only incidentally. I can't utter too many warnings against over-rating these analyses, since after all they only lead to what I have always been dead against: seeing how it is done, whereas I have always helped people to see: what it is! ... I can't say it often enough: my works are twelve-note compositions, not twelve-note compositions! (164-165)
\end{abstract}

György Ligeti's solution has two techniques: one is heterophony; the other is his recognizable micropolyphony. Ligeti uses heterophony in his choral work Lux Aeterna, where a single melodic line is sung at different speeds. This technique sounds like a temporal smearing of the melodic line, as some voices take ten bars to sing the melodic line, while others may only take two. Micropolyphony is defined as a form of chromatic wandering, with a strict interval and registral boundary. An interval vector analysis reveals the intervallic makeup of much of Ligeti's work - the value for such a collection is always 321000 , revealing a weighting towards minor second intervals, with the small possibility of a minor third leap. This discovery demonstrates that Ligeti's structure has a very close relationship to the perceptual result, which sounds like a tight bundle of energy, with very little scalar room to explore (Okonşar 21). Both heterophony and micropolyphony are able to sustain a dynamic relationship between the constitutent parts and the overlying structure. In the case of heterophony, the melodic object exists at all levels of work. On the other hand, micropolyphony is singularly concerned with interval sizes, meaning the audible result is very reflective of the concept itself.

The major difference between Ligeti's textural music and the music of the Romantics is that there is no caricaturing of human affairs in Ligeti's music. Rather, a work like Atmosphères is concerned with cosmic processes. Thomas Adés once said, "The vanishing 
point of any piece by Ligeti is the heat death of the universe" (139). Ligeti originally wanted to train as a scientist, and his music demonstrates the influence of various scientific and mathematics theories throughout his career as a composer. This results in music not concerned with the human-world correlate, but with the object-object relationships of atomic fusion, dying stars and the infinite sprawl of vast nebula. ${ }^{10}$ Considering Ligeti's understanding of integral serialism as a paralytic expression of the pitch series, one may find it ironic that Atmosphères is defined by a complex web of low level processes, which results in tone clusters that have a static quality. It may actually be this criticism of serialism that inspired the work, as there are 24 note series in the string parts at letter $\mathrm{H}$ (Steinitz 110-111). However the difference between the two aesthetics is clear upon listening. The static nature of Ligeti's work is the monolithic force of the piece. As each new texture appears across the auditory horizon, the previous texture fades out subtlety underneath. This non-teleological formal structure is a significant contrast to the Romantic aesthetic, as it does not develop organically, follow the trajectory of a human life, or lead to a climactic end; the opening five-octave cluster is the work's most harmonically condensed section. This upends traditional expectation of conventional pitch-driven formal organization by beginning with the most condensed and dissonant chord in the work.

Atmosphères can be thought of as object-oriented specifically because Ligeti explores his micro-polyphonic cloud as an object through various registers and dynamic profiles, which then dictate the formal organization. Rather than writing a work with formal considerations leading the musical objects, Ligeti allows himself to explore the object as form, through its various sensual qualities and possible relations to other objects throughout the work. Atmosphères is concerned with the variations in adumbrations one can perceive of the work, as a tension between the sensual object and its sensual qualities.

\section{Spectralism and the Harmonic Series}

In Tristan Murail's Désintégrations for orchestra and tape, different kinds of harmonic series are used for the purpose of creating tonal stability and tension. In general, Murail uses the

\footnotetext{
${ }^{10}$ Its not surprising Ligeti had such influences when Stanley Kubrick chose Atmosphéres to play over the final scene in 2001: A Space Odyssey, where the protagonist David Bowman undergoes a cosmic evolutionary process to become one with the stars. 
natural harmonic series (using the equation $f=f * x$ ) for stable sections, while using FM synthesis for harmonic tension $\left(\mathrm{f}=\mathrm{f} * \mathrm{x}^{\mathrm{n}}\right)$. The binary of stability and tension become analogous to the consonance and dissonance of the classical period. The two binaries are not isomorphic however, as instability is used primarily as organizing principle, while dissonance in the classical period is often a short-term developmental technique. However, it is important to note that consonance itself based on the harmonic series. The closer a chord is to the lower partials of a natural harmonic series, the more 'stable' it sounds, while deviating from this will result in inharmonicity and instability. Because of this relationship to the harmonic series, all Western music can be thought of as a caricature of this natural phenomenon.

Murail argues that the Spectral method of composition that he developed with Gerard Grisey goes beyond what Trevor Wishart calls the lattice conception of musical organization. Here Murail explains:

\footnotetext{
Our conception of music is held prisoner by tradition and by our education. All has been cut into slices, put into categories, classified, limited. There is a conceptual error from the very beginning: a composer does not work with 12 notes $\mathrm{x}$ rhythmic figures $\mathrm{x}$ dynamic markings, all infinitely permutable; he works with sound and time. Sound has been confounded with its representations, and we work with these, with symbols (137).
}

Because of this attitude towards music as 'sound in time', Spectralism is concerned with music as a physical and geometric phenomenon: sounds are waves of atmospheric pressure, which cycle a certain amount of times per second, at a specific amplitude, with a particular shape. The harmonic series then is effectively a collection of frequencies related to each other as multiples of a fundamental pitch. While all music is related to the harmonic series, Spectralism is focused on making that relationship as transparent as possible. However what Murail fails to recognize is that this is simply another representation of sound. By favouring one aspect of sound as nature above and beyond others results in correlationism, because this is a level humans have access to in a musical context. The way sound behaves as a physical entity cannot exhaust all relationships to the sound, such as its effect on human culture, plant life, or the resonating body responsible for the vibrations. Because sound is caricatured simply as 'harmonic spectra', the musical and perceptual result of this understanding becomes an unruly disarray of harmonic series stacked on top of each other. 
While baroque instruments were often restricted to the natural harmonic series, composers of this time did not often make use of the harmonic possibilities of the $7^{\text {th }}, 11^{\text {th }}$ and $13^{\text {th }}$ partials, and therefore did not engage with tonality as a continuum of the harmonic series. It is this phenomenon that drives Spectral composers, as the upper odd numbered partials provide colouristic contrast with the fundamental note below - or at least tonal reference to that note through the harmonic tension created between the two pitches. In theory, Spectral composers' occupation with the harmonic series results in music made with sound itself as the primary compositional material. However, while each instrument in an orchestra may play a note as one partial of a harmonic series, the individual timbres of each instrument adds its own overtone series to the overall mix, which results in a caricaturing of the harmonic series. It is this mixture of theory and practicality that makes Spectral music so sonically rich. The electronic analogue of this is additive synthesis with sine wave oscillators, which can certainly create rich timbres (and can in theory create any sound possible - though at an extreme this would require thousands and thousands of oscillators) - but practically speaking cannot readily create the complex textures possible with an orchestra. This is especially true when considering the accidental and individual sounds made by each instrumentalist, not only would these players have their own idiosyncratic playing styles or techniques, the noise associated with the transients of their instruments may not be a part of the underlying Spectral model. These features act as a kind of randomizing feature on each instrument, allowing for subtle variation and the possibility of an imperfect sound. Allowing instruments to sound beyond the ideal then allows the instrument as an object to reveal its accidental sensual features. While oscillators can also vary - as phase distortion or clipping of the signal can create unexpected sound the individual sound of an instrument in the context of an orchestral is readily accepted, and its complexity is incorporated into the texture.

As a compositional approach, Spectralism has an uncomfortable relationship to objectoriented ontology. In one sense, Spectralism falls into the same trap that tonality and integral serialism fell into. While Murail maintains that Spectralism is only an attitude for composing, composers still use Spectral techniques as a systematizing force. Kaija Saariaho has written extensively on how Spectral ideas can be used in the formal planning of a work (104). This approach suggests Spectralism is embroiled in the historical telos of Western art music, in that both the narrative of Spectralism put forth by Murail, and the creative applications of Spectral techniques by Saariaho, presents the history of Western music 
culminating in the revelation of Spectral music. This is troublesome in an object-oriented context as no single music or set of compositional techniques has more inherent value over any other. However, because Spectralism attempts to engage with objects beyond the immediately present - such as the harmonic series and unconventional tuning techniques it fulfills the idea of an object-oriented music. In addition to this, Spectral composers are often concerned with exploring the object and its multitude of real and sensual qualities, as shown in chapter two with the analysis of Grisey's Vortex Temporum.

\section{Sciarrino and the Surfaces of Objects}

Salvatore Sciarrino's works can be thought of as hermetic sound worlds, encapsulating the sonic possibilities of just one or two specific extended techniques, often used with a distinctive gestural profile. Brendan McConville calls these gestures the 'motto' of the work (37). The motto, as opposed to the motif or theme, is often a repeated gesture with a limited ability to vary because of its extreme specificity. For example, the third work from Sei Capricci for solo violin prescribes the use of a circular bowing gesture, which is the only gestural technique in the work. These strict and minimal sound palettes give rise to complex sound objects with a multitude of accidental features. In the case of circular bowing, the bow hair snags on various harmonics, creating accidental sonic artifacts. In prescribing effects that make these accidental sounds, Sciarrino shows he is concerned with drawing the listener's attention to the sensual qualities of musical objects. In addition to this, Sciarrino's works are formally organized as a kind of dramaturgy where no single sound is at the forefront of the stage. Sounds may come and leave without any formal teleological logic. In other works such as All'Aure in una Lontanaza for solo flute, one motto slowly replaces another as the main gesture in the work, giving the impression of a slow transition between two ideas. This is reminiscent of Ligeti's own formal processes in his large orchestral works. These kinds of structures give the impression that form is less of a concern for Sciarrino than the actual musical content; the surface of sound, and the singularity of each articulation of the motto gesture becomes the driving force of the work. His works therefore resist traditional approaches to form that build to climaxes and end with resolutions. For this reason, Sciarrino's music has strong significance for both the SO-SQ relationship, and the broken RO-SQ relationship - allure. Because each repetition of the motto (SO) is adorned in new sensual features (SQ), these features also drift away from the withdrawn object itself (RO). When one hears these new qualities, one is drawn 
into the subtle differences. In reality, these micro-variations occur because the performer or instrument is underequipped for the task at hand - it is humanly (and instrumentally) impossible to exactly recreate the motto, especially when the sound is on the edge of an experimental extended technique. The tension between the prescription in the score to recreate this sound exactly, and the limitations of human performance creates a form of allure. This challenge is why these sounds become hypnotic, and because of this, we become enchanted by this process, which creates new sensual objects for us as listeners. Brian Ferneyhough has commented on how he achieves this in his own music, claiming that the tension created between the score and the performance is an exploitation of the inner essence of the instrument (375). Just in Fereneyhough's music, Sciarrino's motto gesture hides in plain sight; it is constantly adrift in a sea of its own features.

\section{Nature, Process, and the Harmonic Series: Objects and Organization in Georg Friedrich Haas' In Vain}

In formulating any kind of analysis, the general approach is to choose one kind of analytic framework and feed the work through it. Examples include semiotic, traditional harmonic or critical analysis. However, an object-oriented approach would suggest that all of these frameworks are ultimately flawed. This is not to say that it is pointless or irrelevant to undertake such analysis, but instead one should accept the finitude of such analysis. Instead, analysis should be undertaken with the object as the starting point, and let the analytic system collide with the music at hand to see the features that are then revealed.

Georg Friedrich Haas' In Vain is a substantial work for 24 musicians. Lasting just over an hour and played in complete darkness, the players are required to memorize the entire work. Unsurprisingly, this means a sizable section of the score is semi-aleatoric in nature, consisting of musical phrases in box notation and broad tempo and dynamic cues. For example, on page 202 of the score, players are asked to play one phrase looped over the course of thirty seconds, during which the phrase speeds up and is played with a diminuendo. After the section concludes, the next cue begins. The material Haas employs in this work is uniform throughout. While twelve harmonic series are used (all taking their fundamental tone from the chromatic pitches of equal temperament), they are all of the natural series, and can be remembered simply by a number, such as, the thirteenth partial of a harmonic series starting on $\mathrm{C} \#$ is $\mathrm{B}_{d}$ (signified in the score as $\mathbf{1 3}$. B). The only other 
material in the work is an eleven-note chromatic scale played downwards, in the time signature of $4 / 4$ but in various tuplet formations, consisting of seven, nine, ten or eleven demisemiquavers in the duration of a single beat. This structure is used to give the impression of independent time streams within the framework of a single tempo, and allows the object to contrast with various caricatures of it to refract and reflect against the structure. While a traditional analysis of this process might label this as motivic variation, caricature offers a more generalized view, as motivic variation tends to suggest antiphonal music. The nature the structure would not be as successful if the materials themselves were more melodically varied, as the plainness of the chromatic collection, along with its fixed state, means the object can be explored as economically as possible; the object can be contrasted and compared at various points in the work to allow for complex sensuality to emerge.

The work utilizes a limited pool of materials that is used in an economic manner, meaning the work is particularly suited to demonstrate the practicalities of an object-oriented musical analysis. Furthermore, as the materials of the two main objects are so contrasting, each requires a specific set of analytic tools; approaching the object in several ways becomes essential to analyzing the work. This heterogeneous approach suggests that the artwork is substantial in its relational possibilities to both the real and the sensual. The multitude of possible interpretations is a testament to the work itself. In a rare discussion on object-oriented aesthetics, Harman proposes that the more interpretations an artwork can sustain, the more successful it is as an artwork (Guerrilla 212). This view goes beyond subjective value judgments to demonstrate the withdrawnness of objects as the aesthetic power of artworks. Object-oriented ontology relies on two fundamental ideas: human finitude (that we cannot know everything) and primacy of objects as the concern of philosophy. To account for the limitations in analyzing objects independently, the initial discussion about each object will be followed by an analysis concerning how they interact. First however, a discussion about In Vain's relationship to correlationism will help frame the analysis.

It could be said that Georg Friedich Haas's music is defined by a sense of darkness. Literally because so much of his work is played in visual darkness, such as the third string quartet in iij. Nocht and his opera Nacht, but his work is also concerned with darkness figuratively. Far from the ordered hierarchical sound world of Vivaldi's seasons, Haas's 
piece Natures Mortes represents nature as an unwieldy and dangerous force. Therefore, Haas does not represent nature in the Romantic sense of subservient to man, but rather highlights our limited knowledge and experience of nature. While Haas's music is highly teleological in places, it avoids Romantic narrative-driven formal organization. Instead, Haas's work uses a series of distinctive states, where some form of activity is repeated for a particular duration until the next state begins. One can observe this in Hyperion for orchestra, where the first section lasting seven and half minutes is a steady barbers pole of pitch articulation, the string appearing in lower registers and disappearing in higher registers before reappearing below again. Without any transition or warning, the next section begins with a kind of pulsing on the piano. This lack of concern for causal teleology demonstrates the difference between his music and the Romantic conception of teleology. It is because of this, that the objects that inhabit Haas's sound world are treated as objects in their own right. That is, the object is not subservient to the overall schema, and processes are simply left to enact themselves. Haas's use of his materials is therefore economical, as the same resources are used and explored in detail; as Haas says, "For nearly two decades I composed basically with only two chords. And I have not yet exhausted all the possibilities inherent in the relationship between them" (Varga 106). This economy is clear in In Vain also, as the limited pool of materials makes up an hour of music. Haas is able to explore the relationships between the various objects of the work, allowing for new complex objects to arise. Because Haas' music treats the object in this way, Haas' approach can be understood as object-oriented. In finding new inspirations he says, "I trust my sensations. I try to find out how sound and colour and time and dynamics fit together. I do not have any system. I do not trust systems at all" (Reising). This deep suspicion of systematizing music shows a concern that systems fail to recognize some part of the object, and that intuition, informed by the sensual qualities of the materials, is a potentially more successful way to organize music.

The natural harmonic series appears constantly throughout In Vain. All twelve chromatic notes are used as fundamental pitches; so twelve different harmonic series appear, as shown in figure 7. The series as an object is complex, multifaceted and in some respects novel to Western ears because of the microtonality implicit within it. The natural harmonic series is called natural because of its mathematic purity as an expression of multiplication; the word 'natural' has nothing to do with the perceptual result. Thinking in terms of an object's real or theoretical qualities, we can think of a frequency being the partial of a 
fundamental pitch, such as D being the third partial of G. However, we may also perceive a strengthening of $G$ as a stable tone. Similar to Murail, Haas uses the series to create stability. After the first section of downward chromatic motion, one series is used in conjunction with a series on another fundamental pitch, thus creating tension through dissonance. However, similarities between different harmonic series are also deployed, with shared pitches used to create an ambient pad linking series together. When Haas combines two or more series together from A to E, the aural effect is a kind of struggle for resolution. Before one object has overcome the other, pitches from another harmonic series have already infiltrated the texture. Dissonance is formed through the shortcomings of organizing music with the harmonic series. If one attempts to modulate between two different series, the dissonance is so great, and strange, that neither series really fully resolves the tension in a traditional sense. Instead, the relationship between the two series offers its own kind of harmonic logic, as these combinations act as a kind of metaharmonic field, smearing series together to create subtle tensions through voice leadings. This use of shared pitches is similar to the idea of common tone theory, in that triads that share one or two pitches are less contrasting (parsimonious in neo-Riemannian terms) than chords that do not share any pitches. The way these sensual objects interact is similar to how Lutoslawski work Chain III was described in chapter two: certain features are maintained between objects like a translation, while others fall to the wayside. 
As a sensual object, the harmonic series may sound synthetic to people not versed in microtonal music. Yet because of its relationship to the tempered scale, it is familiar enough to understand its construction. Therefore, the tempered and microtonal aspects of the series create a fission that is a feature of the object itself. This is especially the case when certain partials of the series are pulsed against other partials, such as in bb. 125-127. These adumbrations serve to explore this object and the sensual qualities that emerge when one emphasizes its different features. As one listens to the harmonic series and pays attention to its different features, one is drawn into the object as the source of musical interest, above form or narrative. This is a feature of object-oriented music because it 
places emphasis on the presence of the object, while subtlety reminding the listener of the object's withdrawn qualities.

Figure 7: The harmonic series material used in In Vain
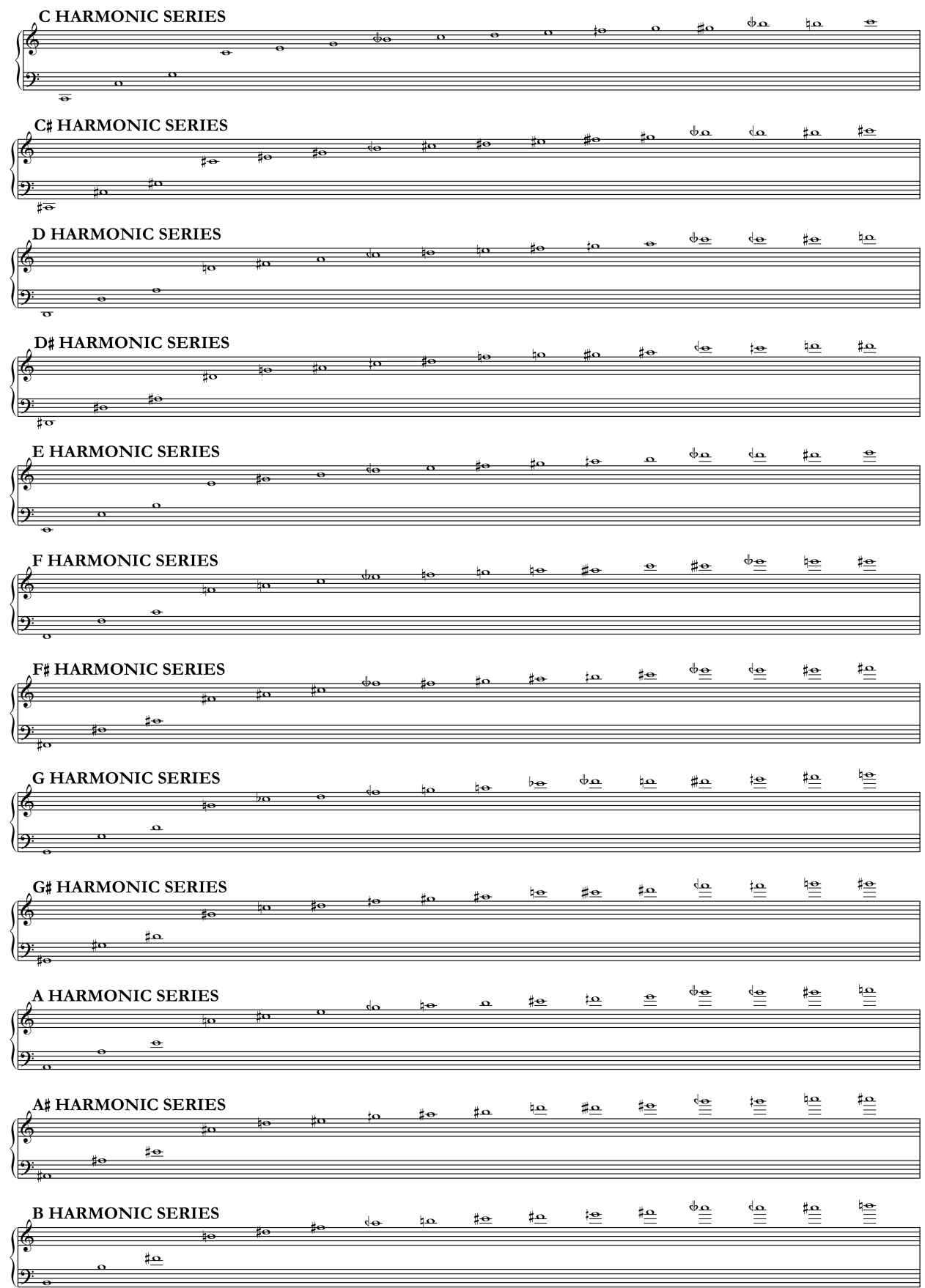

The downward chromatic scale used throughout In V ain appears at the beginning, middle and end of the piece, framing the work. However they do not frame in terms of formal structure. The scale as an object acts as the first state of being in the work. At the 
beginning of the work, the scale is used as process of building energy, increasing in intensity and then slowing releasing it. While this is a form of teleology, it is far more generalized than a Romantic teleology. The scale itself has only one real intervallic feature: the minor second. This results in a tense atmosphere, but because this is the only scale that appears, the harmonic tension never truly changes (indeed there is no possibility of it being resolved in a conventional sense). Instead, it is because of the increasing dynamic volume, registral shift, and changing tuplet subdivision across the ensemble that develops tension. This is interesting because the material based on the harmonic series throughout the rest of the work is almost solely dependent on the tension between the harmony and timbre. The first time one specific intervallic relationship becomes more prominent than the minor second is at bb. 28-29, when the trombones and horns increase dramatically in dynamic. The interval between the two groups changes from a tritone to a perfect fourth through a glissando in the trombones. Rather than providing a sense of stability, the perfect fourth maintains tension because of the glissando and the sudden increase in dynamic. As the tritone is the halving of the chromatic scale, this can be thought of as the slow breaking up the chromatic aggregate as an object first in half, and then gradually into the twelve transpositions of the harmonic series, which becomes more prominent towards the end of this first section. It is clear from this moment that Haas is concerned with reinventing harmonic relationships from the ground up: the chromatic scale is the primary apparatus of chromatic harmony, while the harmonic series is similarly the fundamental material in Spectral harmony.

The Lamento Moti

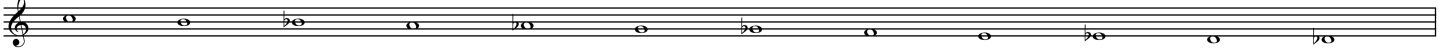

Figure 8: The chromatic scale, also known as the Lamento Motif

It is worth mentioning that the downward chromatic scale, referred to as the lamento motif in Ligeti scholarship, is also a ubiquitous feature in Ligeti's later works, specifically the violin concerto, piano concerto and piano études. As Ligeti's music is quite similar to Haas's, it is in this respect no surprise it appears in the work. The stark difference however, is that Haas uses it in a manner that drives the whole work forward, and with a constant reference to the augmented fourth interval. There is some similarity to Ligeti's chamber concerto also, as towards the end of the first section, leading towards the beginning of the harmonic series section, individual tones from the descending scale are sustained across the still descending texture. The descending chromatic scale's barbershop 
effect is akin to MC Escher's drawings of stairs that end where they began. The sensual effect of this is a stasis through movement. While the descending chromatic scale evokes a telos towards a resolution, no end ever comes. Instead, the object is defined by a selfcontradictory non-teleological teleology. This effect can be said to produce allure, in that the teleological essence of the chromatic scale is made unfamiliar to the listener.

The sense of object-hood in the work becomes quite clear in the notation of the central section of the work, all of which takes place in bb. 529. This section is composed exclusively in box notation, which has three purposes. Firstly and as already mentioned, the box notation has a practical function so performers can learn them before having to play in the dark. Secondly, it removes the need to repeatedly write out each note when the performer is simply repeating a single phrase. Finally, it allows for an organic sense in which each object transforms over time (similar in effect to repetition in Sciarrino's work just discussed). This section traverses a number of harmonic series, seguing from one to the next. There is a considerable similarity here to the downward chromatic section at the beginning, in terms of how tension is developed. While harmonic tension plays a part, the ensemble builds energy through dynamic change, speed and density. These textures even morph back into the chromatic section heard at the beginning. As with all causation in music, the two sections have a vicarious relationship, as many of the qualities of one are integrated into the other. As this section develops, the harmonic series are cycled through faster in a loosely chromatic descending motion, thus making the relationship between the two objects explicitly clear: the harmonic series acts as a prism to the descending chromatic gesture, revealing the hidden qualities in each pitch. This can be shown in bb. 320-343, in which the rhythmic activity of the descending chromatic line is contrasted heavily with the drone-like material of the harmonic series. As each line develops more energy, the harmonic series material begins to develop melodic variation, as shown by the horns and trombones articulating a downward line outlining the harmonic series in bb. 327. Although this relationship gestures towards a musical language based on both the harmonic series and chromaticism, its fate in In V ain suggests such a project is doomed. Just as the work began, the language Haas uses once again becomes a chromatic haze: the measured, unambiguous and codified structure of the equal tempered system. Gesturing towards a new musical language in this way emphasizes the work as a meditation on absence. For Haas - in contrast to the Spectralists - a new musical language cannot be 
understood as a natural music; there is no way to approach musical objects to get at the thing-in-itself, instead any understanding of an object is a caricature of that object.

Ultimately, the relationship between Haas, Ligeti, the Spectralists and Sciarrino, may simply be their rejection, or at very least their suspicion of the codified harmonic language of emotion. And while the Spectralists might be understood as simply replacing tonal harmonic language with another, Ligeti, Sciarrino and Haas attempt to develop musical forms that exploit the object-hood of music, rather than composing with a particular system of organization or seeking a means to justify a musical approach through an a priori sonic reality, a move which OOO would reveal as futile given the withdrawal of the real. This has implications for chromatic harmony, which is also based on the harmonic series. Such a revelation further reinforces the need for an object-oriented music, as tonality and Spectral music both caricature the musical object in some way.

To summarize, object-oriented ontology offers a powerful method to approaching and assessing musical objects. In describing musical objects, we can discuss the real and sensual qualities of objects in a way that will always recognize their inexhaustible nature. This helps to discover how composers may or may not be relying heavily on a subjectoriented approach to composition. Furthermore, the relationship between so-called textural approaches to composition and the non-correlationist attitude of speculative realism has been explicated, in that textural music is far more concerned with musical objects than subject-oriented functionalities of sound. The further implications of what object-oriented ontology has for music theory and musicology will be discussed in the concluding chapter, including a brief overview of how future research may address these concerns. Here, Ian Bogost's idea of carpentry will be addressed - the idea of art that does philosophical work. This concept is important because it emphasizes that new ways of thinking about music afford new ways of practicing music, and vice versa. Carpentry can be thought of as a collapsing of the theory-practice dichotomy onto a single activity. 


\section{Conclusion: Composition as Carpentry, and Reconciling Composer and Material}

Western art music has been consistently concerned with musical objects since the common-practice period, yet only in the past one hundred years has this become a concern for music composition. The contemporary instrumental music explored in this thesis provides a strong example of object-oriented music, demonstrating a move away from a subject-oriented desire to represent the subject-world correlate. It is not only in music that the correlate is an over-privileged mode of examining the world; Timothy Morton traces the birth of continental antirealism as a socio-political zeitgeist to the start of the industrial revolution. The birth of correlationism was also the birth of what geologist Paul Crutzen calls the anthropocene: the time when human life intersects with the geological transformation of Earth. In Morton's words:

\footnotetext{
The very humans that were responsible for the depositing of carbon in Earth's crust also produced philosophies that denied that the humanities could talk about anything other than human access to the real... Humans blindly penetrated Earth while insisting that no human consciousness could know the thing in itself... (2012)
}

The revolution of object-oriented ontology in an era of imminent ecological collapse has ethical implications, and while Harman never explicitly mentions an ethics of objectoriented ontology, Levi Bryant argues that one can be traced through his discussion on withdrawal:

\footnotetext{
Withdrawal is a protest against all ambitions of domination, mastery, and exploitation. What withdrawal says is that all entities harbor - as Graham likes to put it - scarcely imagined volcanic cores bubbling beneath the surface that we are never completely able to master or control. It is this from whence his profound respect for thingshuman and nonhuman -indeed his indignation against those that would try to reduce things to signifiers, concepts, sensations, lived experiences, intuitions, etc., arises. Harman seldom talks about politics or ethics, but who can fail to hear an ethical refrain throughout all his work... (2012)
}

How this ethics can be expressed in music can be difficult to reconcile given the power dynamic between a composer and his or her material. This is why the constraints of an object-oriented music were outlined in the introduction - they demonstrate how a composer may self-limit their power to rely on systems-based thinking or representation as a compositional tool. Because organizational tools reduce the object as the symptom of a 
wider organizational understanding, they caricature the object in a way that denes the ontology of the object. To recapitulate the constraints of an object-oriented music, the traits are:

* The object is shallow - at least perceptually. An object-oriented music would be concerned about the perceptual object itself as pure presence, even as perception never exhausts the object's qualities.

Recognition of the withdrawn nature of things. Objects are explored through their inexhaustible qualities and as relational entities. For example, the major scale was never truly exhausted by the common-practice, as shown through the "revitalization" of non-tonal scalar practices of Igor Stravinsky and György Kurtág.

* No reliance on one particular system of pitch organization. Such organization is overly concerned with the determinations of the subject, such as tonality and the codification of emotion.

* Rejects the Romantic conception of teleology as a representation of human experience. Teleology itself is acceptable, but it needs to have a critical and reflexive relationship to the object's own features, and not be subservient to formal organization.

My own hope is that I have managed to engage with these ideas in my own creative work in the portfolio that accompanies this thesis. The manner in which I have explored musical objects and the way they may interact demonstrates how one may compose with an object-oriented approach.

\section{Reconciling Object-oriented Music and the Portfolio}

The work Noumena, for orchestra, is concerned with two musical objects: one being the harmonic series, and the other being a chromatic textural micro-polyphony. The harmonic series is built on four pitches - C\#, E, G, Bb-a diminished seventh chord, and an equal division of the octave. The micro-polyphony is similar to Ligeti's, as there is an interval boundary of a minor third. To evoke the idea of the real object - the inaccessible thing-initself of each object - the work is defined by an absence. Neither idea is ever explored fully by the orchestra; the objects are expressed through only one or two instrumental groups. 
This culminates in a tension between the two ideas as they push up against each other in the last third of the work, in an attempt to explore the relationship between the two objects while maintaining their own particular identity. Their qualities then become enmeshed and the result is a sustained drone, shimmering with semitonal activity. This shallowness of the work articulates a surface instead of any kind of representation, and because the two pitch systems are very different from one another, they never truly reconcile, and no stability is reached. The issue here is that there is no need for the two objects to resolve, as they are very different kinds of objects that struggle to translate each other. This tension is the focal point of the work.

Rift, for string quartet, is a compositional experiment in expressing the extremes of register in the string quartet, and the colouristic similarities and differences between each voice in the ensemble. The work begins high above the fingerboard on each instrument, requiring the players to voice notes just next to the bridge on their highest string, with either a finger nail or a pencil to produce a purer frequency. What results from this is a tension between a thin sliver of pitch and a delicate noise band from the bow rubbing against the string. Register itself is explored as an object, starting from the highest possible pitches. The middle of the work then expands to two different directions once the middle of the registral space is reached. The two violins move back upwards, while the viola and cello continue to move towards their lowest pitches. The register becomes the object in question as the glacial movements of the quartet explore both the extremes in registral space and the subtleties in between the semitone division so common to Western ears. This is exemplified by the use of both long glissandos and microscopic eighth tones. While highly teleological, the work utilizes the teleology implicit within the object itself, as the total and extreme registral abilities of the string quartet cannot be explored all at once. This differs from a Romantic telos as no arrival point is reached, instead, register is explored to find the extremes of pitch production and discover what sounds lie beyond them. The exceptionally austere formal outline helps to emphasise the object - very few embellishments are used, and the gestural lines are almost always purely geometrically linear. The tension in the work is instead developed through timbral and dynamic processes acting like electronic filters on the instrumental sound.

The work for organ and live electronics, Ether, explores both sound and the organ itself as physical and spatial objects. By amplifying the organ and processing the sound across a 
surround sound eight-channel system, the organ's physicality is not only a force on the space it inhabits, but also upon an extension of that space. This demonstrates a concern Smalley has with space, that "[t]he trouble with space is it's the whole piece. It's the sounds and everything. Space is the whole thing" (Austin, 2000). While this attitude overmines musical objects, reducing them to the larger entity of musical form, it does emphasize the spatial aspect of music, without which sound would fail to travel across rooms. This physicality of sound evokes the withdrawn nature of music; while it is unseen, it continues to traverse space whether coming from a single loudspeaker or thirty musicians. Meanwhile, the Spectral processes that are undertaken in the MaxMSP patch caricature and reveal qualities inherent in the sound objects, transforming the organ gestures into uncanny objects. The electronics also serve as a memory net; the recording of the live sound is to be referenced later in the work. This plays with the audience's memory, as gestures they heard at the beginning of the piece may potentially sound towards the end. The listener encountering the same sound object at a different time highlights the object's adumbrations while emphasizing the difference between the sound object and the subject - while the object has not changed, the subject has. While this is one of Husserl's essential ideas, it still has place in object-oriented ontology as it recognizes the limitation of the subject to fully grasp the totality of the object. Finally, the score itself is object-oriented in the way it approaches the prescriptive organization of the work. Using box notation, the performer repeats gestures for a set duration before moving onto the next instruction. This repetition emphasizes the object as an object, while affording subtle variations between articulations of the gesture, creating different access points to perceive the object.

\section{The Carpentry of Things}

Harman uses the word carpentry to describe how objects shape each other, while for Ian Bogost, carpentry can be a human and philosophical activity. The portfolio of work undertaken here can be understood to be a kind of Bogostian carpentry - the idea of creative activities that do philosophical work. Bogost writes that philosophy as writing is over privileged, and that it can in fact be done in other exercises. He explains:

Like mechanics, philosophers ought to get their hands dirty. Not just dirty with logic or mathematics, in the way Bertrand Russell and Alfred North Whitehead's Principia Mathematica investigates the logicist view of mathematics by doing mathematics, but dirty with grease and panko breadcrumbs and formaldehyde. I give the name carpentry to this practice of constructing artifacts as a philosophical practice (92). 
Bogost's idea endorses a speculative and creative practice. As a composer, this might be an object-oriented music, or perhaps what is referred to in a contemporary context as research-led composition. Such a practice reinforces the idea that research-led composition can aid in the discovery and practice of new musical concepts, at least within an object-oriented context. If one thinks of the written part of this thesis as the theory, and the portfolio as the practice, they can actually be considered two sides of the same coin, as both are engaged in the practice of doing philosophy.

The idea of philosophical carpentry is in tension with the problems of authorial intent, as for Bogost, the object needs to be intended for philosophical use. This prescription implies that one needs to be aware of the creator's intent to understand the object. However, such a tension forgets that object-oriented ontology does not deny hermeneutic thinking, but rather demonstrates that objects themselves are involved in their own version of this, which is neither logo-centric nor linguistic in nature. While authorial intent may be a problem for philosophers of language, any concerned may be alleviated by the words of Wimsatt and Beardsly themselves:

\footnotetext{
It is only because an artifact works that we infer the intention of an artificer. A poem should not mean but be. A poem can be only through its meaning - since its medium is words - yet it is, simply is in the sense that we have no excuse for inquiring what part is intended or meant (4).
}

However, if one does not view the object as a piece of philosophical work, that aspect of the object would remain withdrawn. In other words, the philosophical content of the object would not be accessible to those who are not looking for it.

My hope is that I have practiced carpentry by approaching my compositional output with a focus on the musical objects themselves, rather than as either a tool of self-expression or in a way that reduces the objects. By composing beginning with the object, rather than starting with a set of material parameters, the musical content can evolve in a way that resists conventional and teleological consolation.

\section{Potential Future Avenues of Research}


This thesis attempts to begin to bridge the fields of music and object-oriented ontology. In doing so, a number of further research topics beyond the scope of the thesis have emerged: primarily, reconciling the phenomenological tradition that already exists within music, and this new object-oriented approach. Pierre Schaeffer, Dennis Smalley, and Don Idhe all at least reference the primacy of experience above theory, though in a way are all very rooted in the Husserlian attitude, especially concerning epoché, the phenomenological reduction of the world to intentional objects and consciousness. Idhe does make some reference to Heidegger, but only about his hermeneutic revelations in 'The Origin of the Work of Art.' Idhe argues this can be understood as a 'second phenomenology', and that experience must be understood in its cultural and historical context (20). This deeply correlationist perspective can be developed to encompass objectoriented perspectives. Such a task would require a critique of Smalley's spectromorphology and Schaeffer's typo-morphologies of sound objects, furthering critical research into how electronic music can be understood as object-oriented, an undertaking that has begun with Chuck Johnson's speculative essay referenced in the introduction. This kind of project would aid in contextualizing object-oriented ontology within the wider critical tradition of musicology.

Chapter two had a short section on Harman's concept of allure. This is only one of four types of broken links between the fourfold. Further research in this area could help develop an aesthetic theory of object-oriented music, similar to the way in which Harman analyses H. P. Lovecraft's works through fission, fusion, and metaphor. Harman argues that Lovecraft's descriptive writing style resists a totalizing representation of characters and monsters; instead, Lovecraft draws attention to the narrator's feelings of weirdness and horror, which caricatures reality (Lovecraft 234). In Lovecraft's The Call of Cthulhu, he writes, "I shall not be unfaithful to the spirit of the thing... but it was the general outline of the whole which made it the most shockingly frightful" (169). Harman demonstrates that Lovecraft never literalizes in his descriptions, instead relying on the human fear of the unknown. This has some significance in music because of its evanescent and withdrawn nature, and brings to mind the problems inherent in replicating frequency spectrums across an orchestra, whose own set of overtones and noise bands ends up distorting the spectrum anyway. Such a project would require the development of the aesthetic theory of object-oriented music discussed briefly in this thesis. 
However, perhaps the richest avenue of research is that of composition itself as a means of investigating the ontology of musical objects. As shown throughout the thesis, the practical activity of composition can aid in exploring the essences and qualities of things. Through orchestration, experimentation with timbre, and music technology, composition can explore how objects relate, attract and repel each other through numerous sensual and real levels. By exploring relationships and tensions within Harman's fourfold, musical concepts can be discovered, developed, and practiced. 


\section{Works Cited}

Adès, Thomas, and Tom Service. Thomas Adès: Full of Noises : Conversations with Tom Service.

Farrar, Straus and Giroux. 2012.

Adorno, Theodor. Negative Dialectics. Trans. E.B. Ashton. London: Routledge. 1973.

Attali, Jacques. Noise: the political economy of music. Minneapolis: University of Minnesota Press, 1985.

Bernard, Jonathan W. "Inaudible Structures, Audible Music: Ligeti's Problem, and His Solution.” Music Analysis 6, no. 3 (October 1, 1987): 207-236.

Bogost, Ian. Alien Phenomenology, or, What It's Like to Be a Thing. Minneapolis: University of Minnesota Press, 2012.

Bryant, Levi. "Harman, Withdrawal, and Vacuum Packed Objects: My Gratitude.” Larval Subjects. 2012. Web. Feb. 19, 2014.

Butterfield, Matthew. “The Musical Object Revisited.” Music Analysis 21, no. 3 (2002): 327-380.

Carpentier, Gregoiré, and Jean Bresson. "Interacting with Symbol, Sound, and Feature Spaces in Orchidée, a Computer-Aided Orchestration Environment." Computer Music Journal 34, no. 1 (2010): 10-27.

Cohn, Richard. "Introduction to Neo-Riemannian Theory: A Survey and a Historical Perspective." Journal of Music Theory 42, no. 2 (1998): 167.

Deleuze, Gilles, and Félix Guattari. A Thousand Plateaus Capitalism and Schizophrenia. London: Continuum, 2008.

DeNora, Tia. "Music and Self-Identity," in The Popular Music Studies Reader, eds. Andy Bennett, Barry Shank, and Jason Toynbee (New York: Routledge, 2006), 141-147.

Ferneyhough, Brian, James Boros, Richard Toop, and Jonathan Harvey. Collected Writings. Amsterdam: Harwood Academic Publishers, 1995. 
Fink, Eugen. Sixth Cartesian Meditation: The Idea of a Transcendental Theory of Method. Trans. Ronald Bruzina. Bloomington: Indiana University Press. 1995.

Fisher, John Andrew. "What the Hills Are Alive with: In Defense of the Sounds of Nature." The Journal of Aesthetics and Art Criticism 56, no. 2 (April 1, 1998): 167-179.

Harman, Graham. ‘On Vicarious Causation', Collapse Vol 2: Speculative Realism, ed. Robin Mackay, Urbanomic, 2012: 187-221

Harman, Graham. "Time, Space, Essence, and Eidos: A New Theory of Causation.” Cosmos and History: The Journal of Natural and Social Philosophy 6, no. 1 (November 9, 2010): 1-17.

Harman, Graham. Guerrilla Metaphysics: Phenomenology and the Carpentry of Things. Chicago, Ill. [u.a.: Open Court, 2005.

Harman, Graham. Heidegger Explained: From Phenomenon to Thing. Chicago: Open Court, 2007.

Harman, Graham. Prince of Networks: Bruno Latour and Metaphysics. Prahran, Vic.: Re.press, 2009.

Harman, Graham. The Quadruple Object. Reprint. Zero Books, 2011.

Harman, Graham. Tool-being: Heidegger and the Metaphyics of Objects. Chicago: Open Court, 2002. Harman, Graham. Weird Realism: Lovecraft and Philosophy. Winchester, UK; Washington: Zero Books, 2012.

Harper, Adam. Infinite Music: Imagining the Next Millennium of Human Music-making. Ropley: Zero, 2011.

Hasegawa, Robert. "Gérard Grisey and the 'Nature' of Harmony.” Music Analysis 28, no. 2-3 (2009): 349-371.

Heidegger, Martin, and David Farrell Krell. "The Origin of the Work of Art.” Basic Writings: From Being and Time (1927) to The Task of Thinking (1964). New York: Harper Perennial Modern Thought, 2008: 139-213.

Heidegger, Martin, Joan Stambaugh, and Dennis J Schmidt. Being and Time. Albany: State University of New York Press, 2010. 
Ihde, Don. Listening and Voice: Phenomenologies of Sound. Albany: State University of New York Press, 2007.

Johnson, Chuck. "World on a Wire: Sound as Sensual Objects." Leonardo Music Journal 23, no. 1 (2013): 75-77.

Kant, Immanuel. Lectures on Philosophical Theology. trans. by Allen W. Wood and Gertrude M.

Clark, Ithaca and London, Cornell University Press. 1978.

Kramer, Jonathan D. "Moment Form in Twentieth Century Music." The Musical Quarterly 64, no. 2 (April 1, 1978): 177-194.

Kropfinger, Klaus. "Latent Structural Power versus the Dissolution of Artistic Material in the works of Kandinsky and Schoenberg." Schoenberg and Kandinsky: An Historic Encounter. Ed. Konrad Boehmer. Netherlands: Harwood Academic Publishers. 1997: 9-66

Lakoff, George. Women, Fire, and Dangerous Things: What Categories Reveal about the Mind. University of Chicago Press. 1987.

Leppert, Richard. “Temporal Interventions: Music, Modernity, and the Presentation of Self." Structures of Feeling in Seventeenth-Century Cultural Expression. Ed. Susan McClary. University of Toronto Press, 2013: 338-360

Lerdahl, Fred. “Atonal Prolongational Structure.” Contemporary Music Review 4, no. 1 (1989): 6587

McClary, Susan. Feminine Endings: Music, Gender, and Sexuality. Minneapolis: University of Minnesota Press. 2002.

McConville, Brendan P. 'Reconnoitering the sonic spectrum of Salvatore Sciarrino in 'All aure in auna lontanaza'. Tempo 65 (255), 2011, pp. 31-44

Meillassoux, Quentin. After Finitude: An Essay on the Necessity of Contingency. Translated by Ray Brassier. Bloomsbury Academic, 2010.

Morton, Timothy. "On Entering the Anthropocene (MP3).” Ecology Without Nature. 2012. Web. Feb. 192014. 
Murail, Tristan. "Spectra and Sprites." Contemporary Music Review 24, no. 2-3 (2005): 137-147

Okonşar, Mehmet. "Micropolyphony: Motivations and Justifications Behind a Concept Introduced by G. Ligeti.” Mehmet Okonşar: Offical Website. Web. 01 Jan. 2014.

Parker, Roger. The Oxford Illustrated History of Opera. Oxford: Oxford University Press, 2001.

Reising, Sam. "5 Questions to Georg Friedrich Haas (composer)". I CARE IF YOU LISTEN. Web. February 18, 2014.

Robin Mackay. Collapse Vol. IV: Concept Horror. Urbanomic. Web. Feb. 72014.

Saariaho, Kaija. "Timbre and Harmony: Interpolations of Timbral Structures.” Contemporary Music Review 2, no. 1 (1987): 93-133.

Schaeffer, Pierre. Machines a Communiquer. Paris: E’ ditions du Seuil. 1970.

Schoenberg, Arnold. Letters. Ed. Erwin Stein, tr, Eithe Wilkins and Ernst Kaiser. London: Faber and Faber. 1964.

Small, Christopher. Musicking: The Meanings of Performance and Listening. Hanover, NH: University Press of New England, 1998.

Smalley, Denis. "Spectromorphology: Explaining Sound-shapes." Organised Sound 2, no. 02 (1997): 107-126.

Steinitz, Richard. György Ligeti: Music of the Imagination. Boston: Northeastern University Press, 2003.

Taruskin, Richard. "Chapter 5 Polyphony in Practice and Theory." The Oxford History of Western Music. . New York: Oxford University Press. Web. 17 Feb. 2014.

Toop, Richard. "Stockhausen's Klavierstück VIII". Miscellanea Musicologica (Adelaide) 10. 1979: 93130

Tymoczko, Dmitri. A Geometry of Music: Harmony and Counterpoint in the Extended Common Practice. New York: Oxford University Press, 2011. 
Varga, Bálint András. Three Questions for Sixty-five Composers. Rochester, NY: University of Rochester Press, 2011.

Whittall, Arnold. The Cambridge Introduction to Serialism. New York: Cambridge University Press, 2008.

Wimsatt, William and Beardsley, Monroe. "The Intentional Fallacy.” The Verbal Icon: Studies in the Meaning of Poetry. Lexington: University of Kentucky Press, 1954: 3-18 


\title{
J A S O N P O S T
}

\section{Portfolio of Works}

\author{
Noumena FOR ORCHESTRA \\ Rift FOR STRING QUARTET
}

Ether FOR ORGAN AND LIVE ELECTRONICS

Submitted in partial fulfillment of the requirements for the degree of Master of Music in the New Zealand School of Music, 2014

Wellington, New Zealand 



\section{Contents}

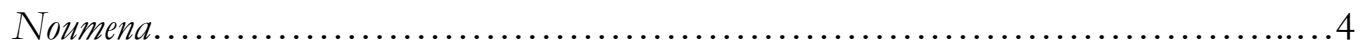

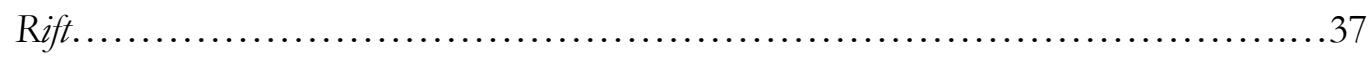

Ether................................................................. 48

Explanation of Live Electronics in Ether..................................5 53

\section{Contents of CD}

Electronic copies of each score

Recording of each work

MaxMSP Patch for Ether

Electronic copy of thesis 


$$
\text { J A S O N P O S T }
$$

noumena

F OR ORCHESTRA

2013 


\section{Programme Note}

The title of this work refers to an object beyond our phenomenal experience of it. Throughout the piece, listeners are presented with two musical ideas: a cloud-like micropolyphony, and a collection of harmonically rich sustained chords. However, both ideas are defined by an absence; neither idea achieves a stable equilibrium with the other, and neither ever commands the full focus of the orchestra. Consequently, the two ideas are locked in an ever-evolving relationship: never in direct contact, yet always absorbed in each other's existence. While negotiating space, the two ideas simultaneously reveal their hidden qualities while also hinting at a deeper world of activity underneath.

\section{Duration: $c .8$ Minutes}

jason.w.post@gmail.com www.jasonpost.info 
Instrumentation

2 flutes $(\mathrm{I}=$ Piccolo)

2 oboes

2 clarinets in $\mathrm{Bb}(\mathrm{I}=\mathrm{E} b$ clarinet $)$

2 bassoons

4 horns in $\mathrm{F}$

2 trumpets

2 tenor trombones

1 bass trombone

tuba

timpani

2 percussion

harp

strings

the score is transposed

Percussion

marimba

vibraphone

tam-tam

glockenspiel 


\section{performance notes}

Microtones are used extensively throughout the work: these are notated as:

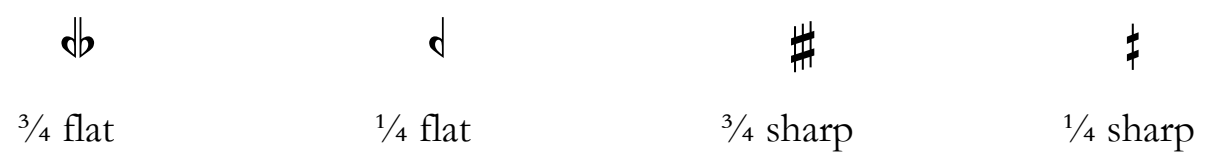

The work articulates a series of harmonic fields based on four harmonic series $(\mathbf{E}, \mathbf{G}$,

$\mathbf{B} \mathbf{b}$ and $\mathbf{C} \#)$, as such, each pitch that is part of these fields is assigned a number corresponding the partial of a harmonic series. For example, the horns often play a sounding D quarter flat, which is the seventh partial of an $\mathrm{E}$ harmonic series, this is notated as E. 7 above the pitch. While this information is primarily useful for the conductor, players should try to tune their microtones to these series as accurately as possible.

\section{Woodwinds}

Flute fingerings for microtones can be found attached to the flute parts; these should be relatively stable in pitch.

Oboe microtones can most easily made through lipping a note a quarter sharp or flat; these can be quite difficult and require careful listening on the part of the performer to control.

Clarinet fingerings for microtones can be found attached to the clarinet parts; these are quite easy to play and maintain, and if the performer finds easier fingerings to each pitch, $\mathrm{s} /$ he may use them.

Bassoon microtones are most easily made through lipping a note a quarter sharp or flat.

\section{Brass}

The horns play a number of quartertones, which is made possible through using the 'wolf tones' of the instrument, utilizing the $7^{\text {th }}, 11^{\text {th }}$ and $13^{\text {th }}$ partials of the pedal tones. These fingerings are notated through the bold type above any microtonal note, for example: Bb23 (B quarter flat in the middle of the treble staff). This should help differentiate between the player instruction and general harmonic field information, which is in a much larger type. 


\section{Harp}

The $\mathbf{H a r p}$ tunes their treble staff $\mathrm{B} b$ down a quartertone, to approximately $453.238 \mathbf{~ H z}$

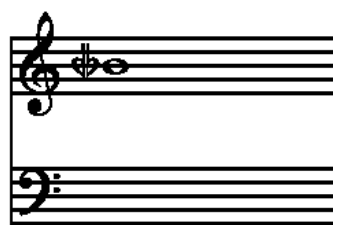

Strings

Bow positions

S.T. $\quad$ Sul Tasto

S.P. Sul Pont.

M.S.P Molto Sul Pont.

Ricochet should be played in one bow stroke, like a ping bong ball bouncing faster and faster, the note should then be played normalé once bouncing has stopped. 
noumena
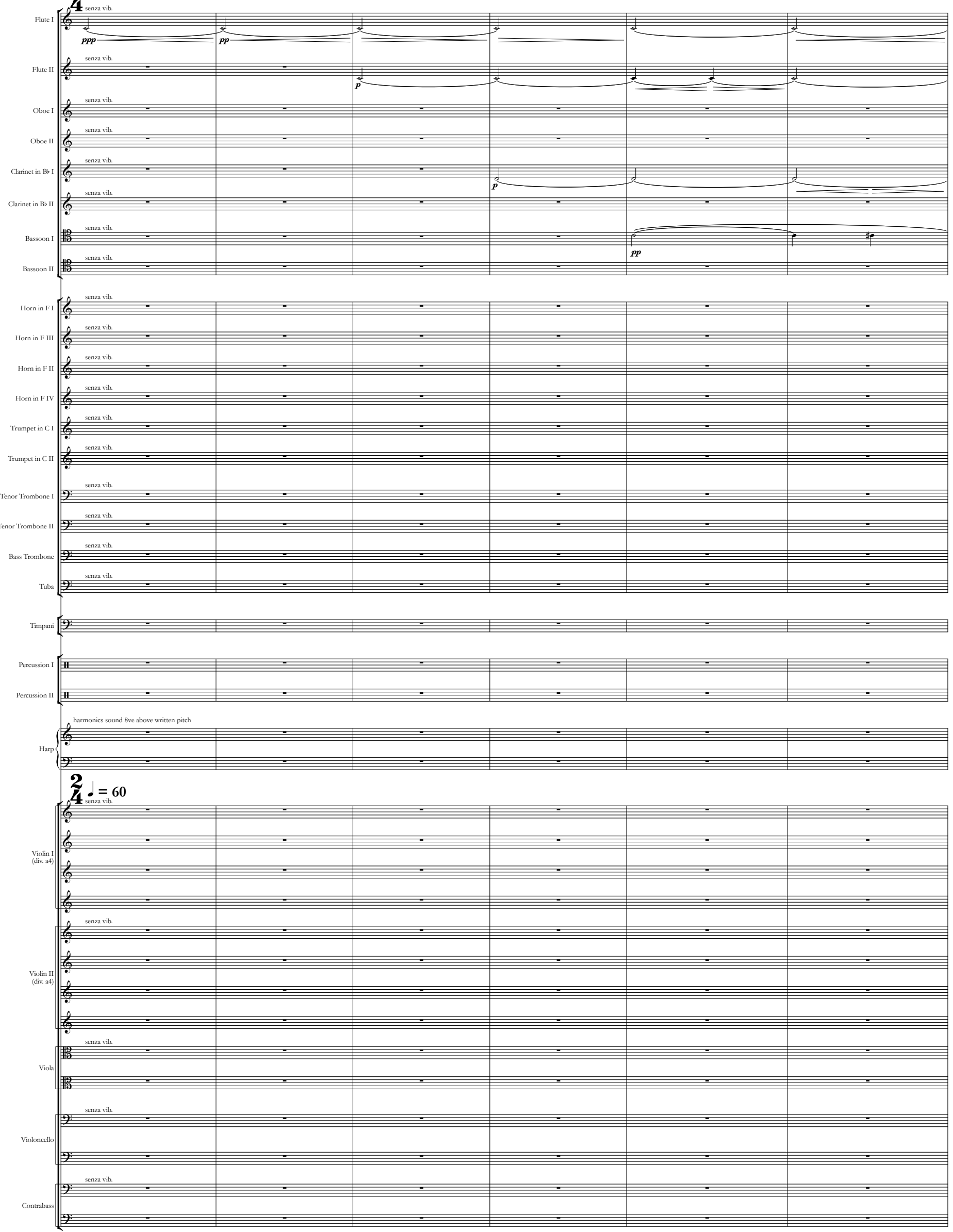


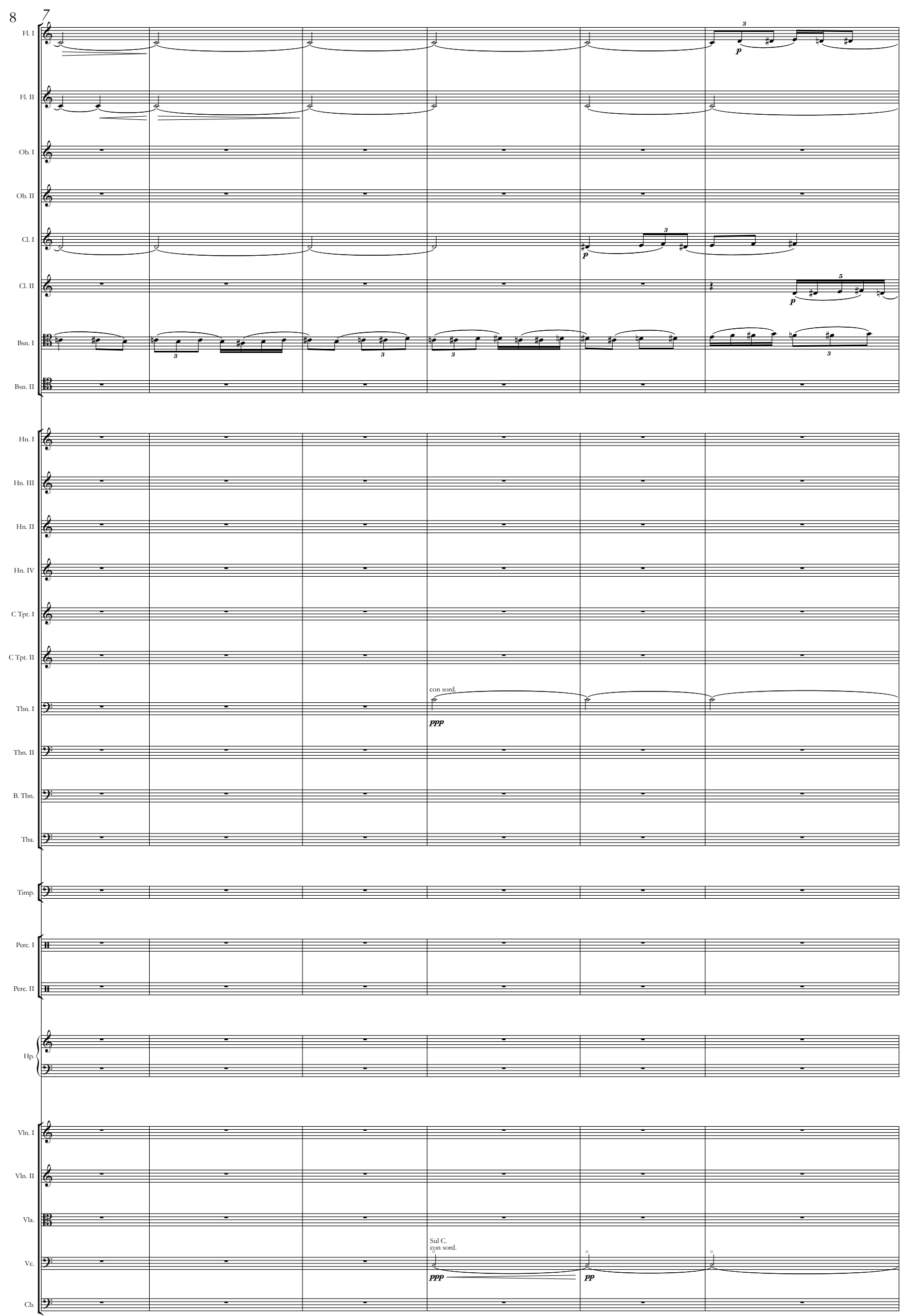


A
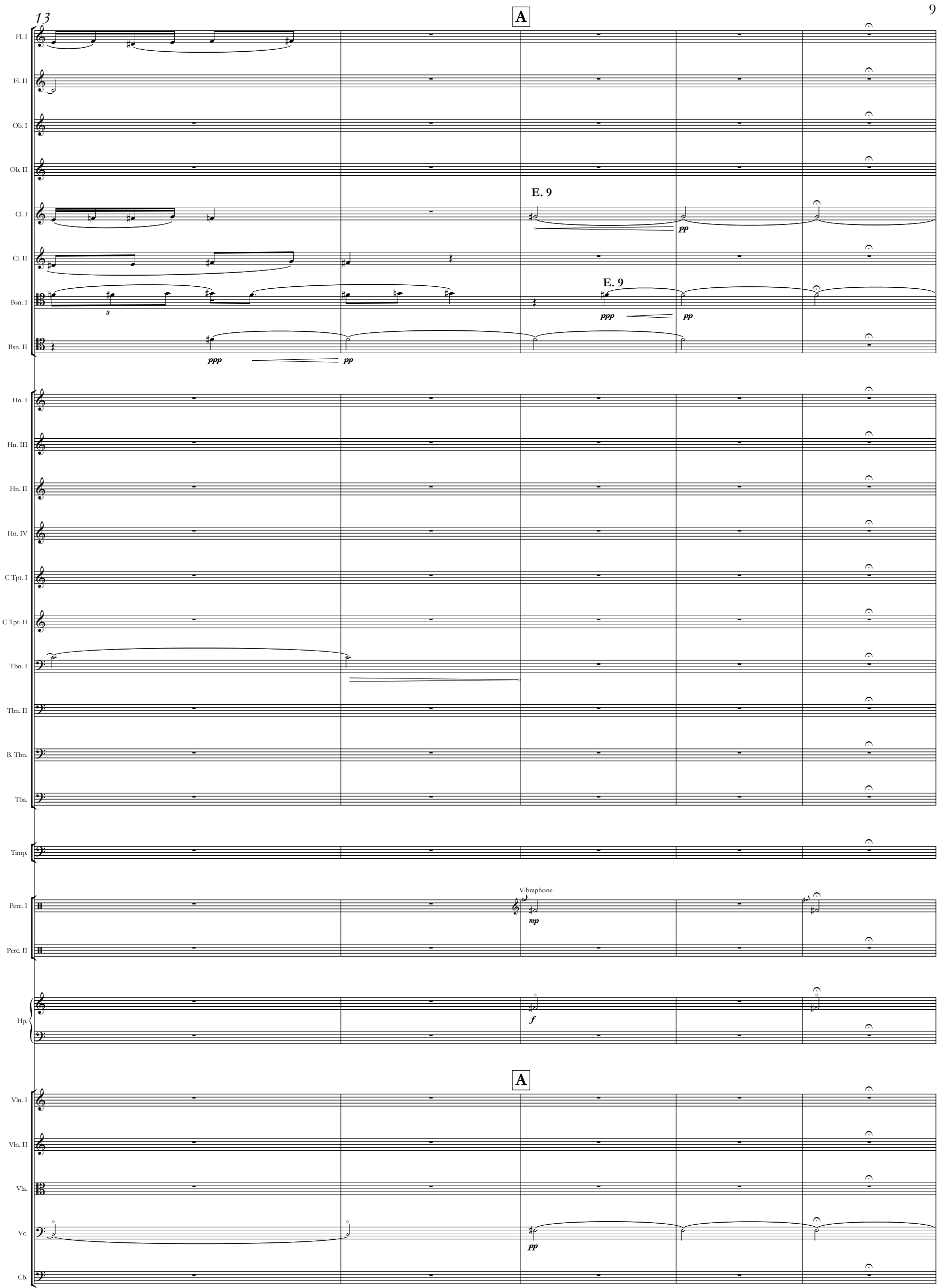

A

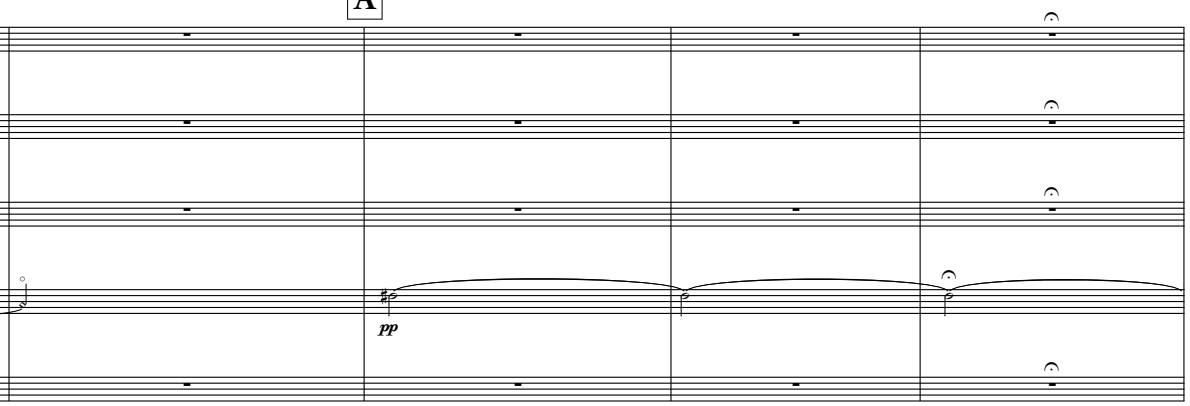




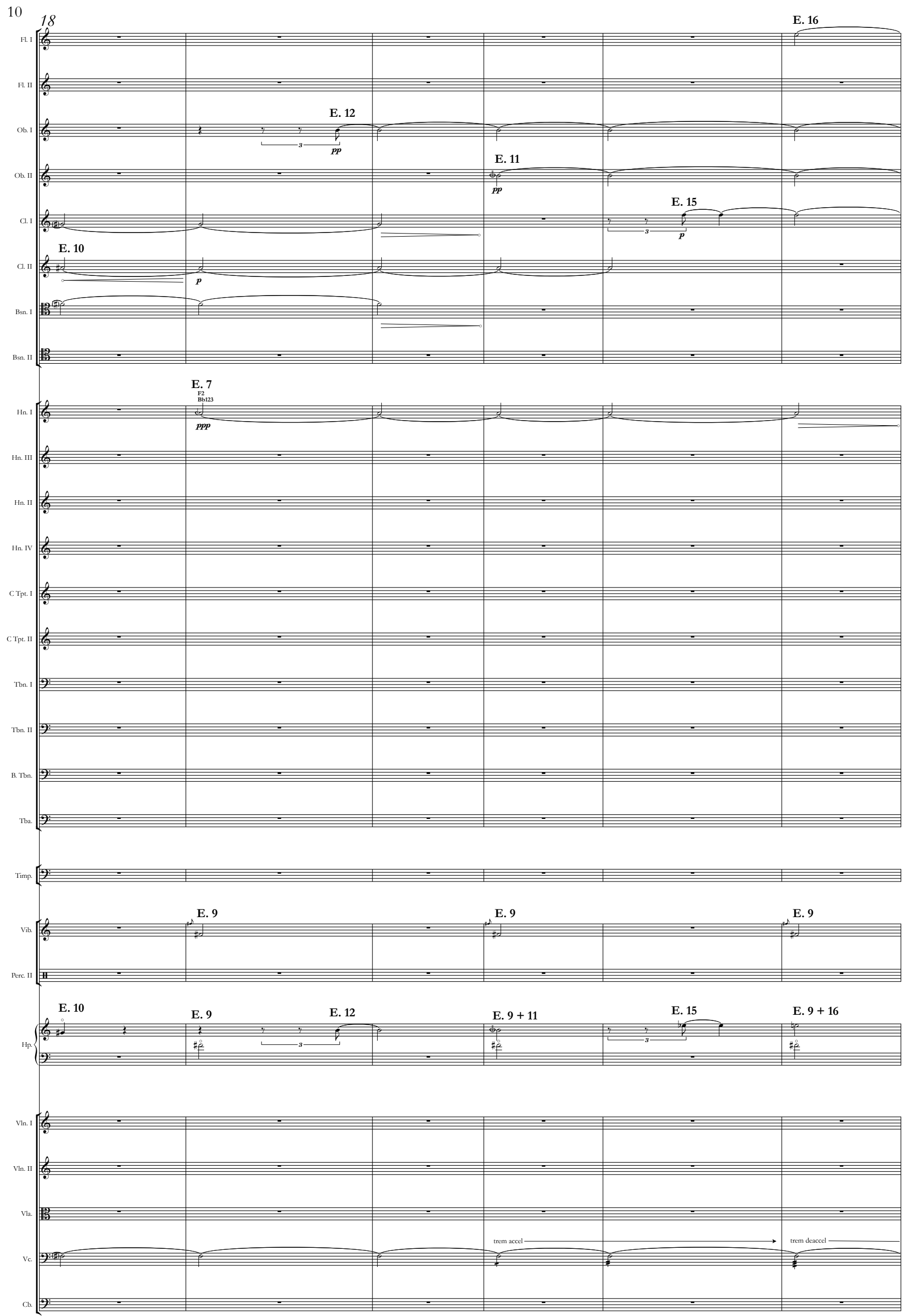



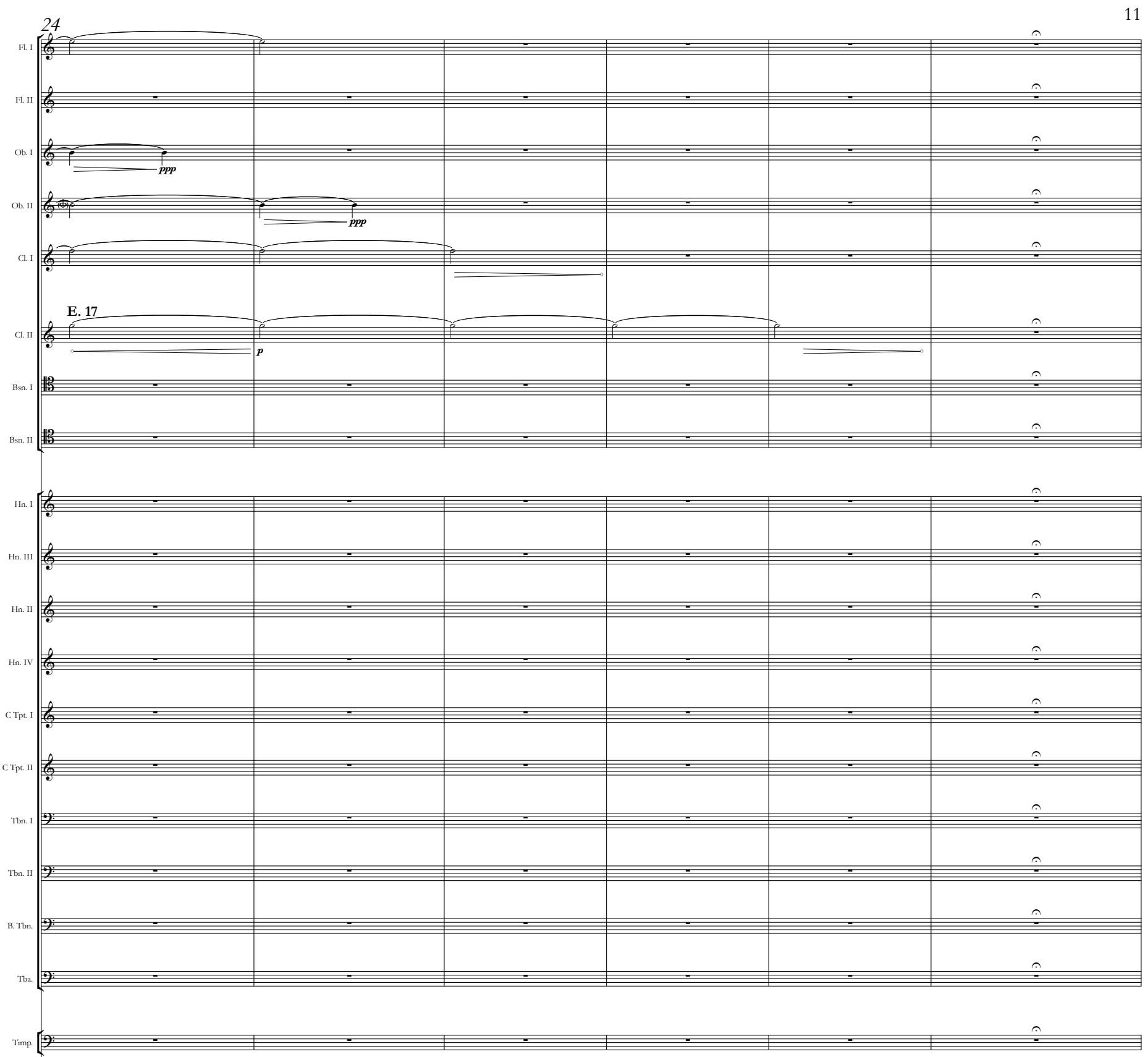

\section{E. $17+19$}
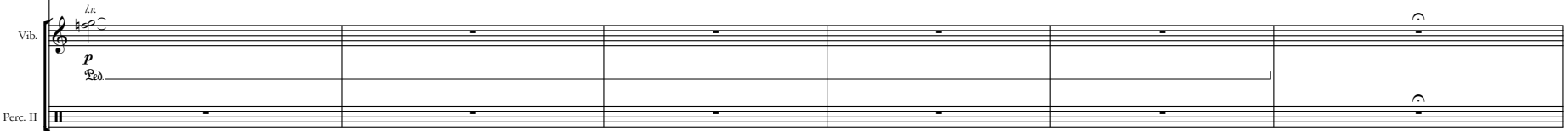

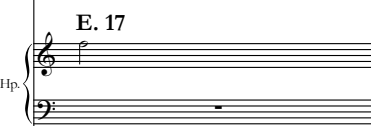
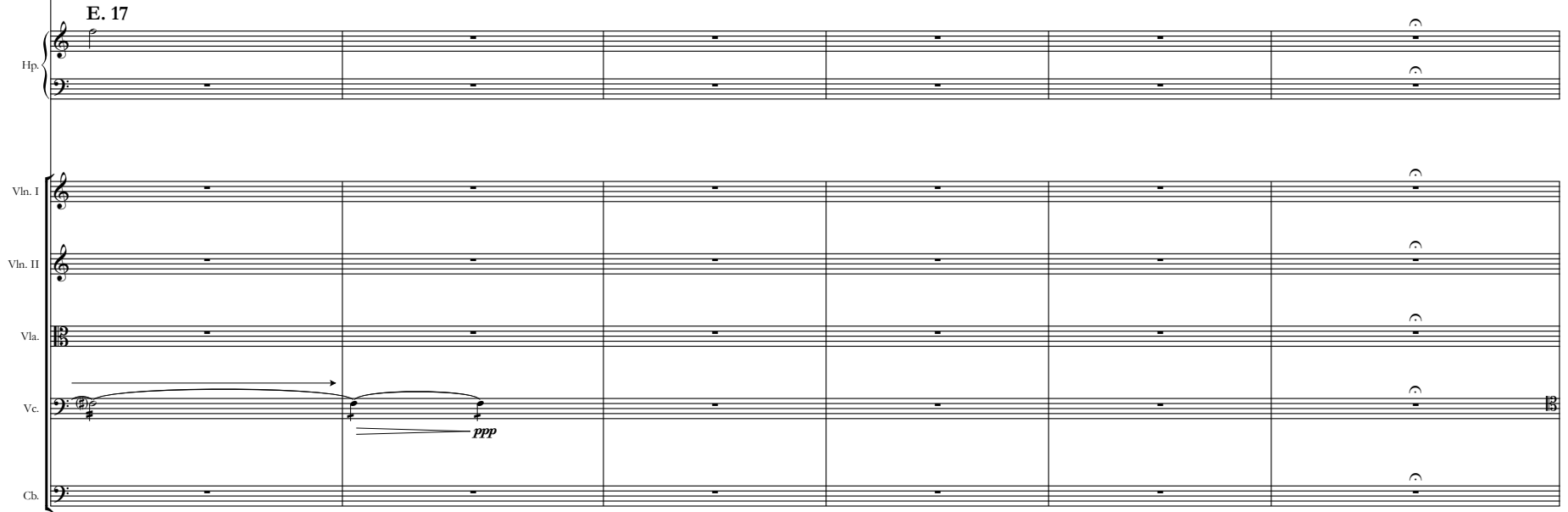

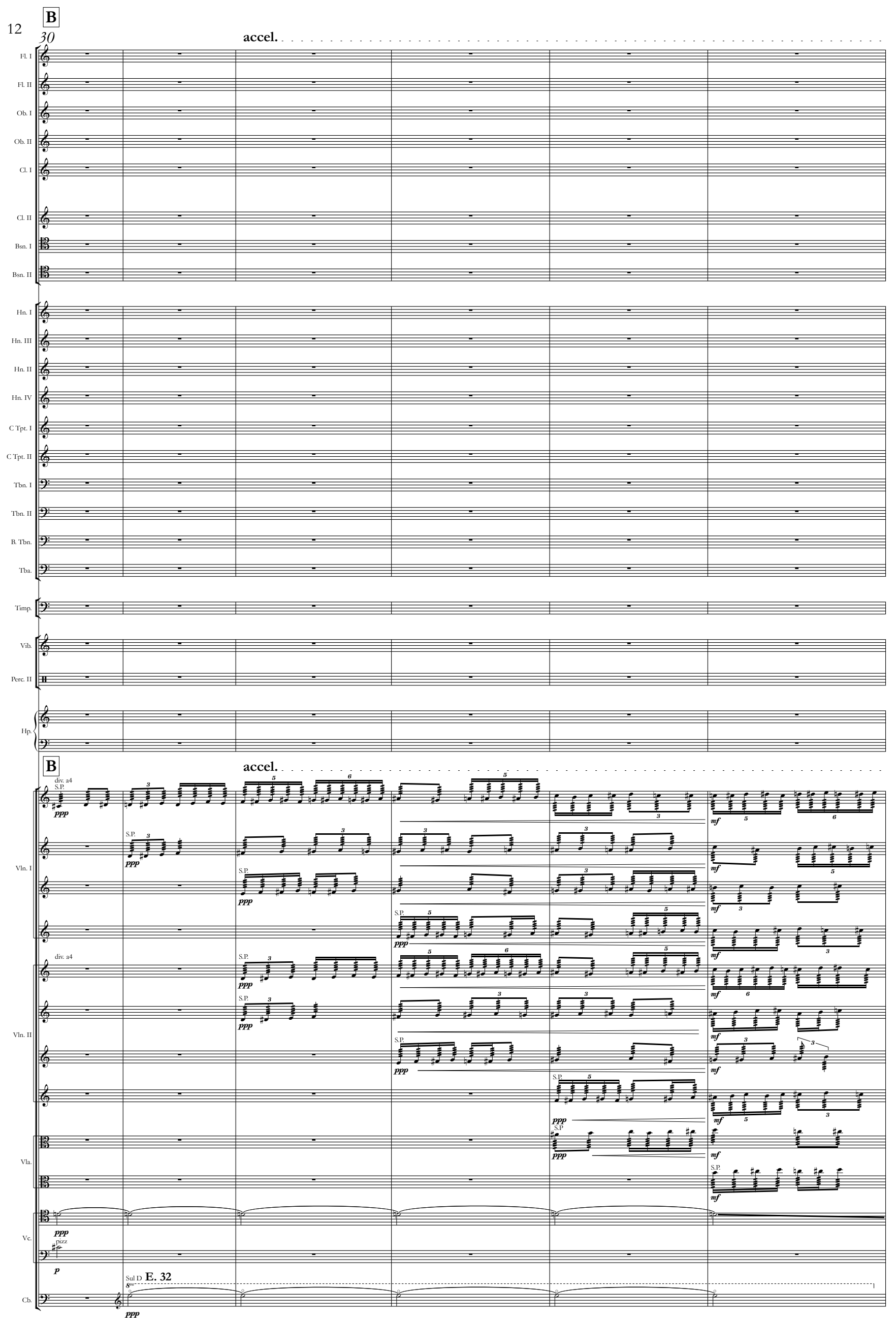
C
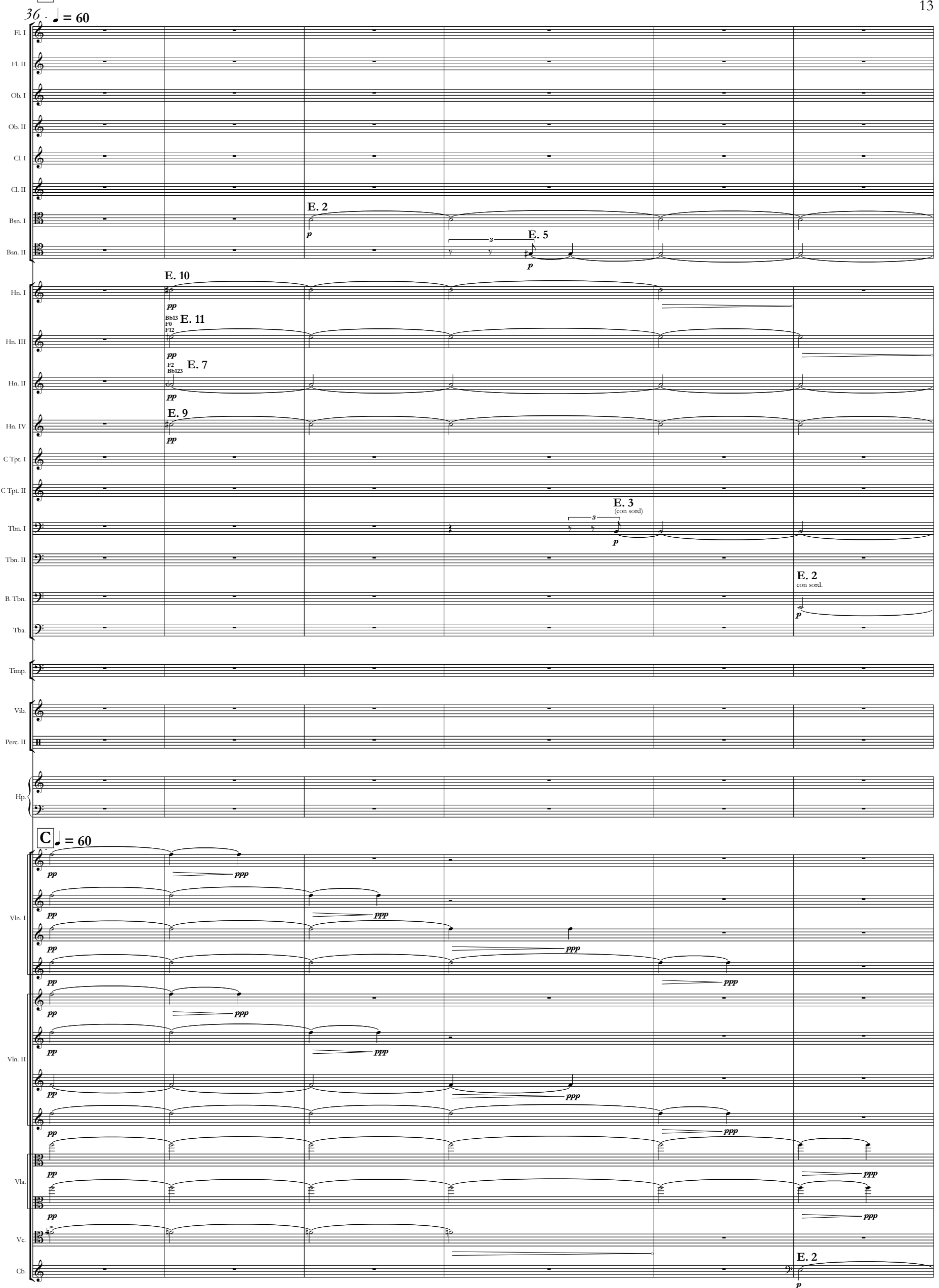


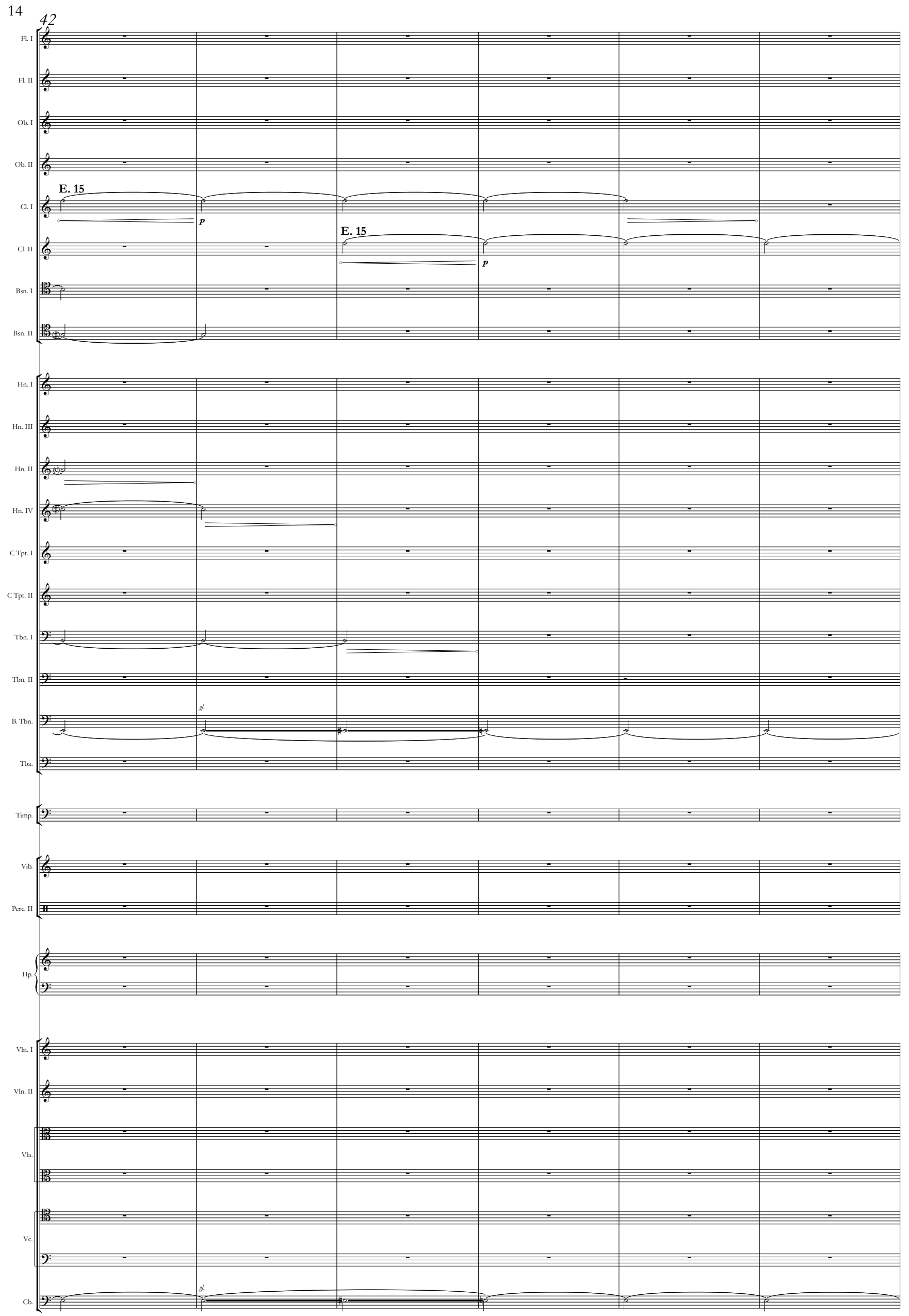


D

15
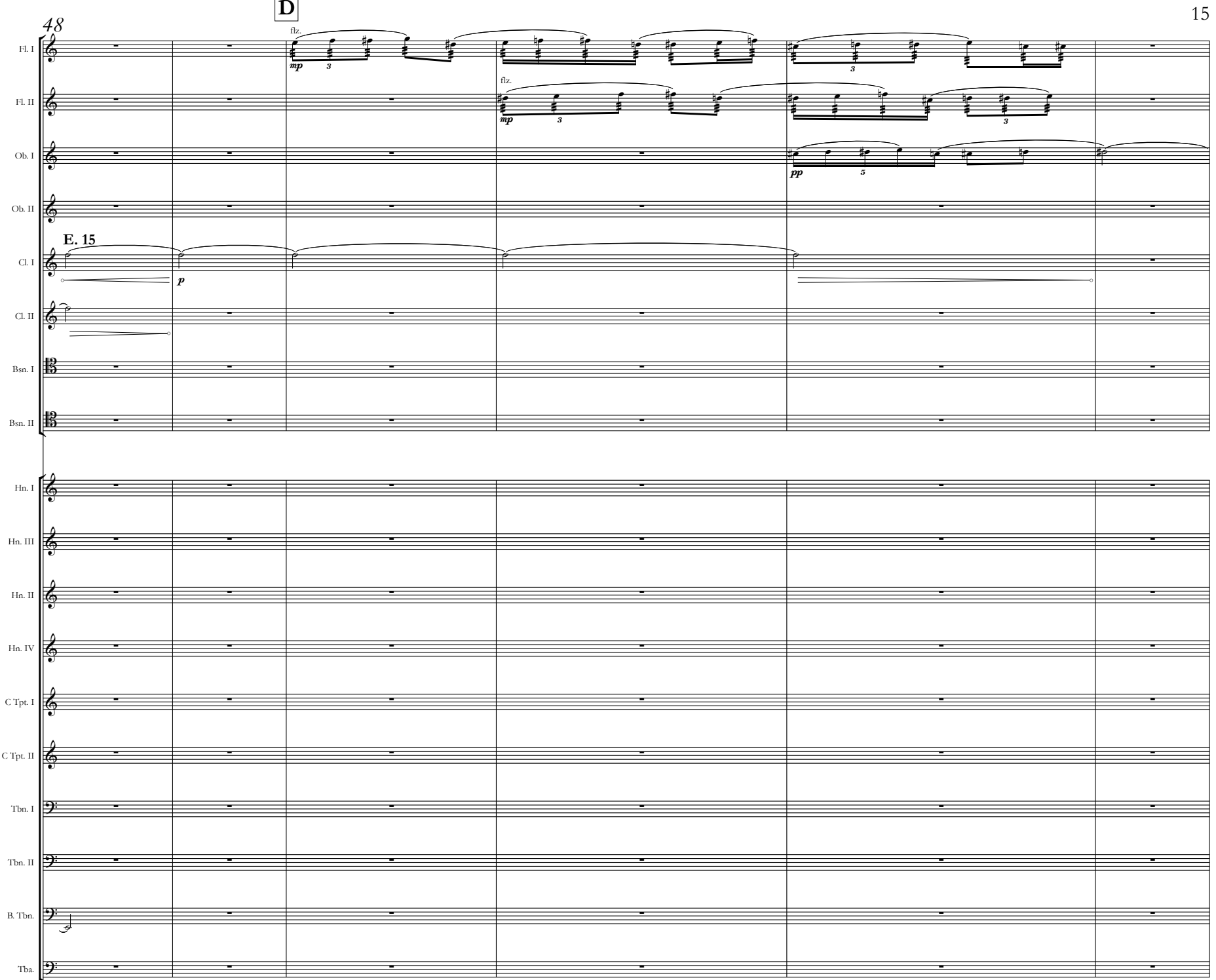

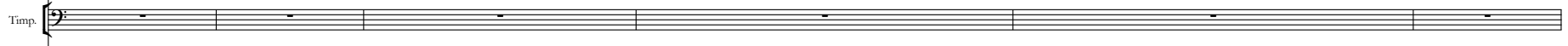
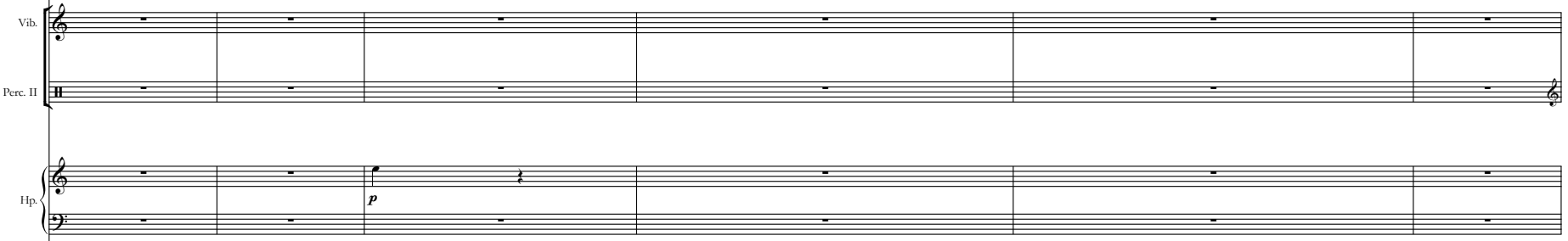

D

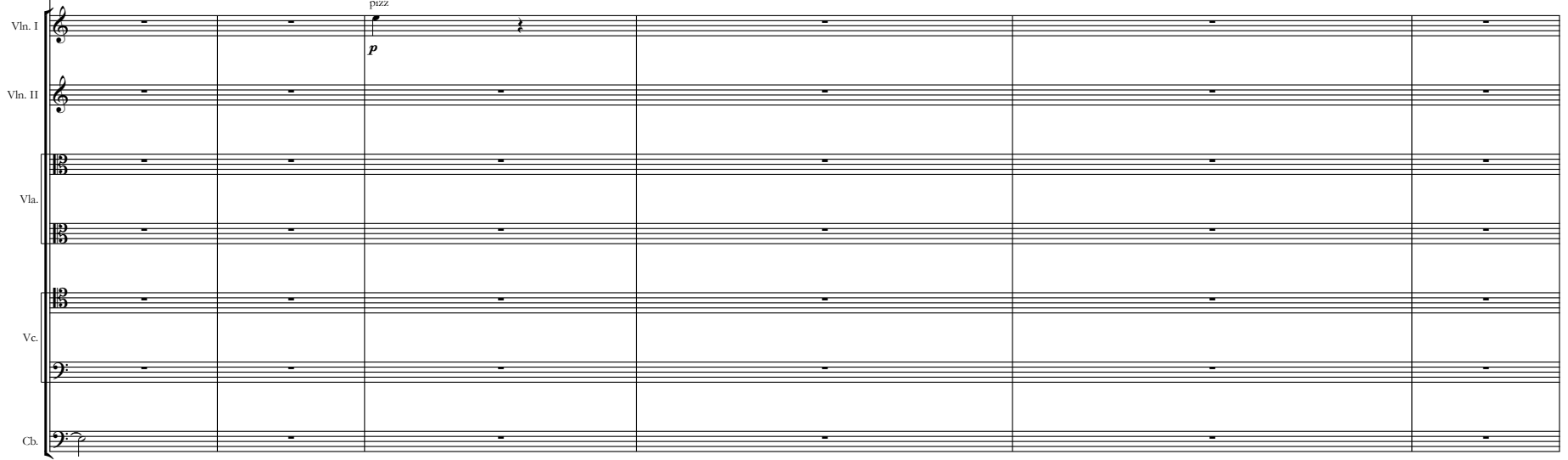



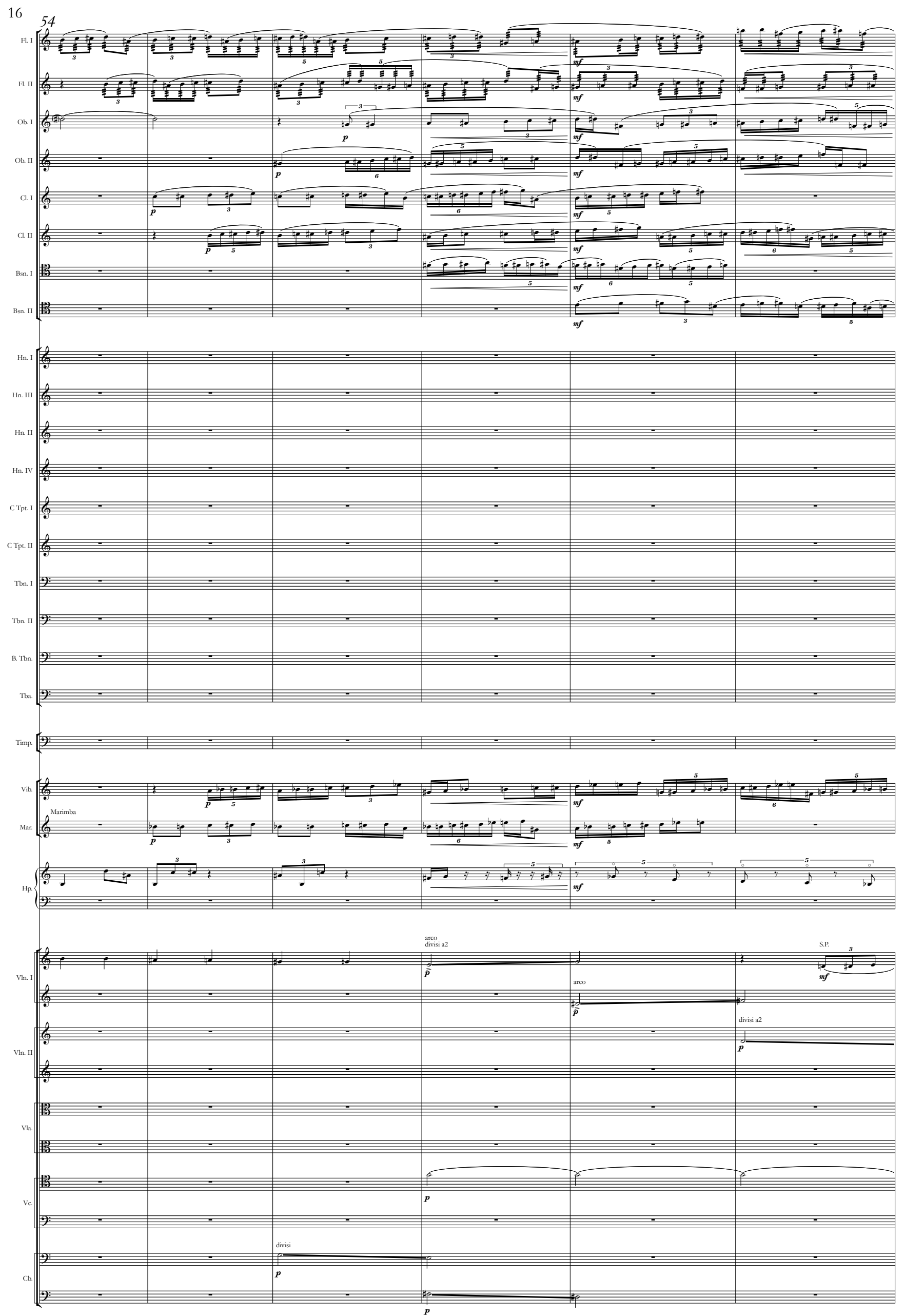


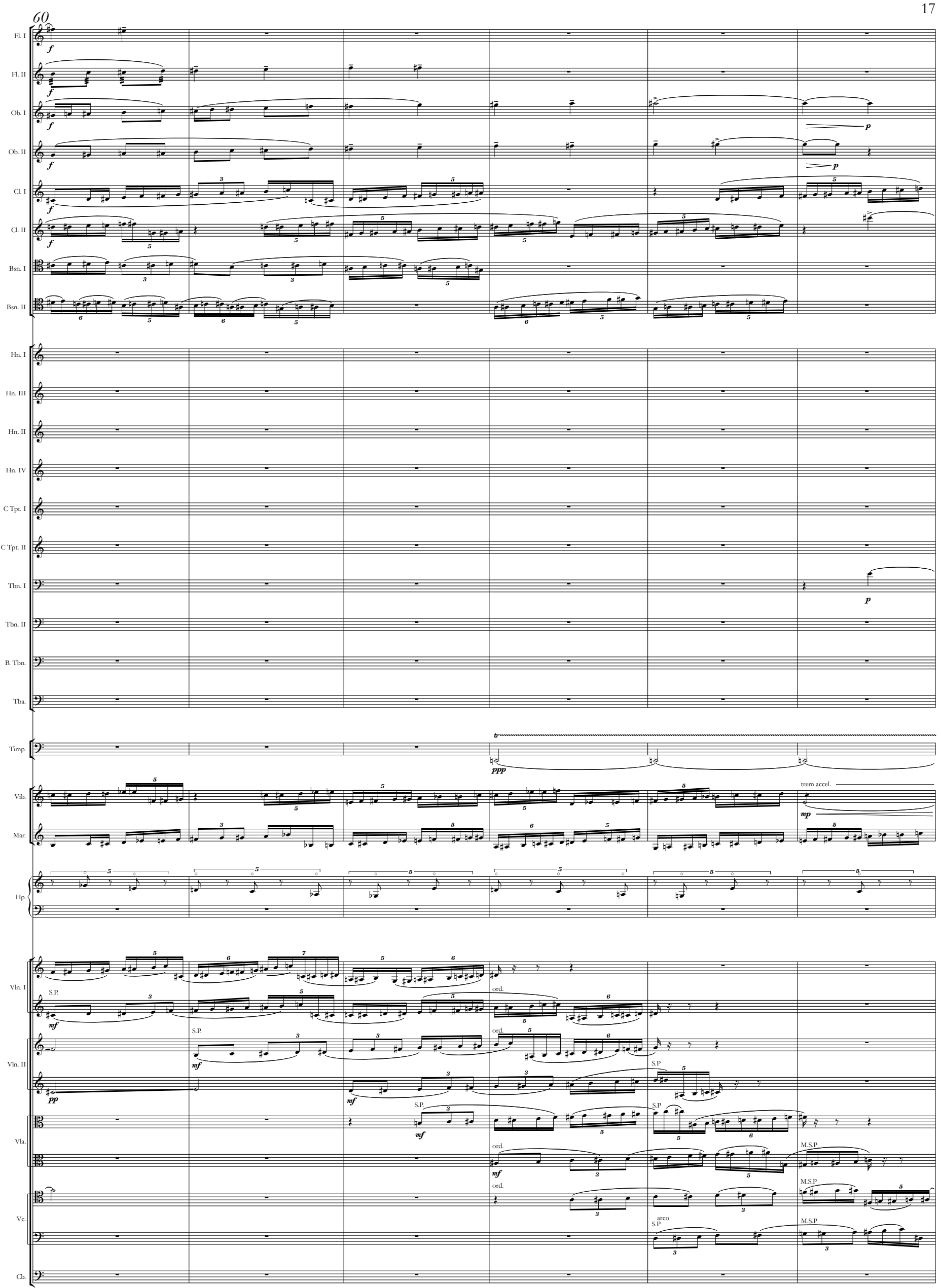



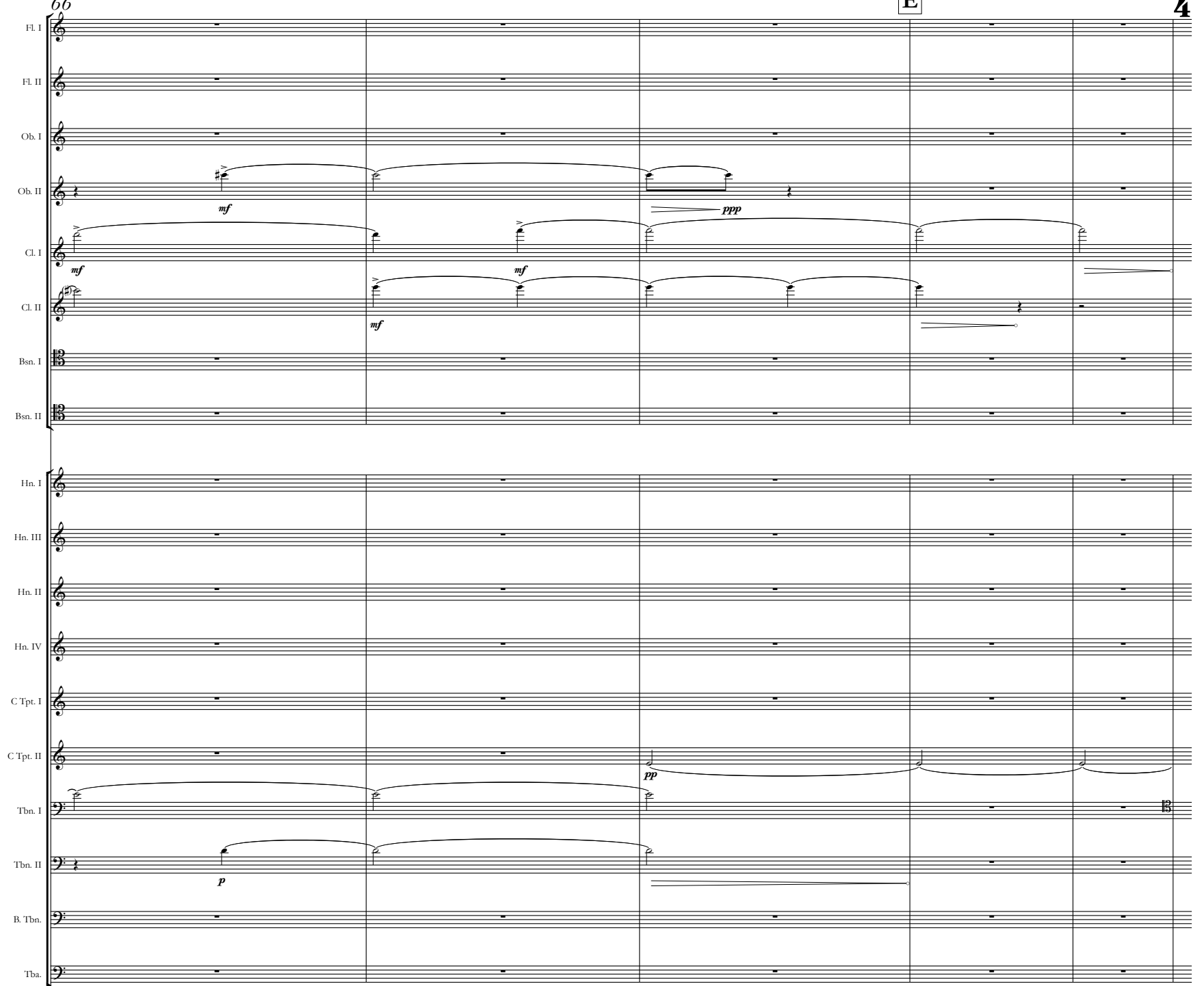

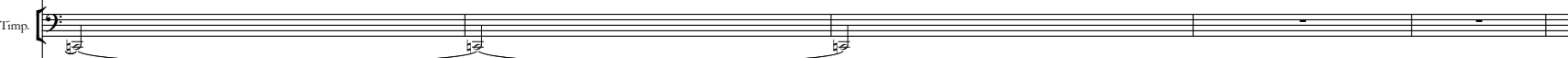
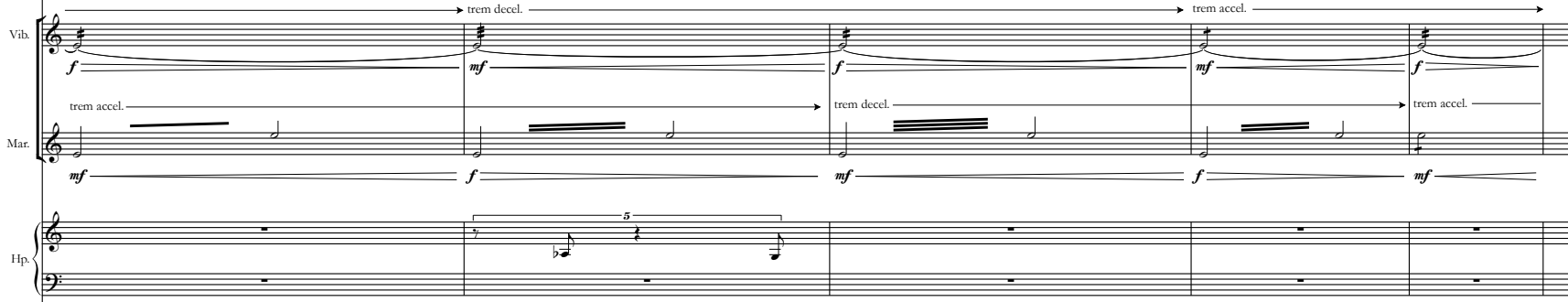

E. 32

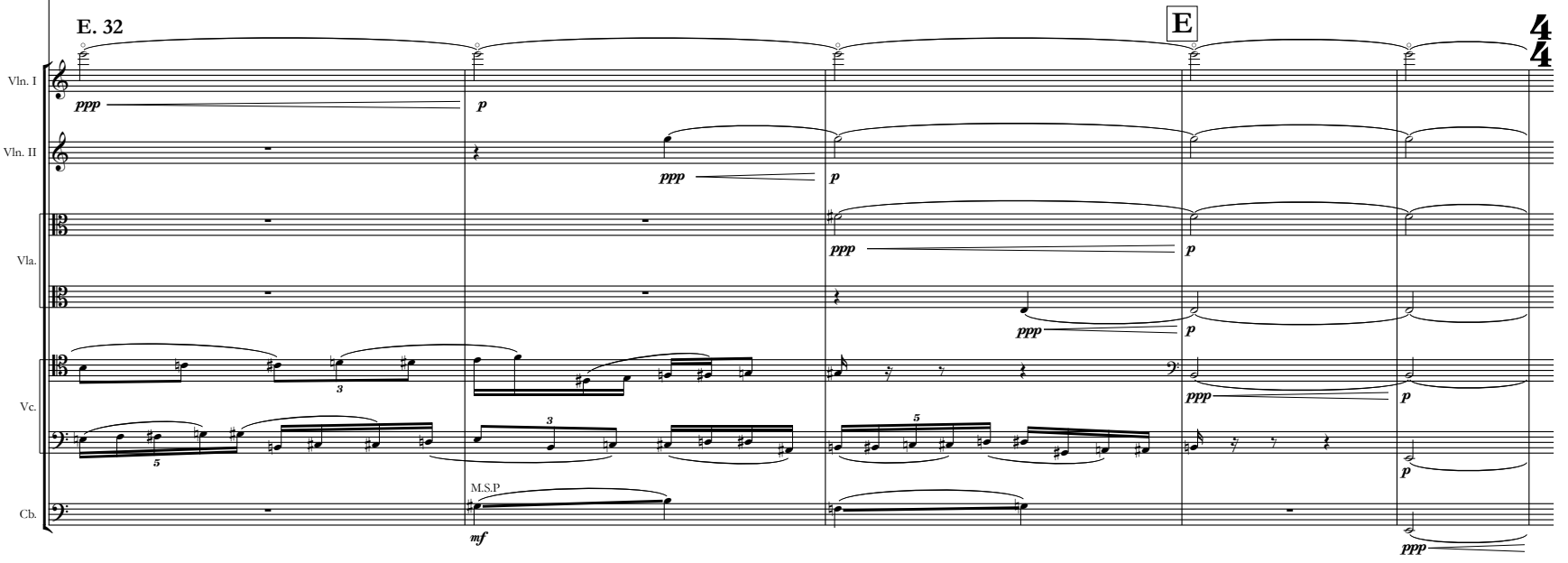

E 

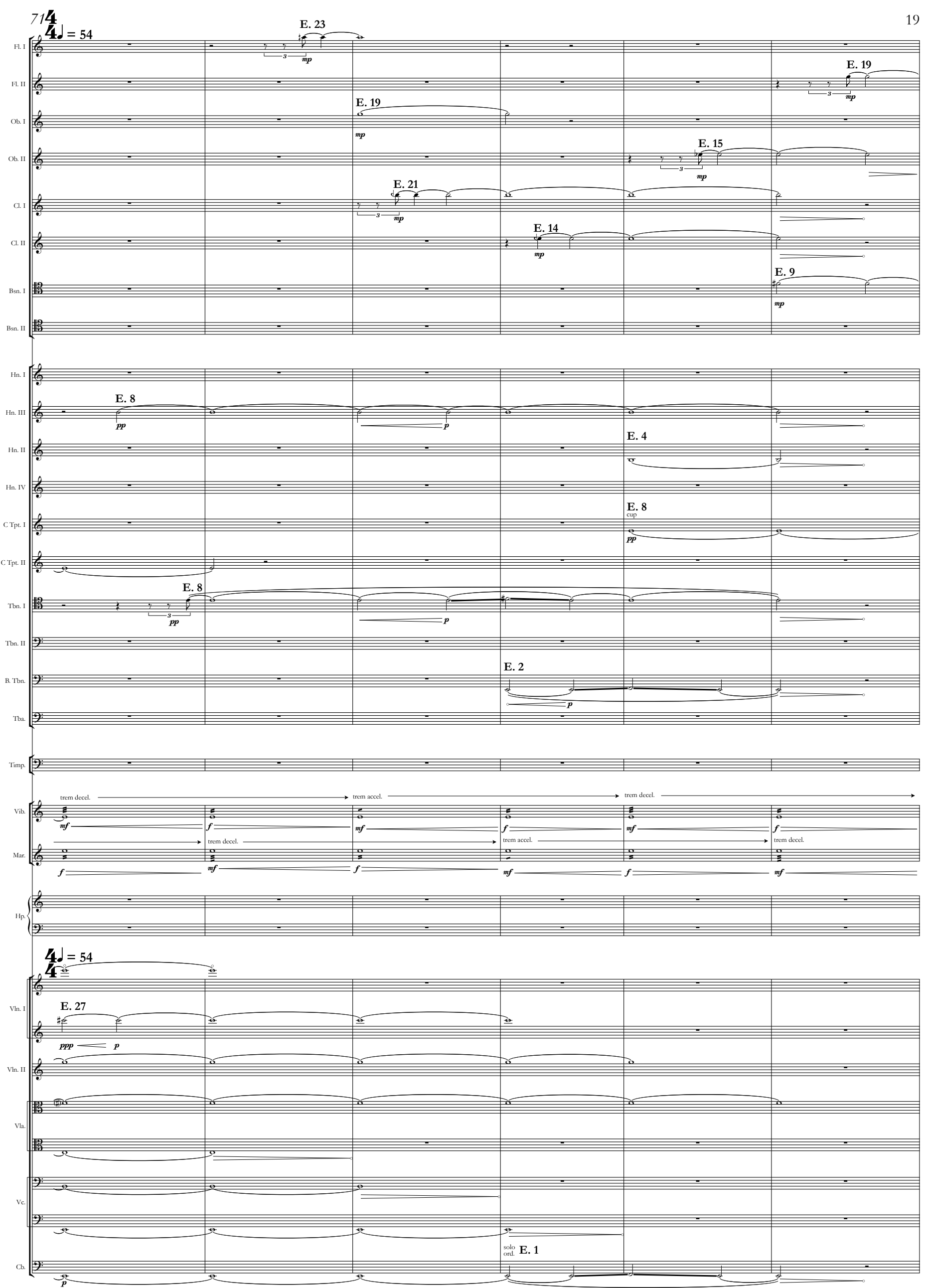

$\stackrel{8}{\underline{*}}$ 

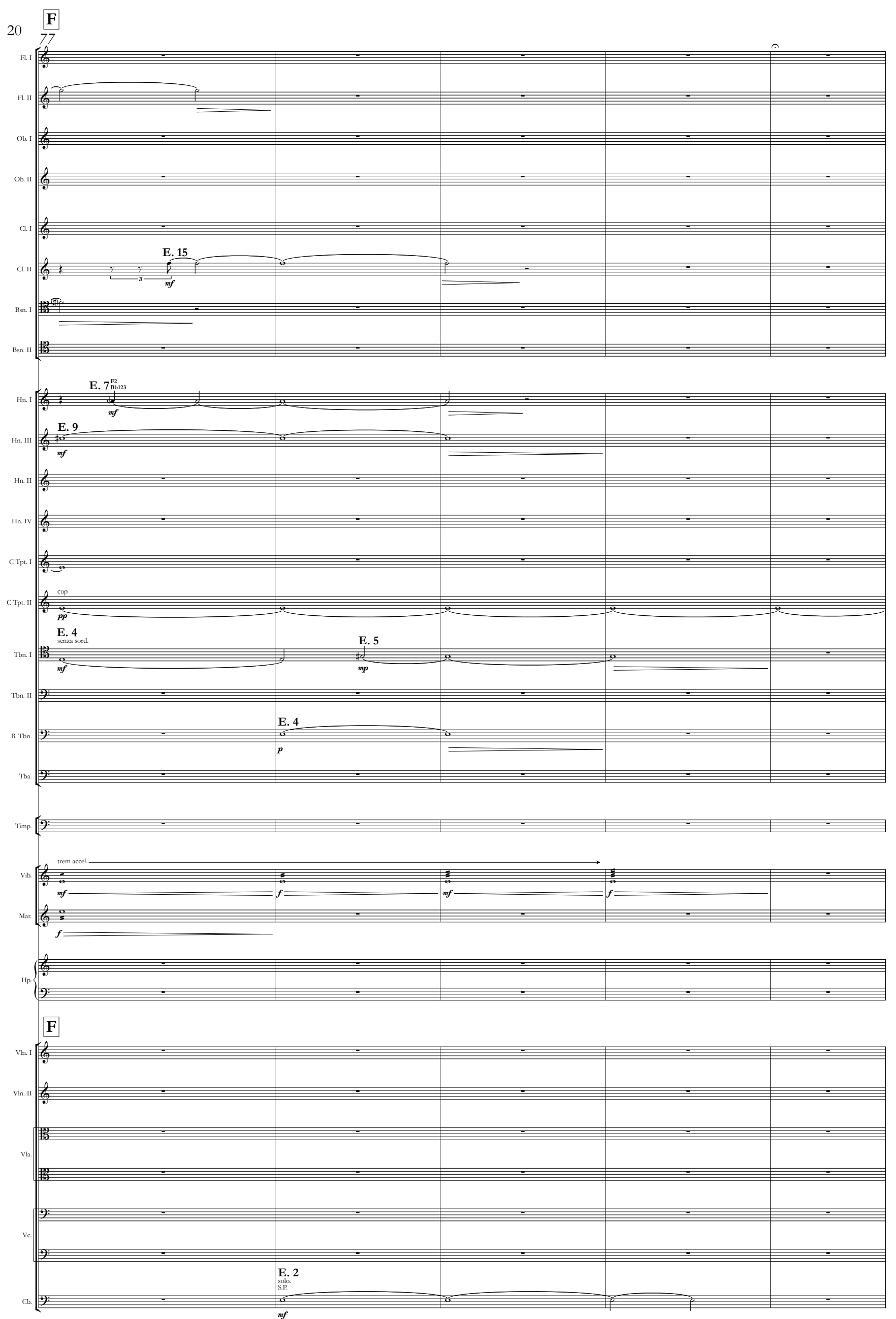
G
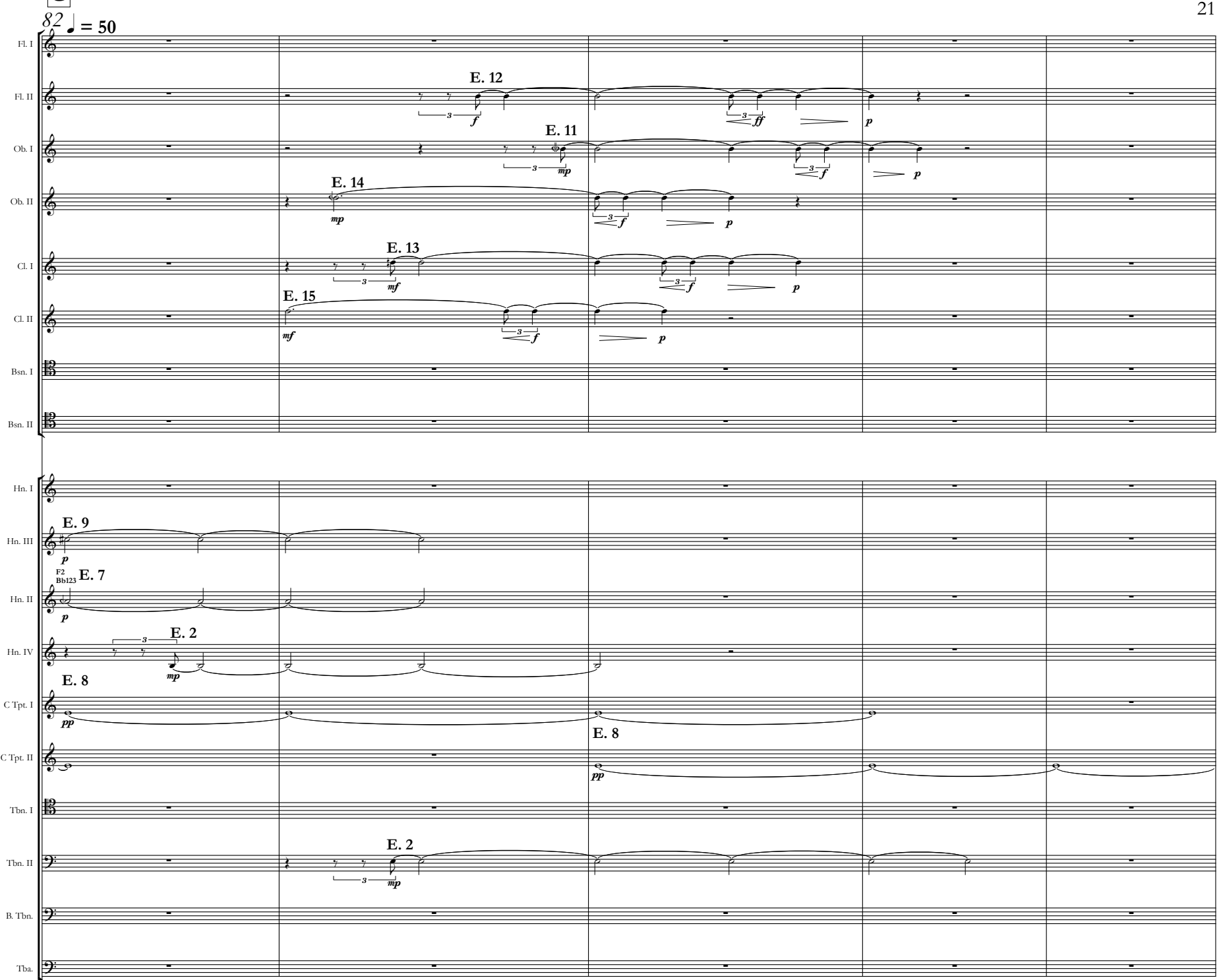

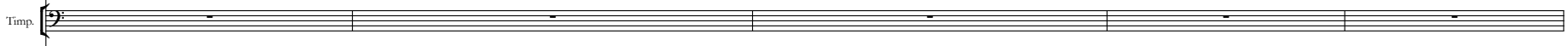

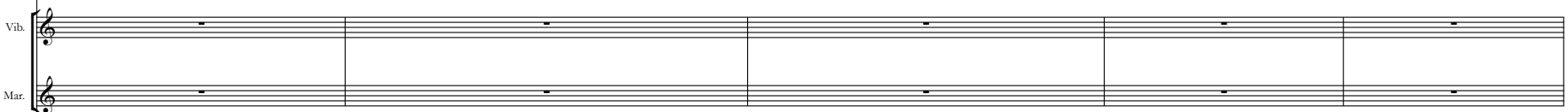

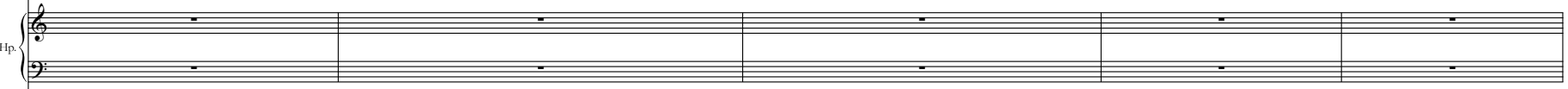
G

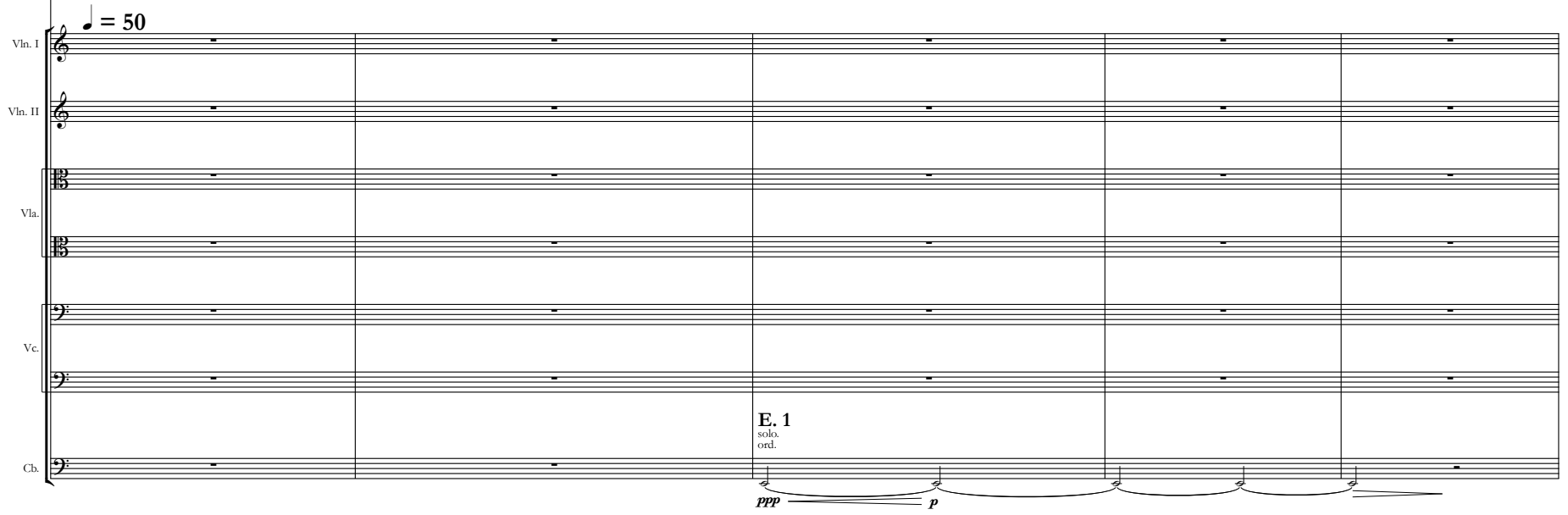




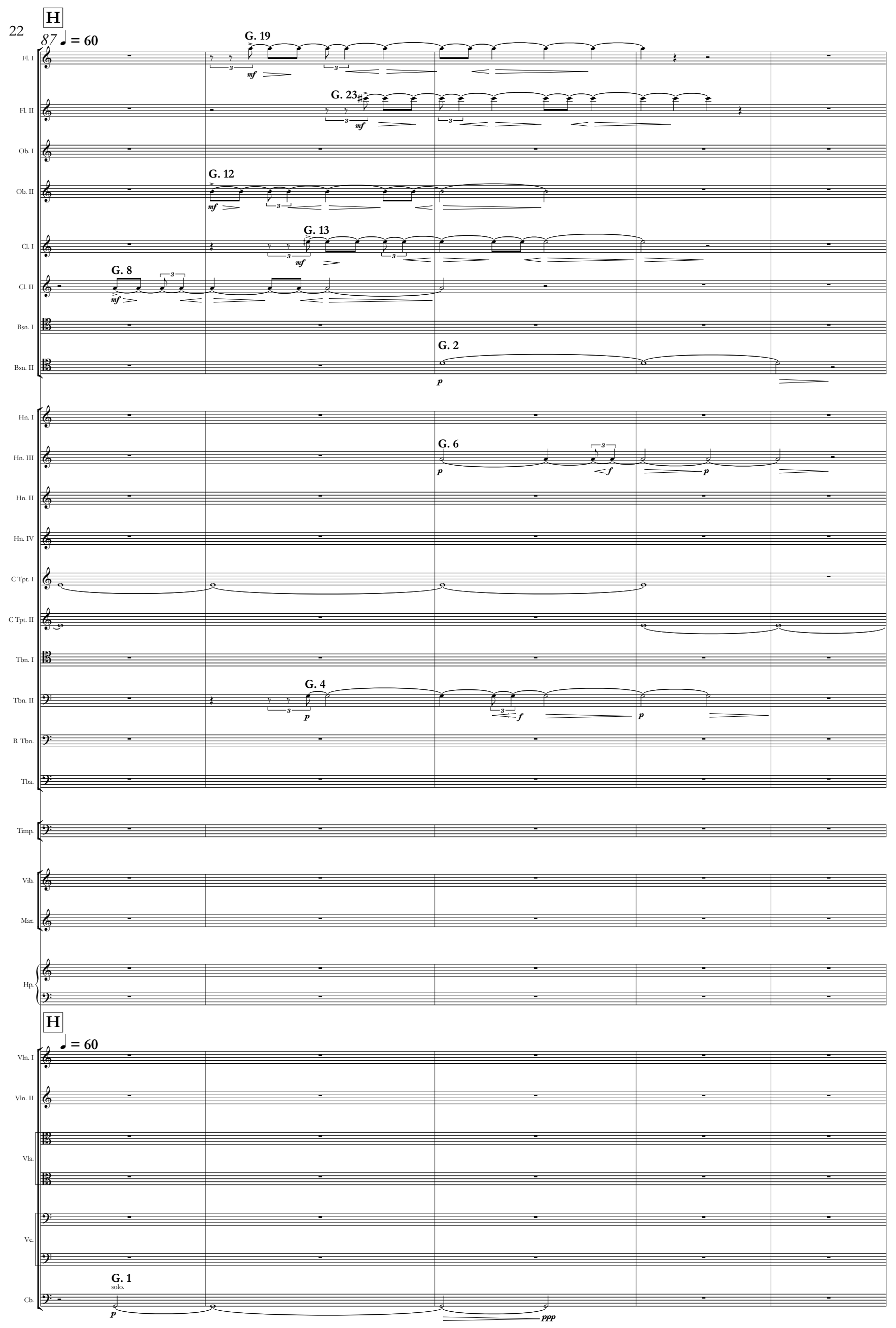



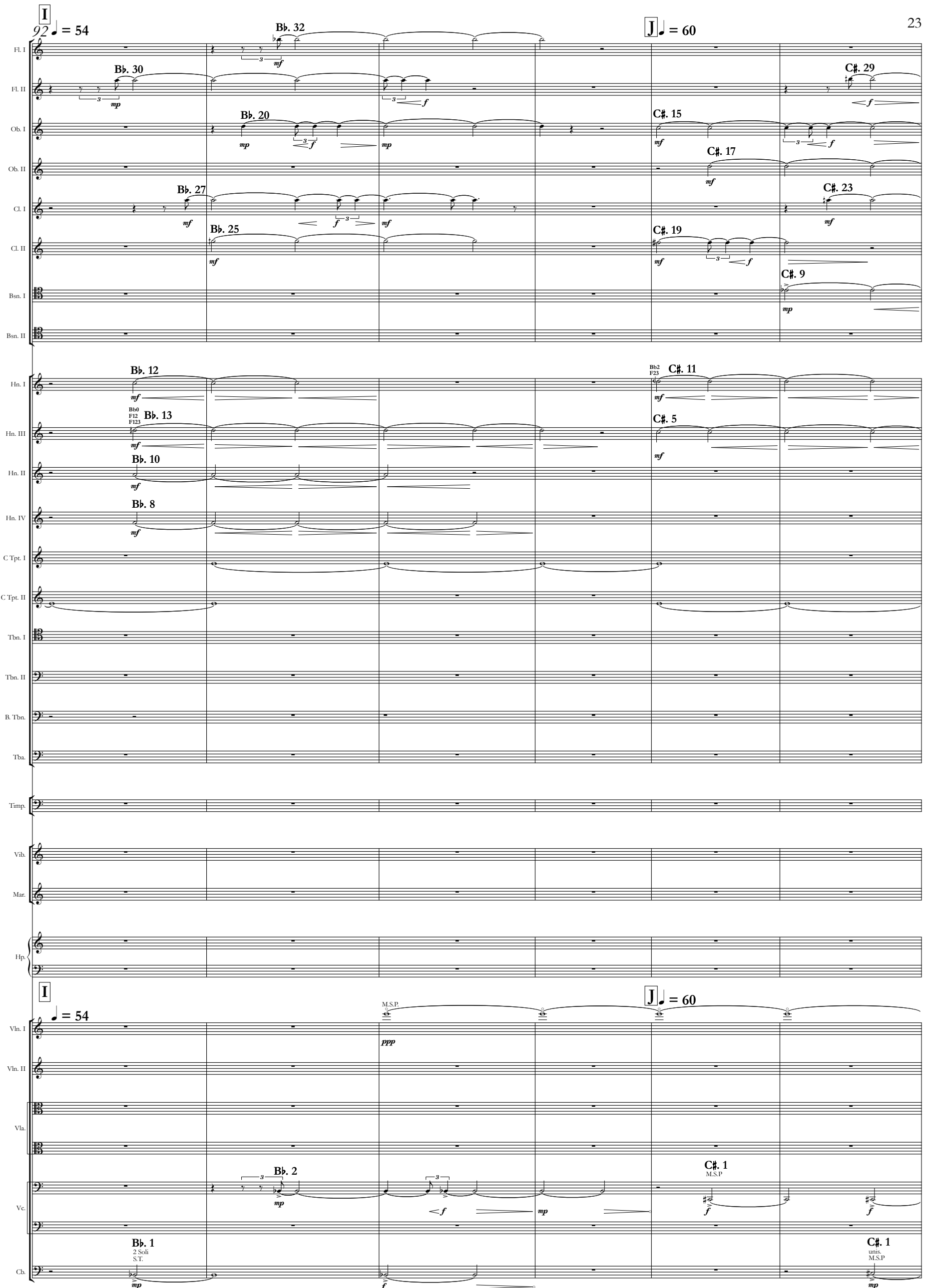

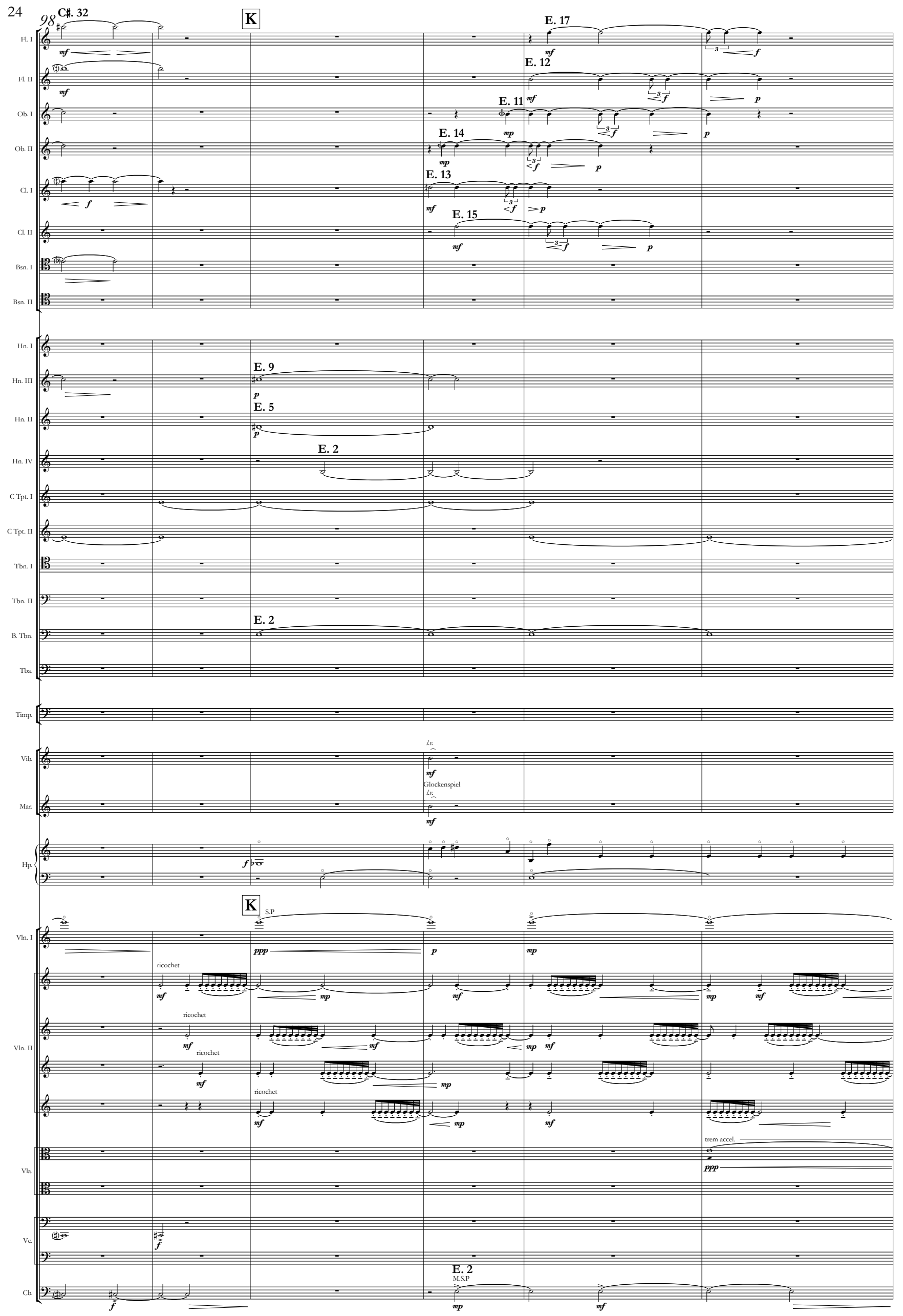
$\mathbf{L}$
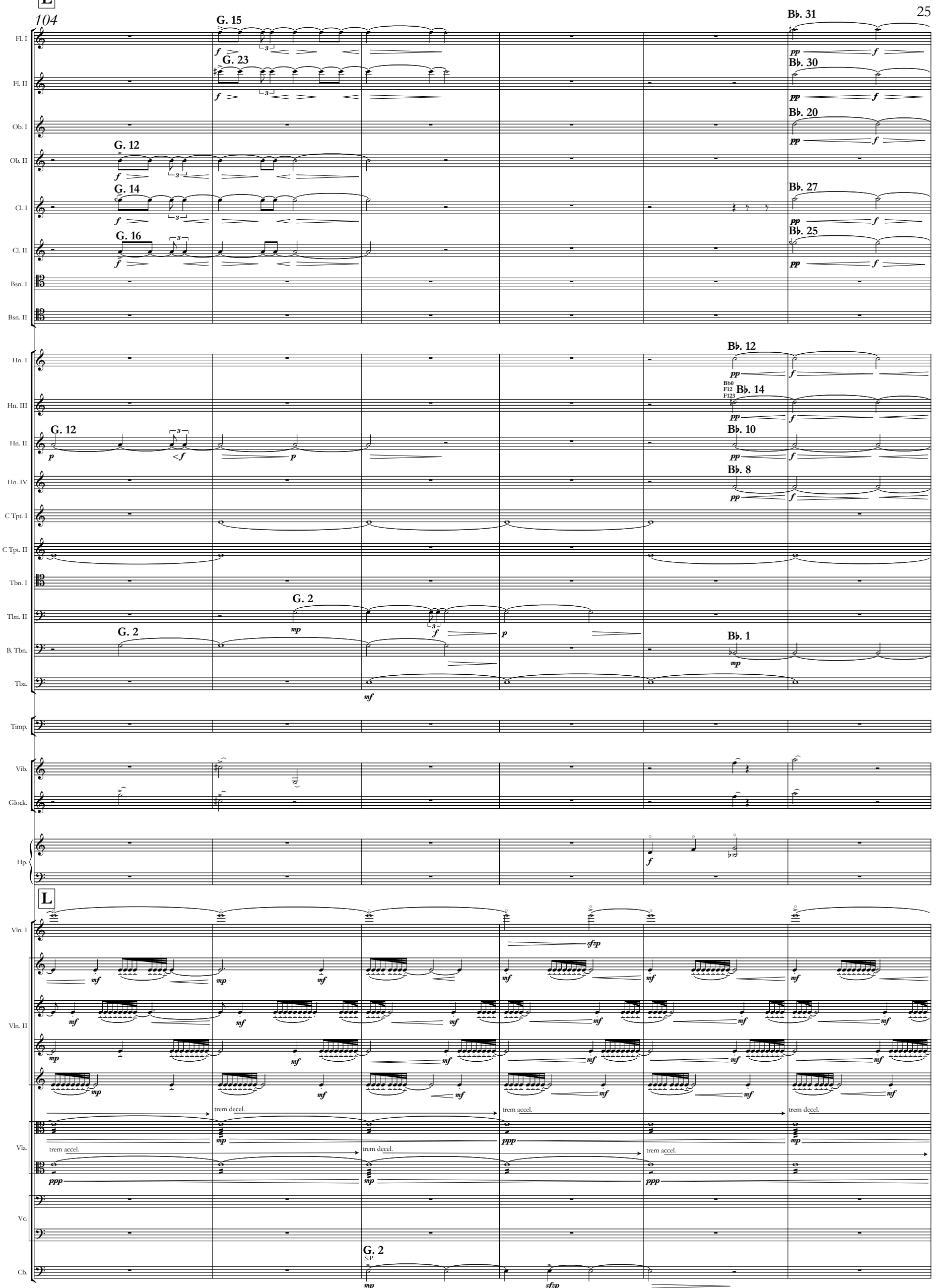
M
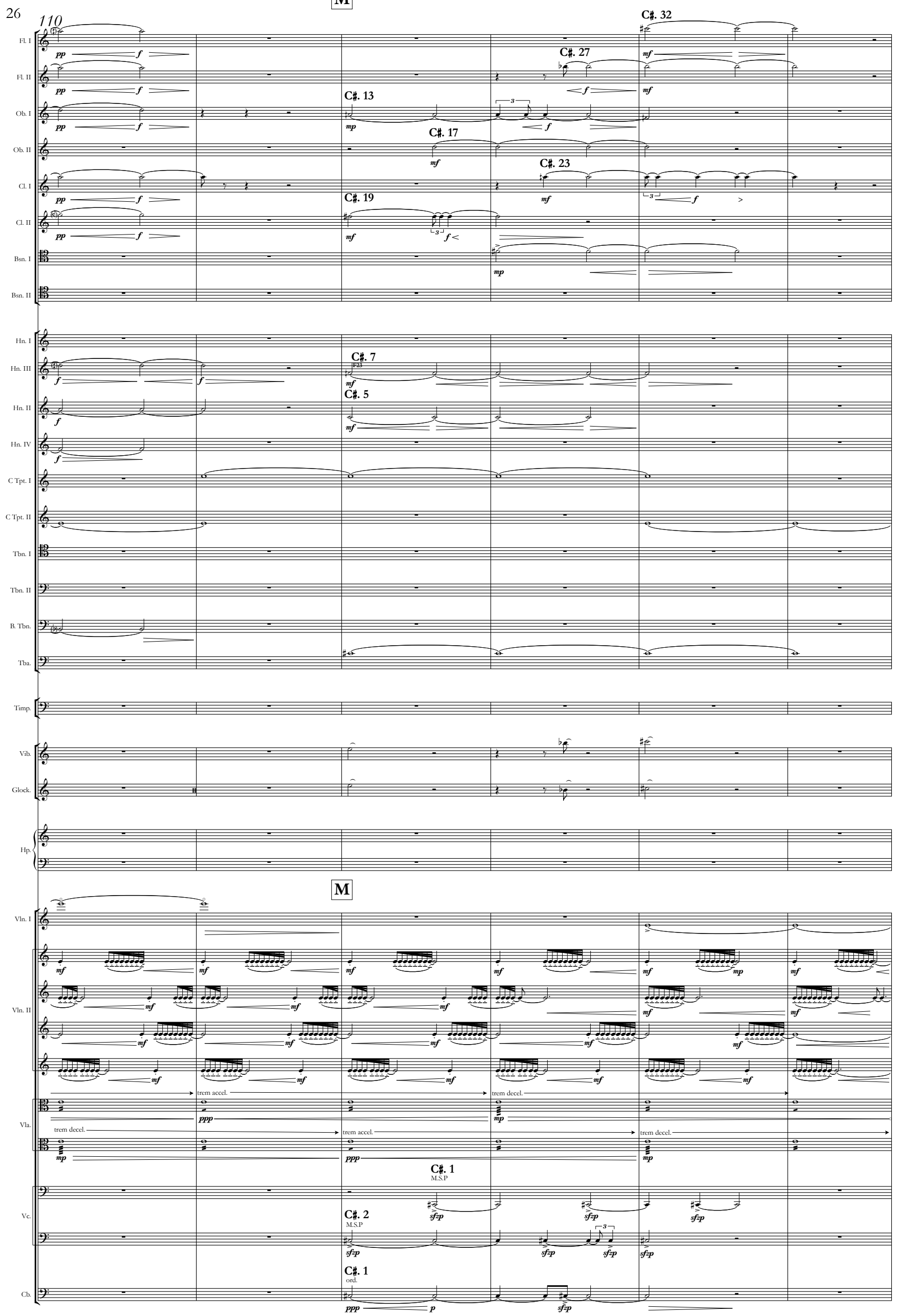
$\mathbf{N}$

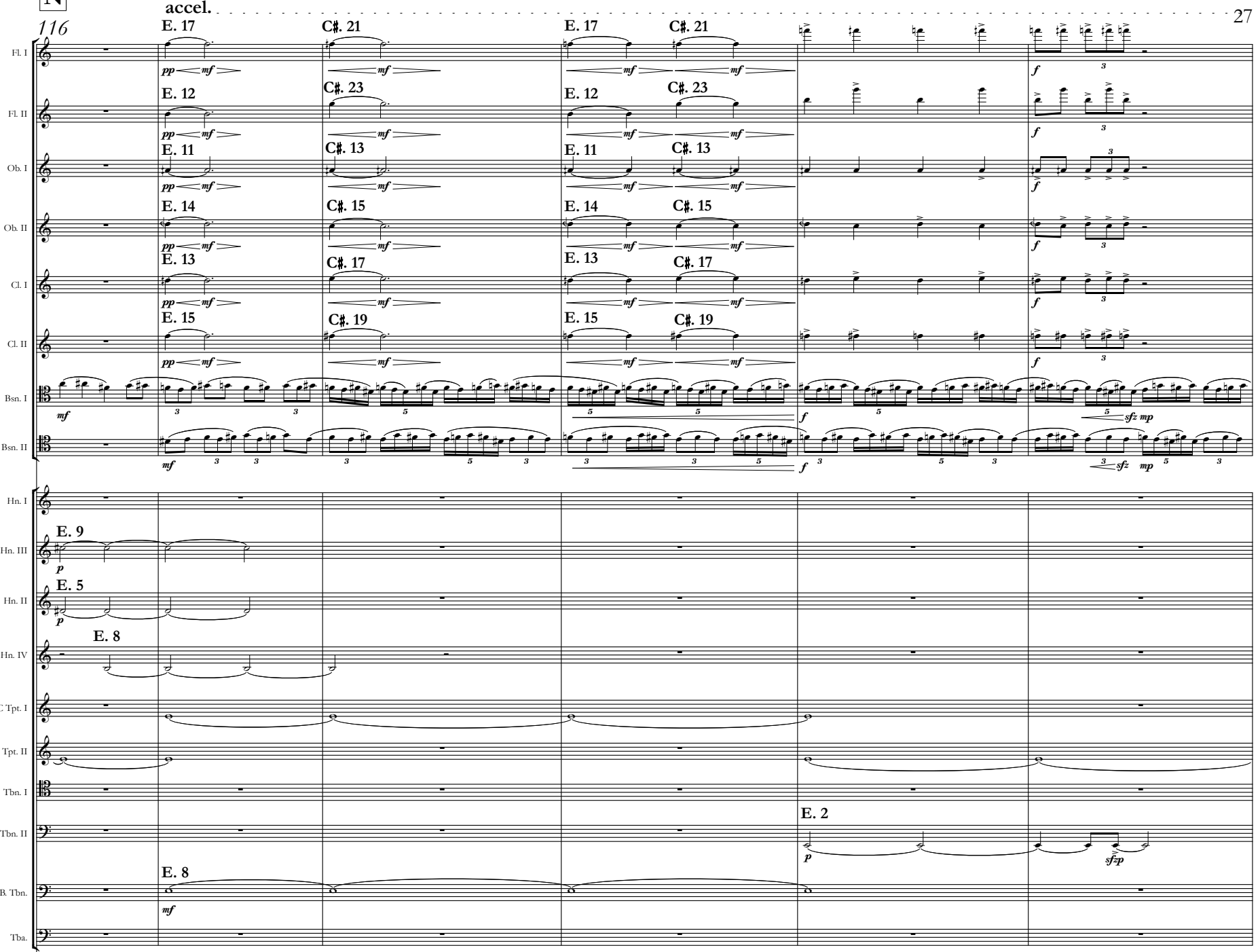

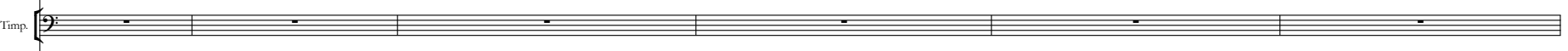

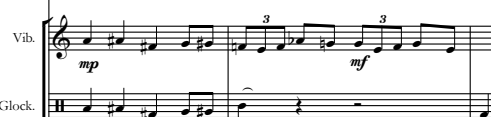

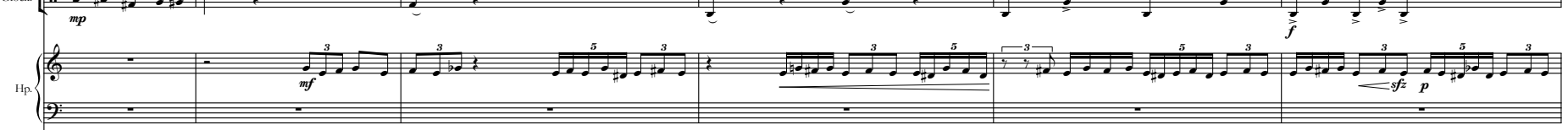

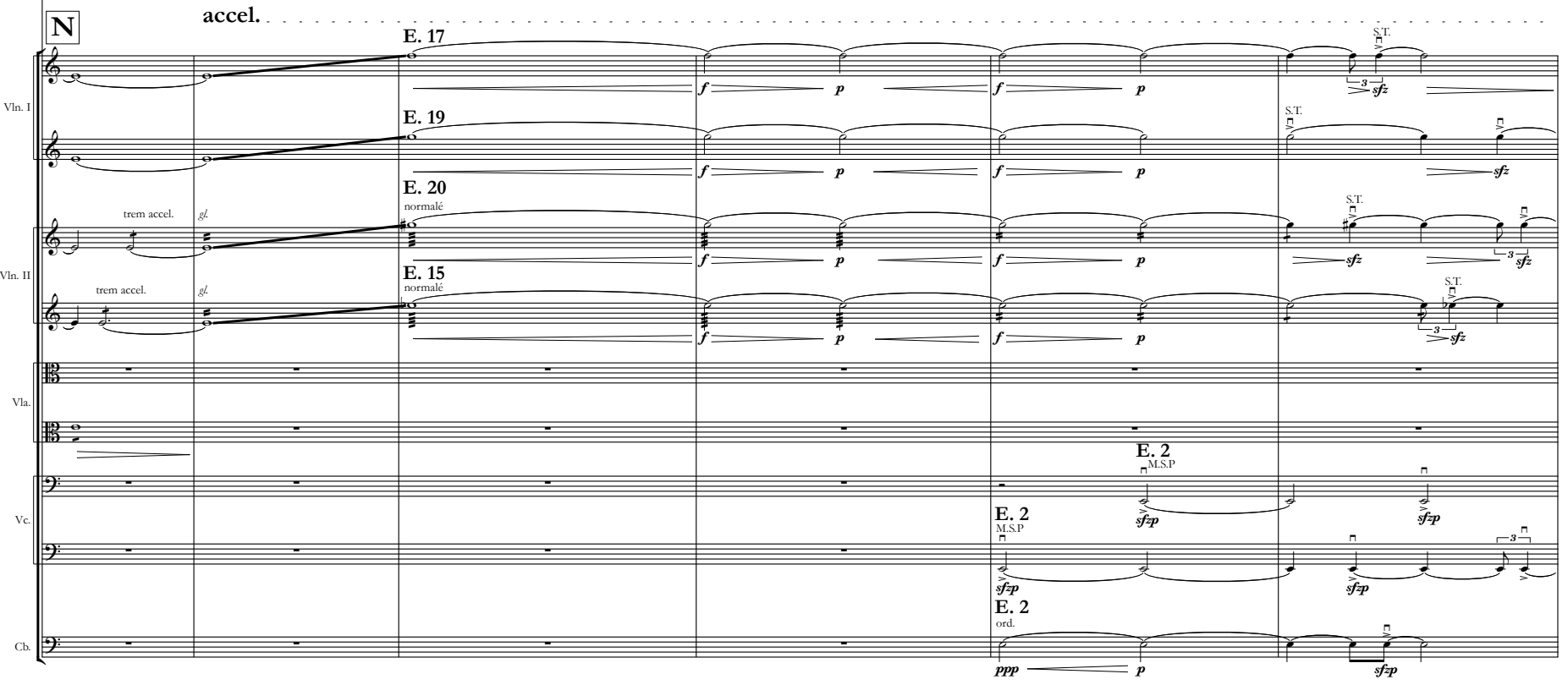


28

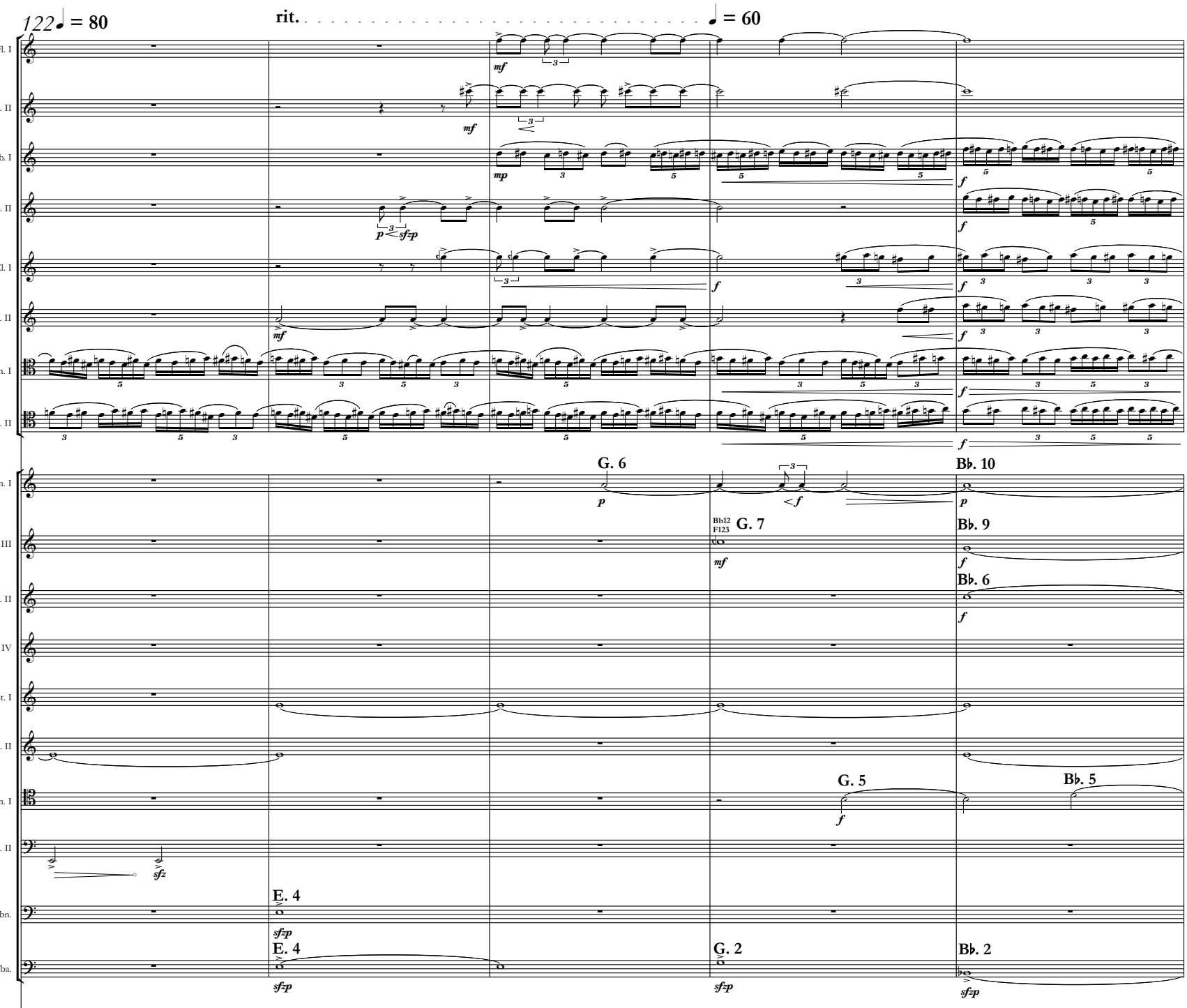

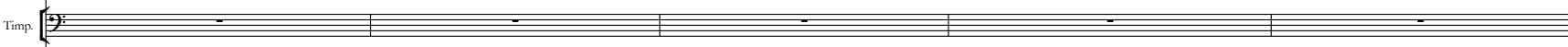

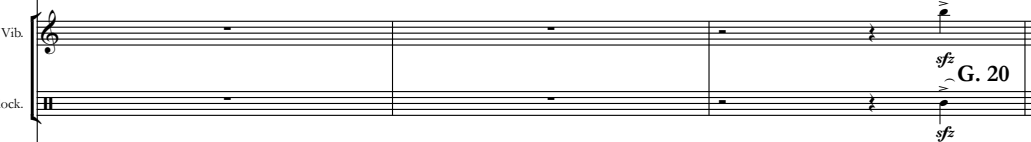

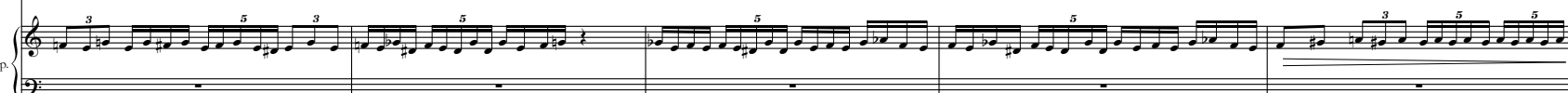

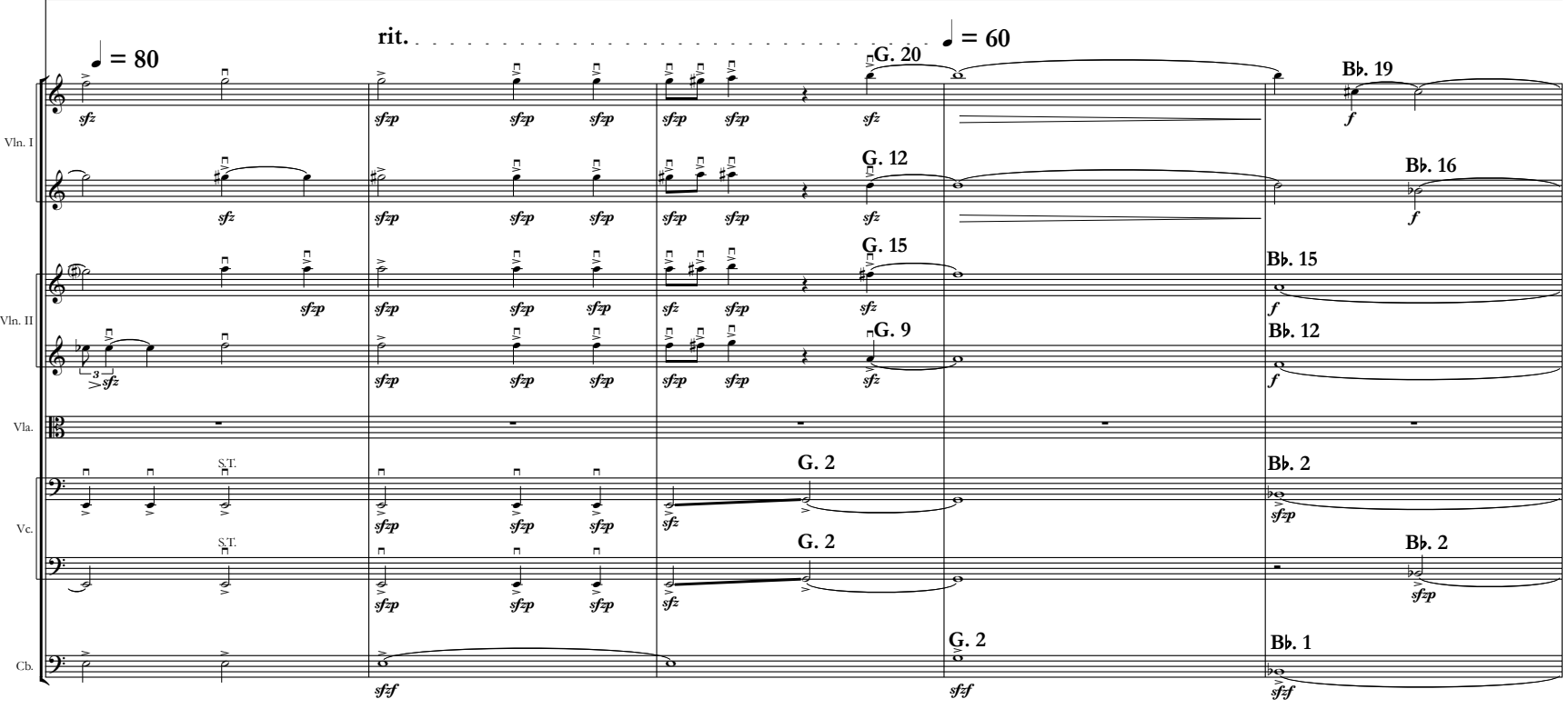


O

29
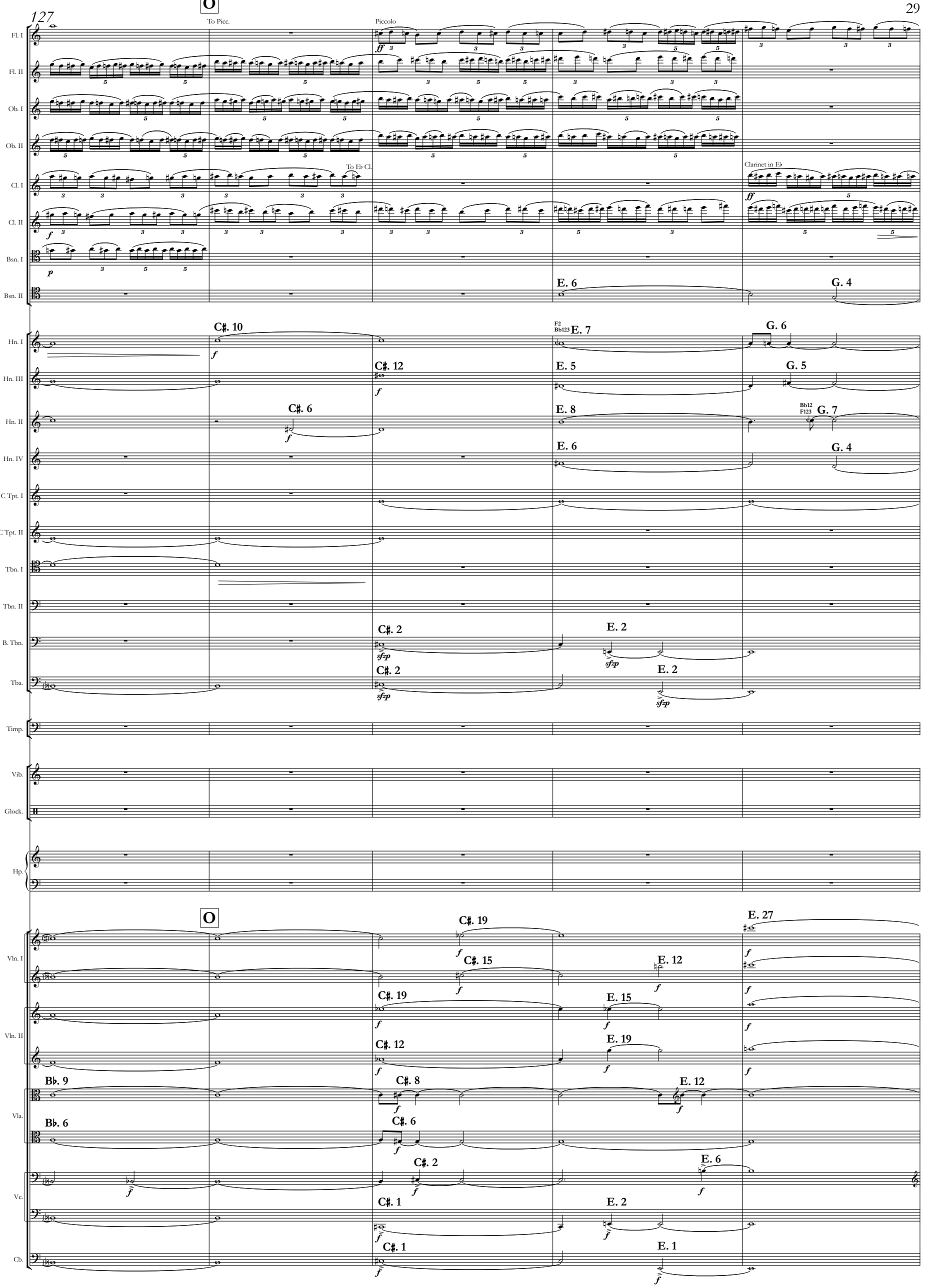

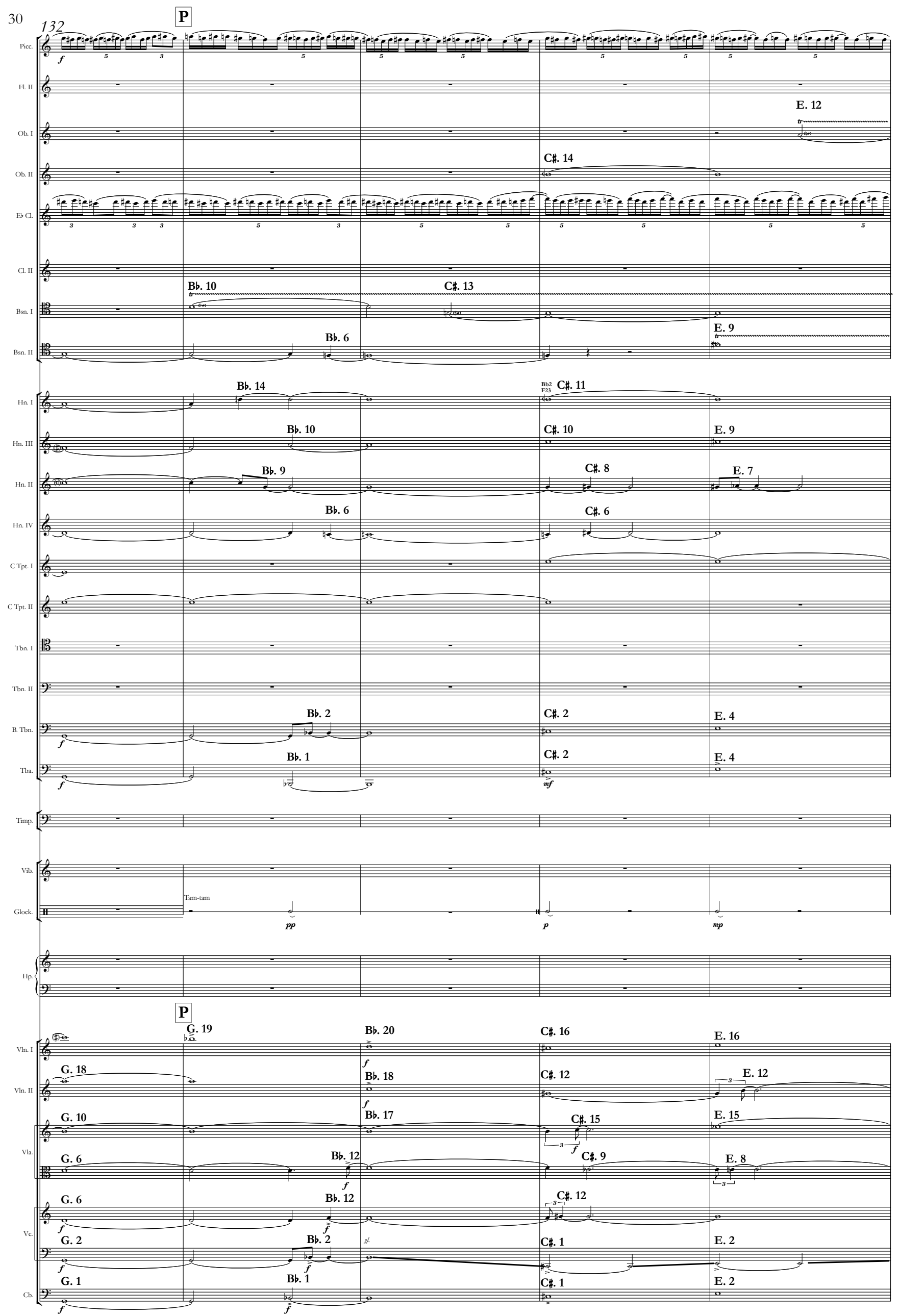
Q

$\left(\begin{array}{lll}137 \\ 0\end{array}\right.$

accel.

31

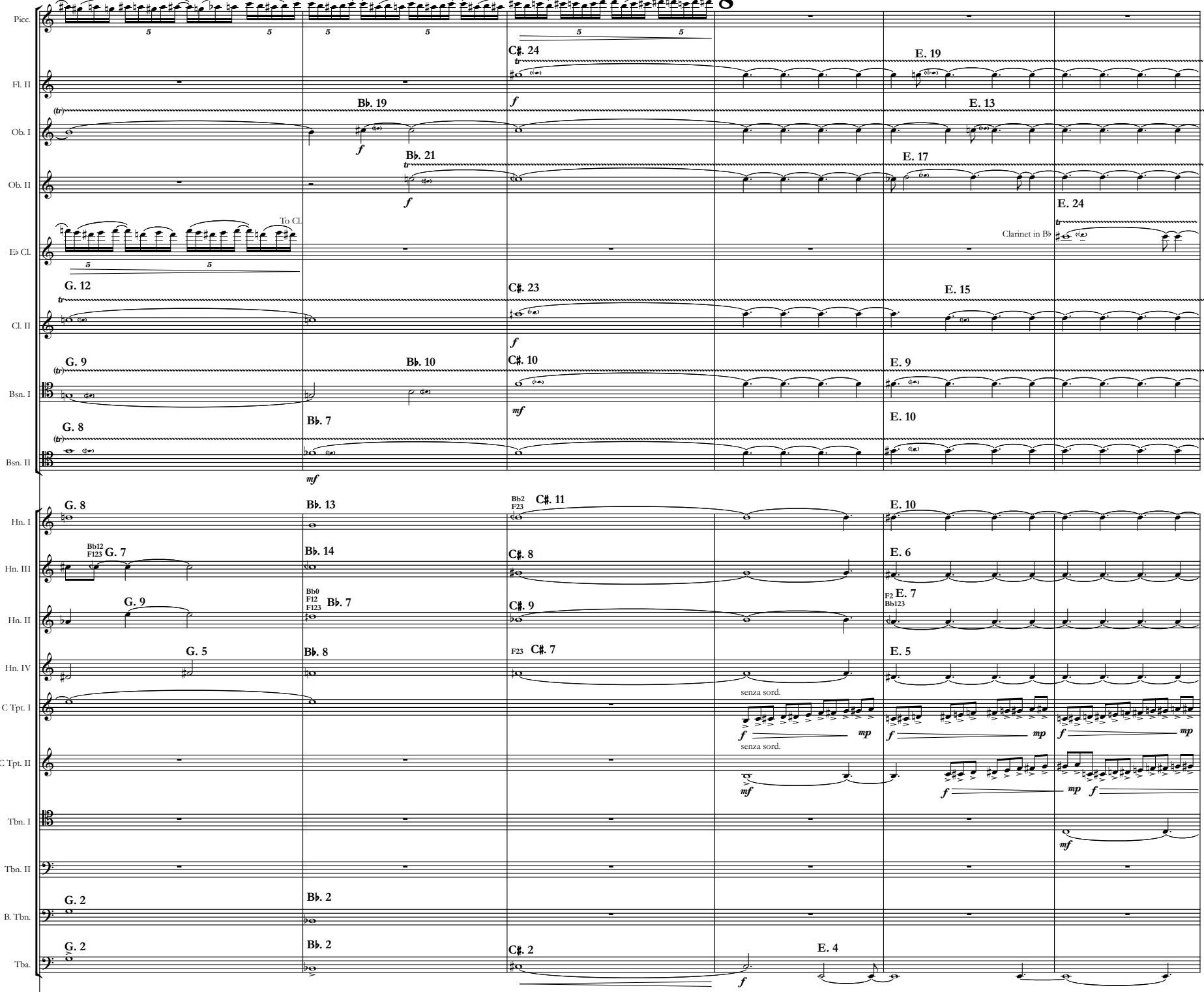

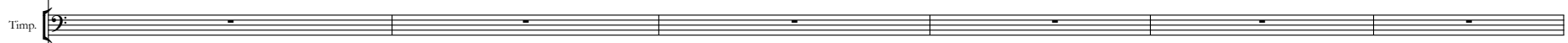

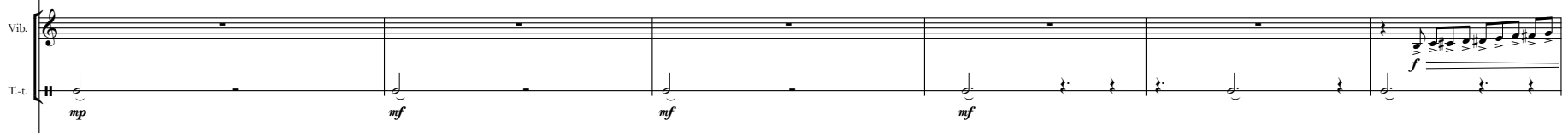

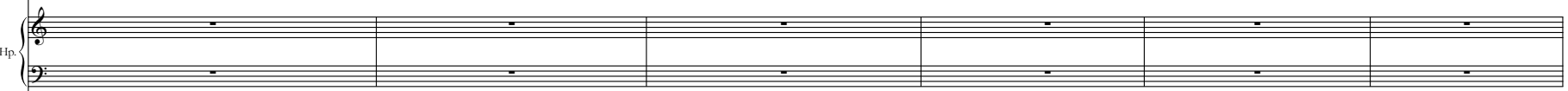

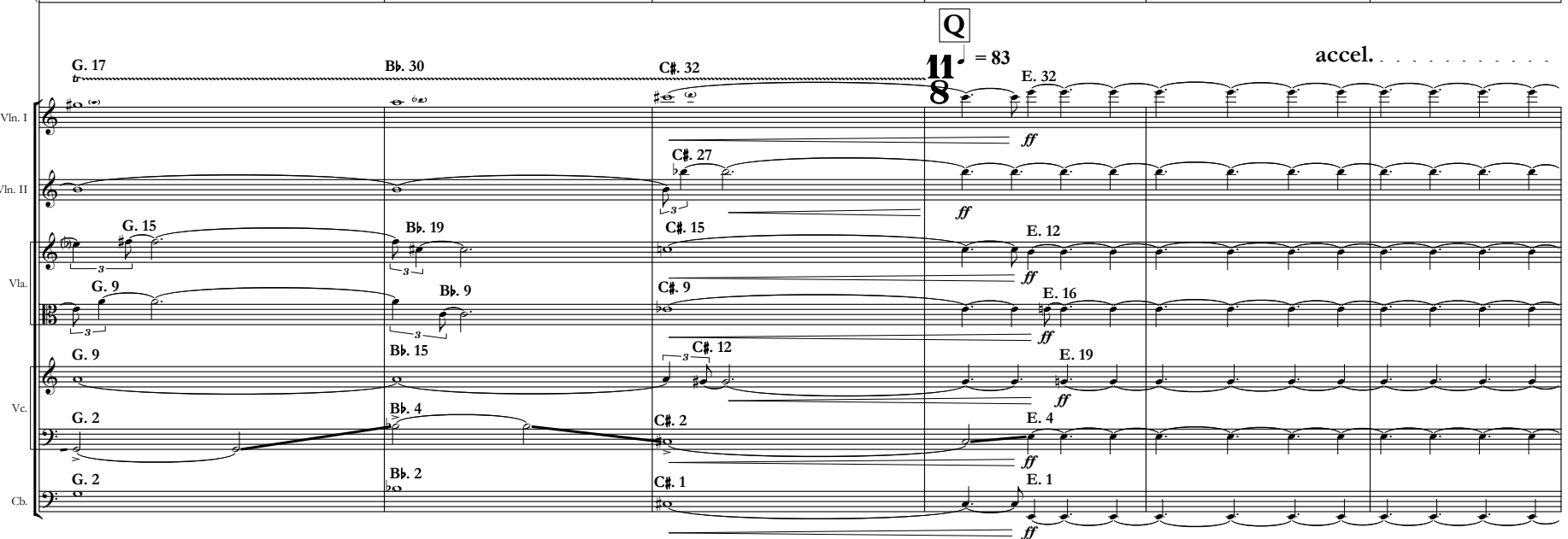


$\mathbf{R}$

32

Bb. 30

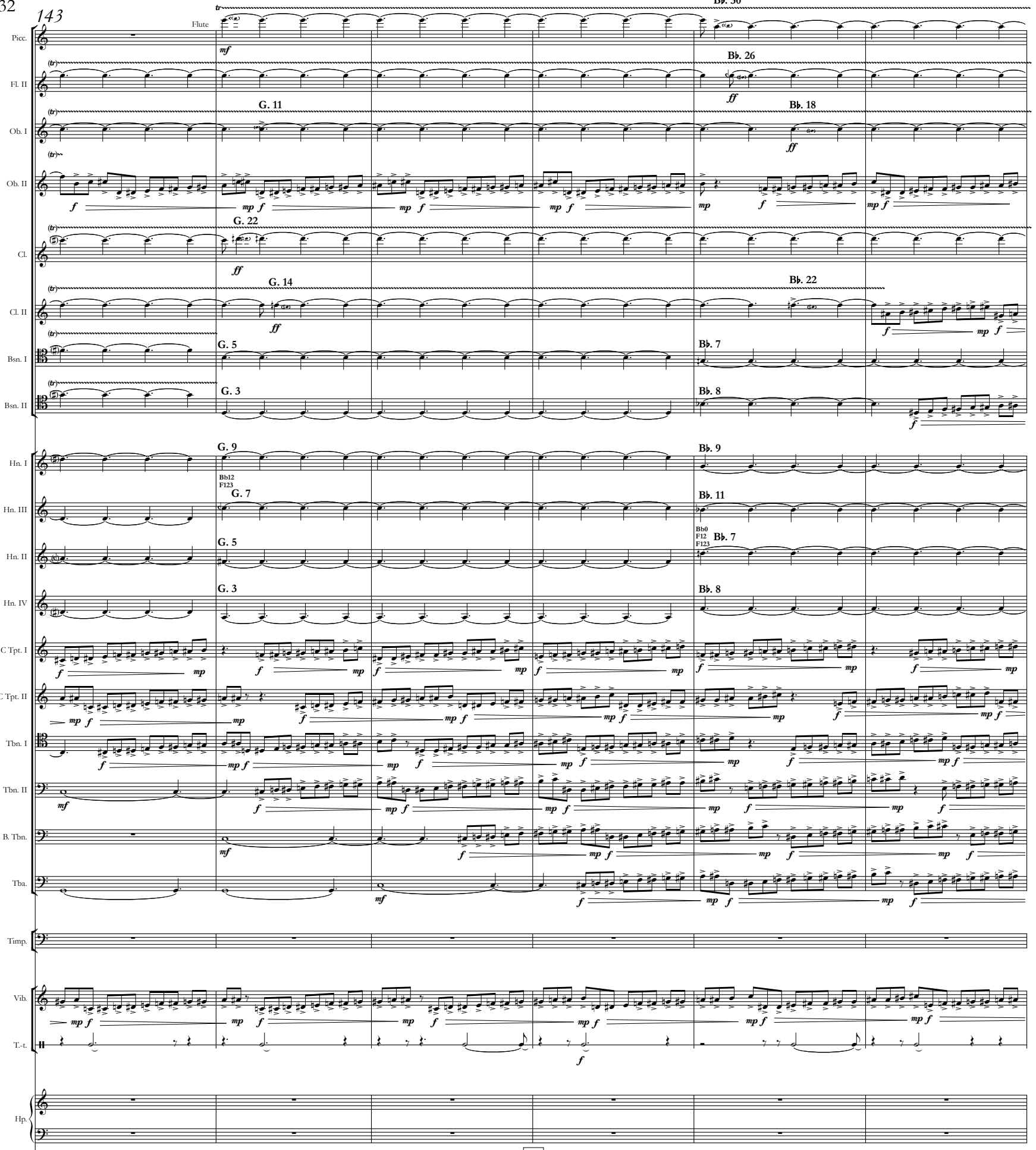

$\mathbf{R}$

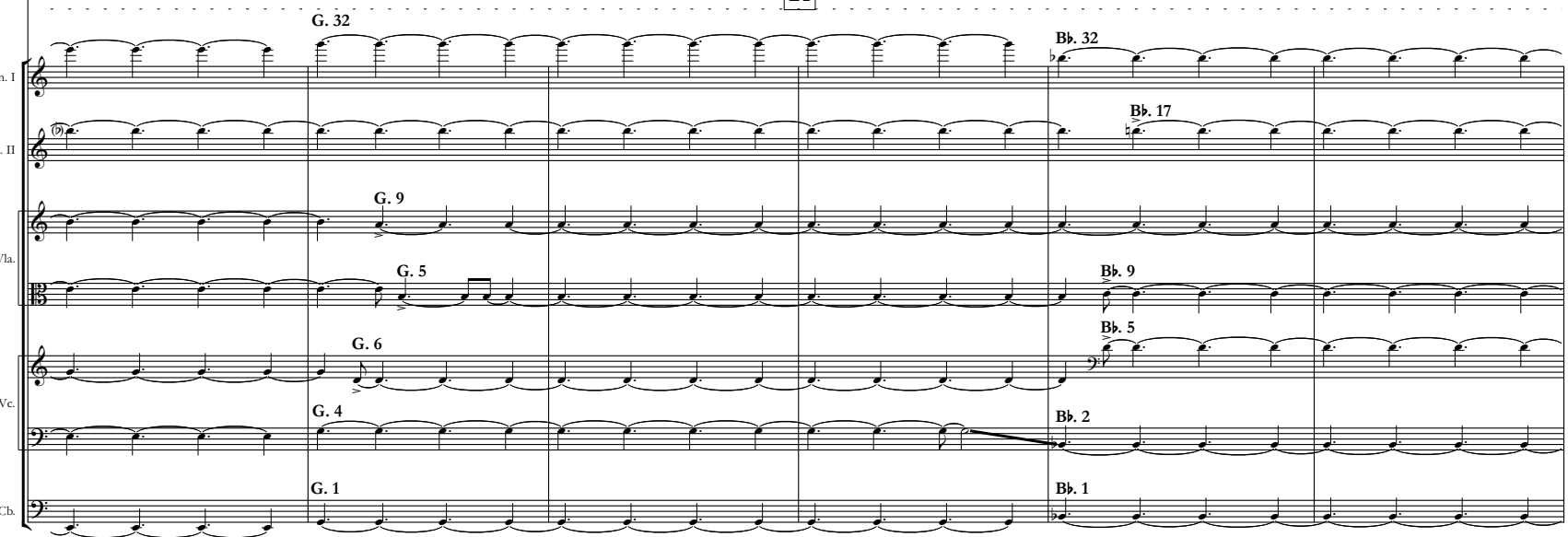


- = $110 \quad$ rit

(t)

${ }_{m p f}=$

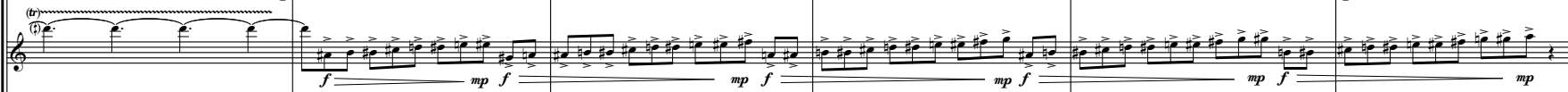

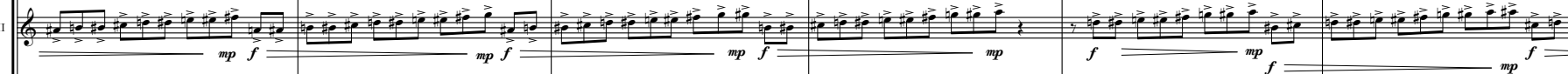

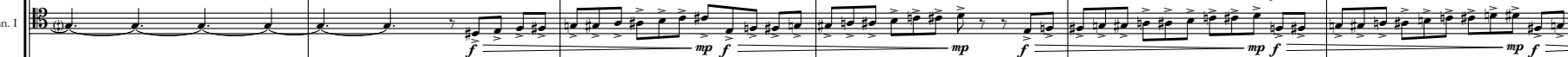
SnO II 30 (1.1 H. III H. II H.IV

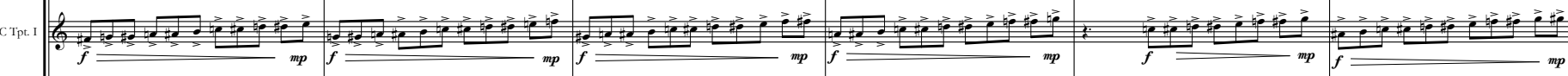
$\mathrm{CP}_{\mathrm{P} \mathrm{II}} \mathrm{mp}_{\mathrm{f} f}$ ${ }_{\mathrm{Tb}}$ Tha

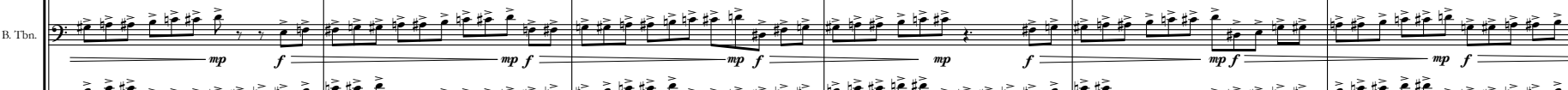

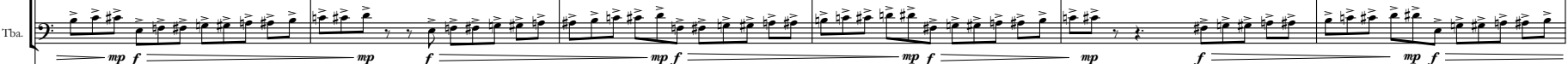

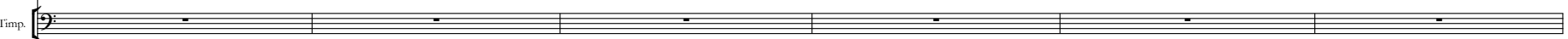

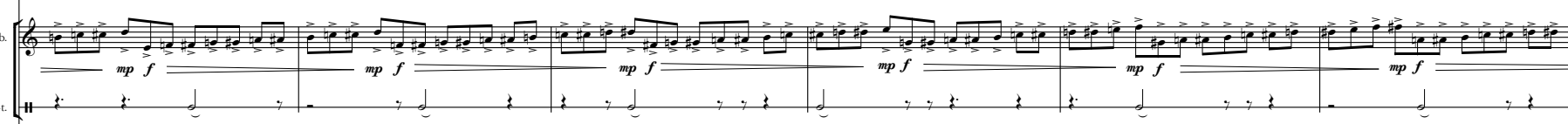
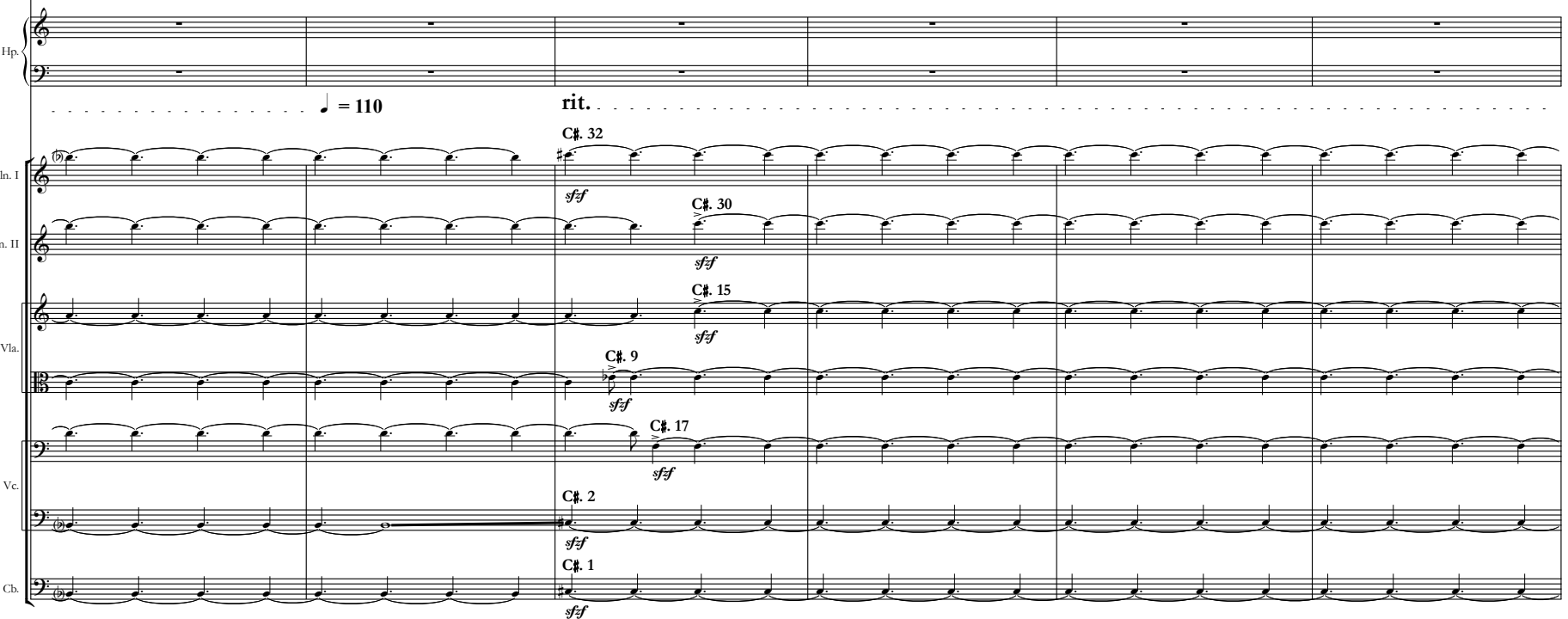
34155

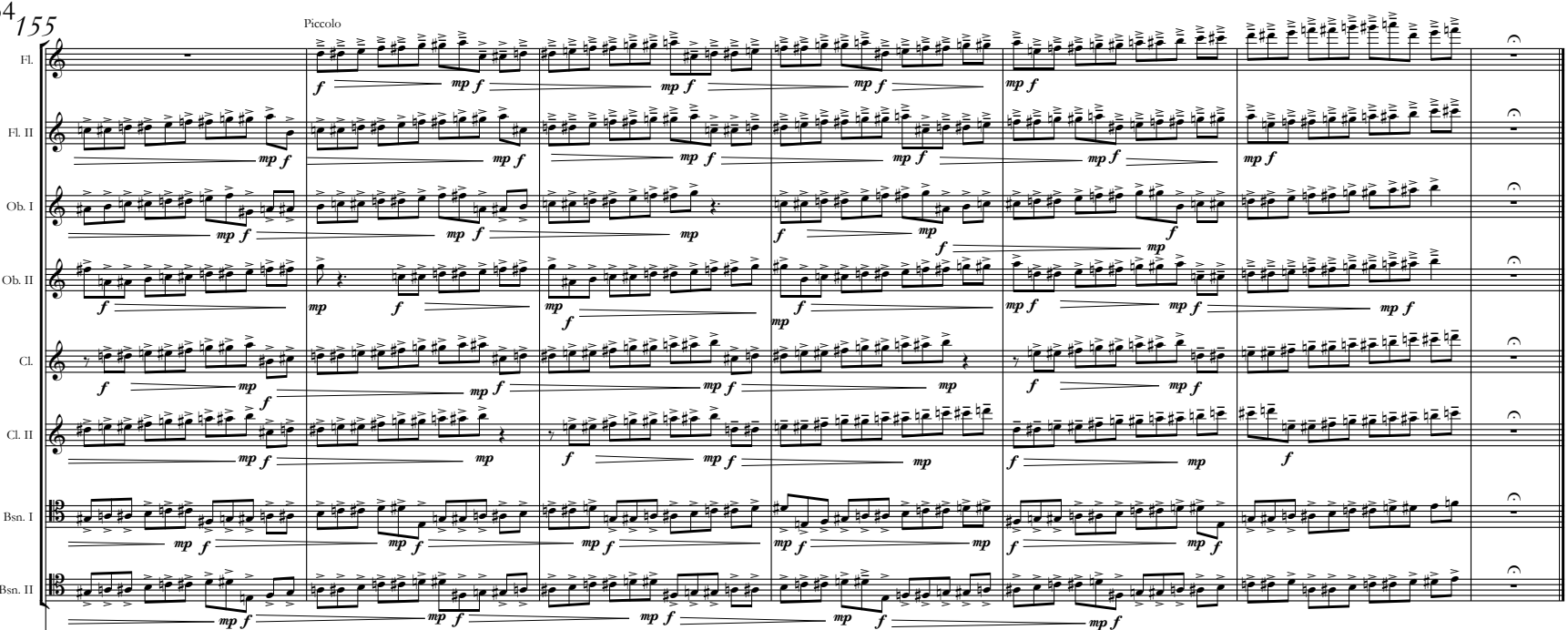

(1)

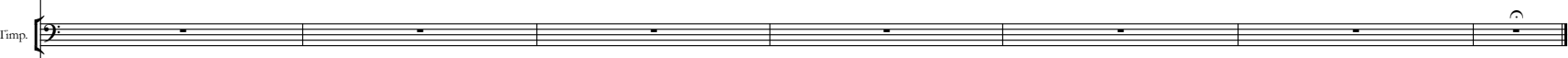

$m_{m p f}^{2}$

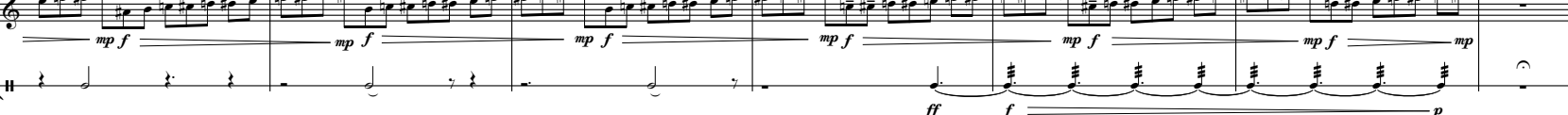

$\begin{cases}2 \\ 3\end{cases}$

\begin{tabular}{|l|l|l|l|l|}
\hline & & & & 0 \\
\hline
\end{tabular} .$=60$

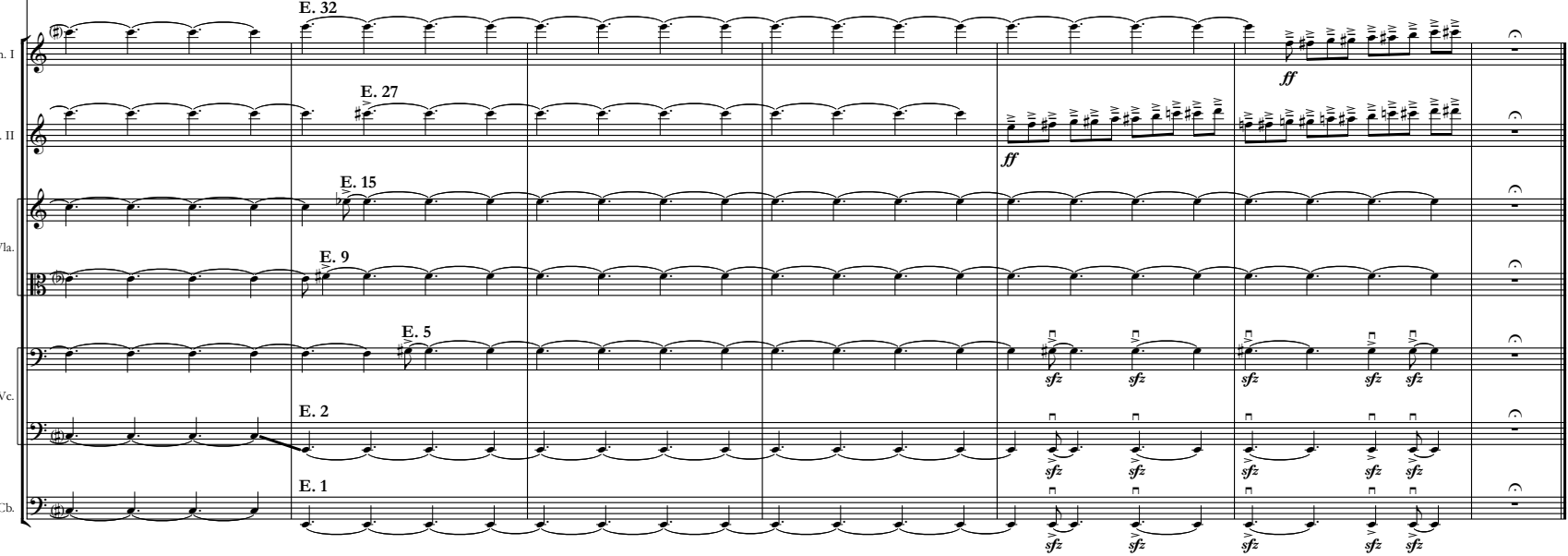


J A S O N P O S T

FOR STRING QUARTET

2013 


\section{Programme Note}

Rift is defined by an austere formal structure, and by a handful of focused musical gestures. The ensemble slowly makes its way down the playing range of the quartet, beginning at extreme highs above the fingerboard. As the players descend, they begin to splinter from their strict unified origins, resulting in factions.

\section{Duration: $c .8$ minutes}




\section{Performance Notes}

\section{Microtonality}

Quartertones are used throughout, and towards the end of the work, eighth tones. These are notated as:

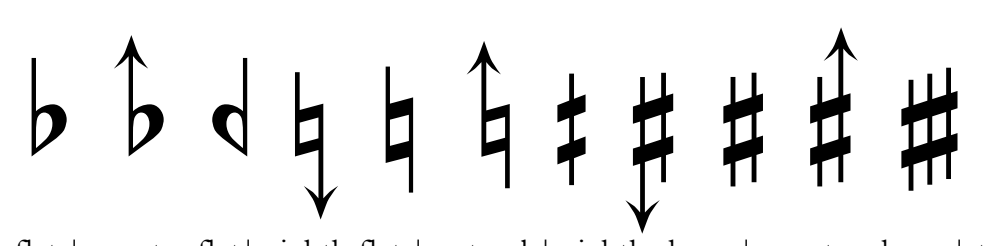

flat | three eights flat $\mid$ quarter flat $\mid$ eighth flat $\mid$ natural | eighth sharp | quarter sharp | three eighths sharp | sharp | five eighths sharp | three quarters sharp

The other possibilities (five eighths flat etc.) are not used in the piece.

\section{Vibrato}

The work should be played without any vibrato throughout, unless especially asked for with the following symbols:

Regular vibrato $\|$

\section{Glissandi}

Glissandi are used throughout the work and will end on either a bracketed or nonbracketed note head. If the note head is bracketed, the gliss should end exactly on the pitch and not continue after. A non-bracketed note head should be played normally i.e. the pitch should be played for its full rhythmic duration.

\section{Scratch Tone}

Scratch tones are notated with a line as scr. - follow the dynamic instruction for the amount of overpressure applied to the string.

\section{Bow Positions}

$\begin{array}{lr}\text { M.S.T. } & \text { Molto Sul Tasto } \\ \text { S.T. } & \text { Sul Tasto } \\ \text { S.P. } & \text { Sul Pont } \\ \text { M.S.P. } & \text { Molto Sul Pont }\end{array}$

S.P and S.T. should be played in the traditional positions, though M.S.T. and M.S.P. should be extreme (i.e. right over the fingerboard, and as close to the bridge as possible). 


\section{Additional Items Required}

The pitch material in the first section of the work is mostly in between the fingerboard and the bridge, and is played by placing a hard object on the string such as a nail or a pencil in place of a finger to create clarity of pitch. While this section will still be mostly bow noise, the pencil or nail should be enough let a thin sliver of pitch penetrate the texture. 


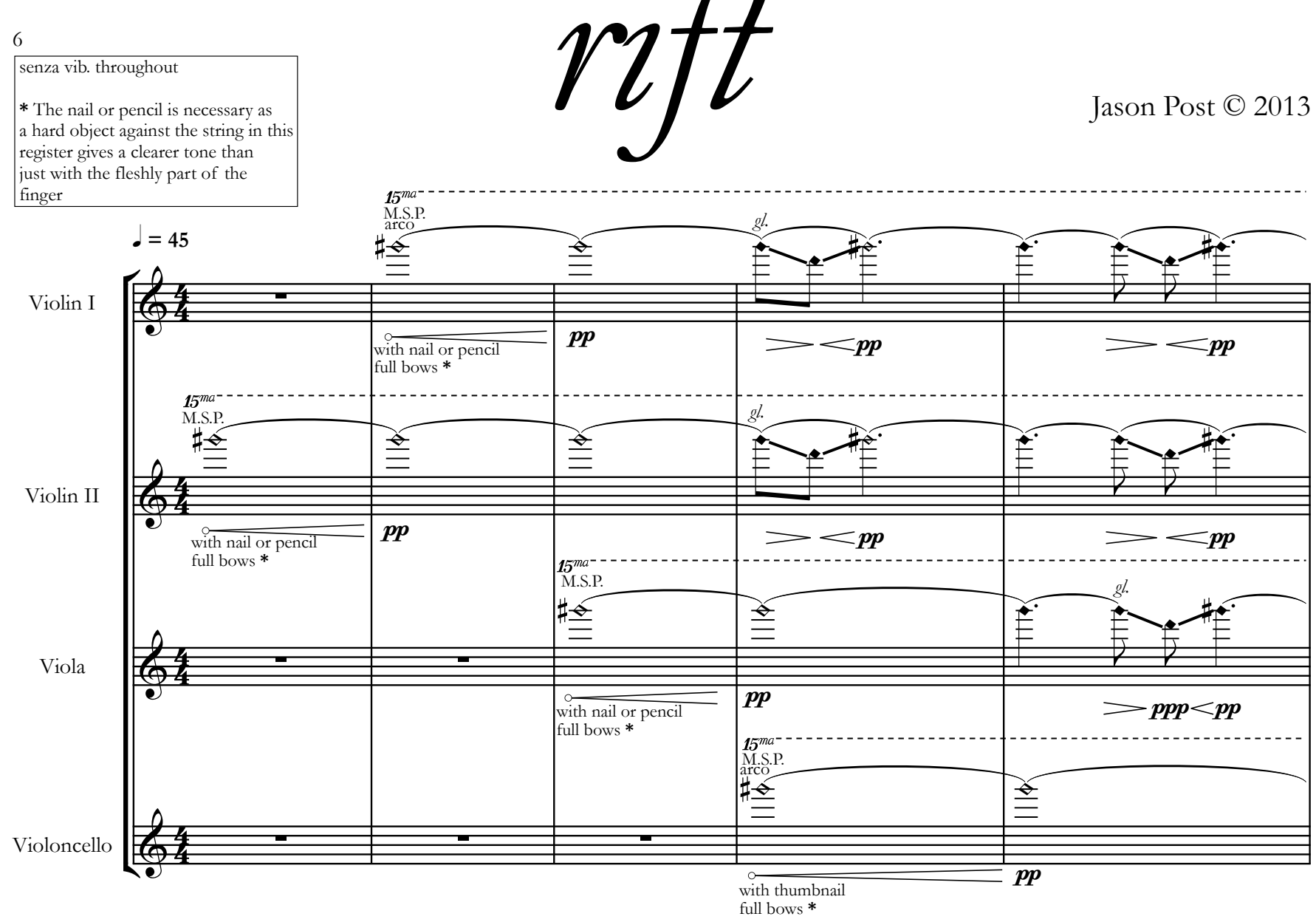

A

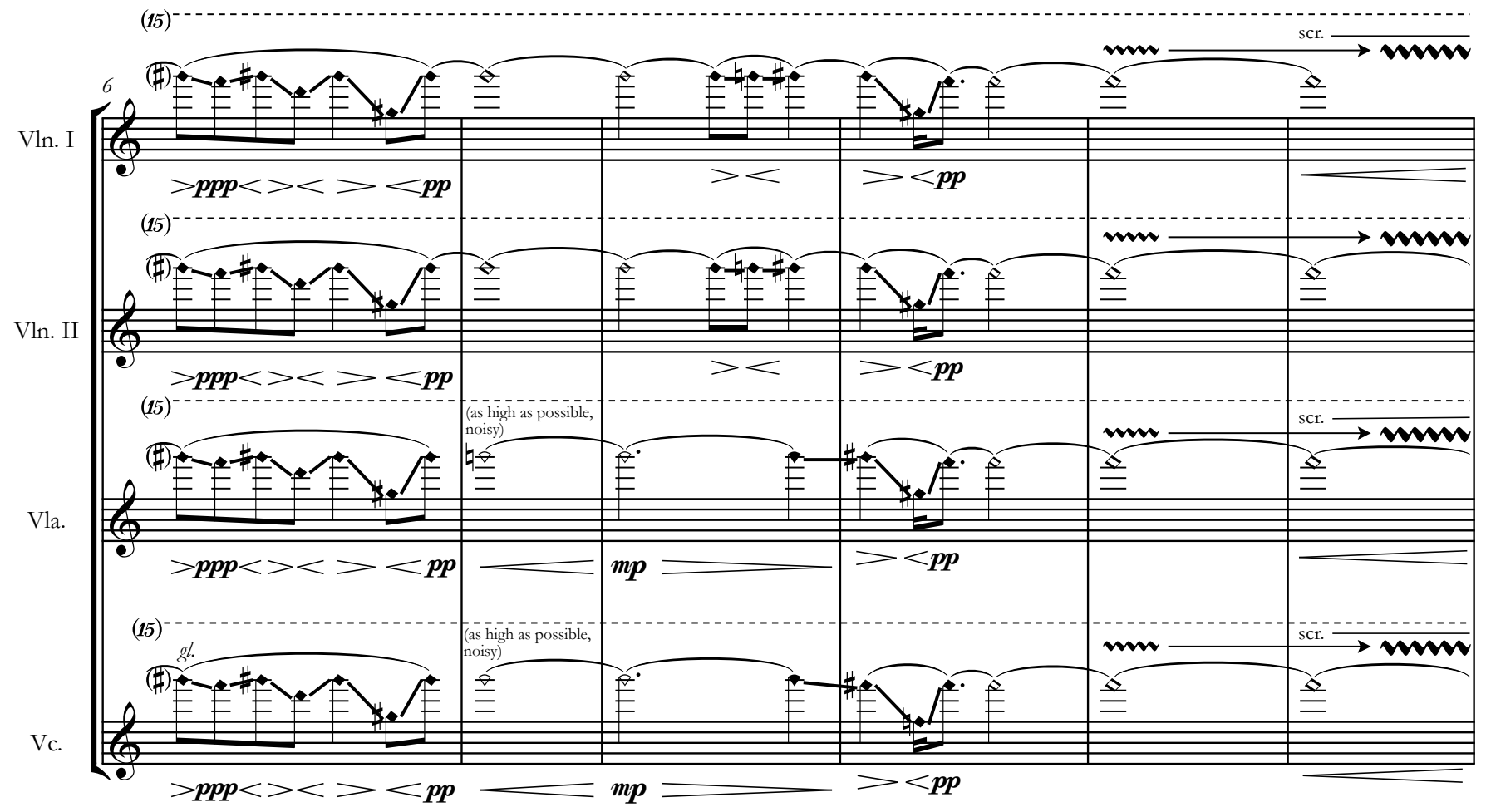


(15)

Vln. I

$18(15)^{3}$

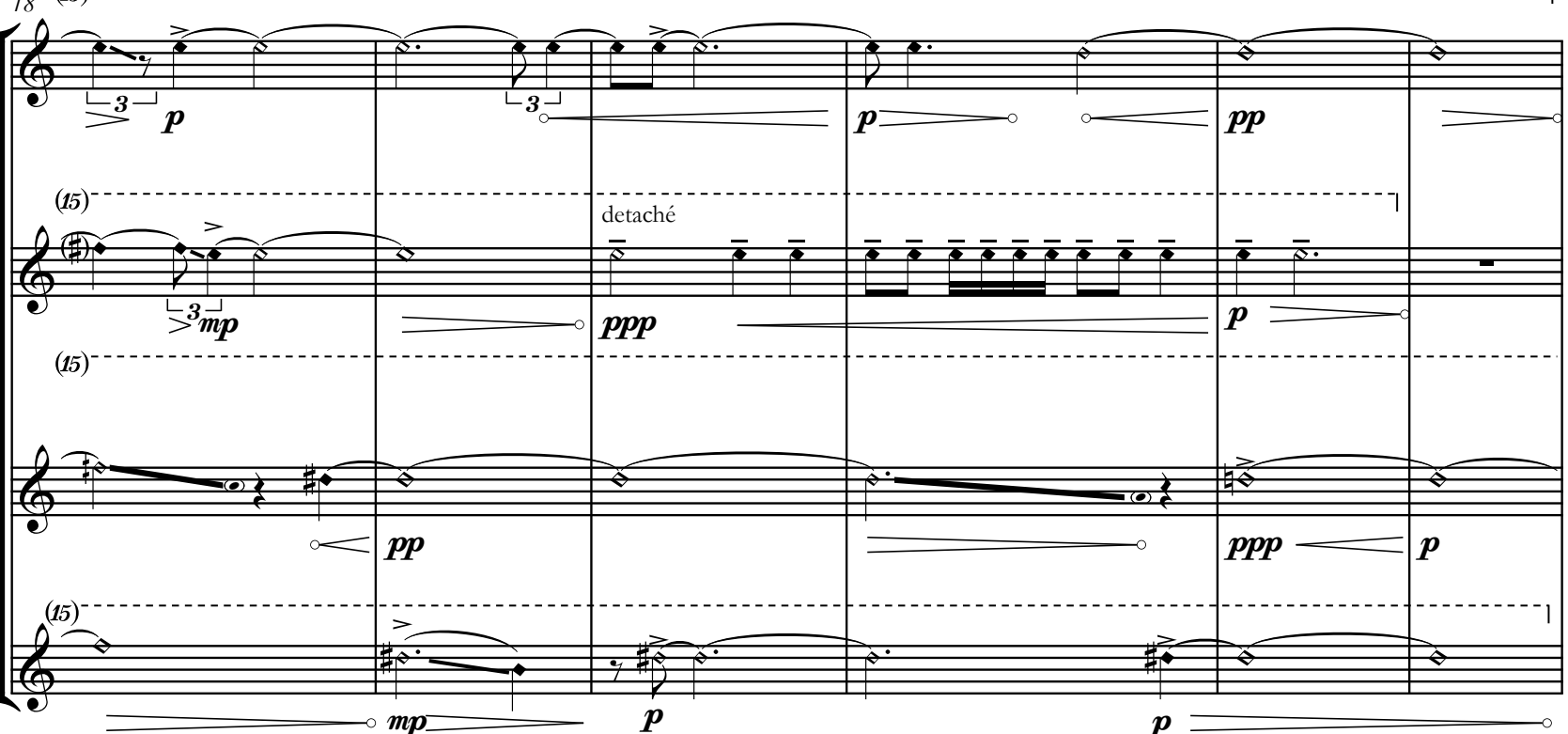

B

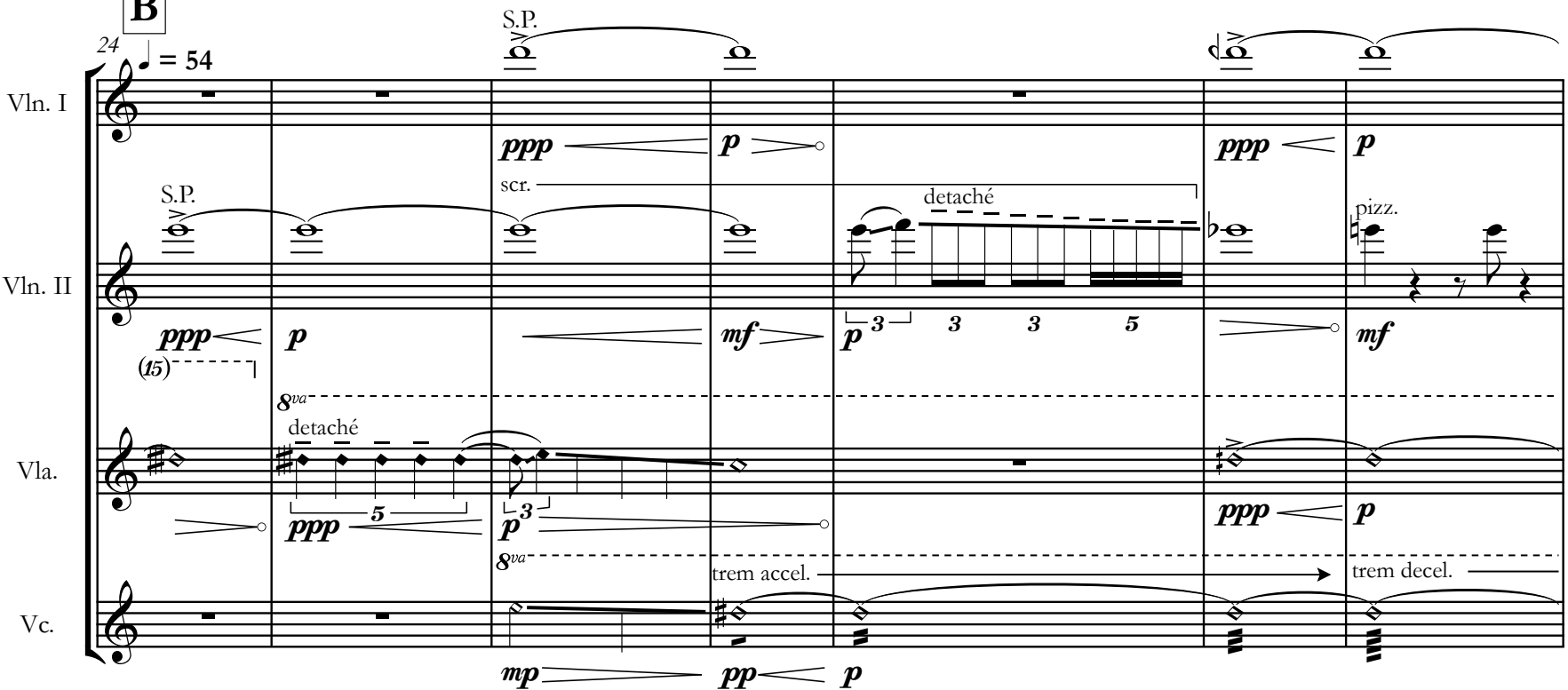




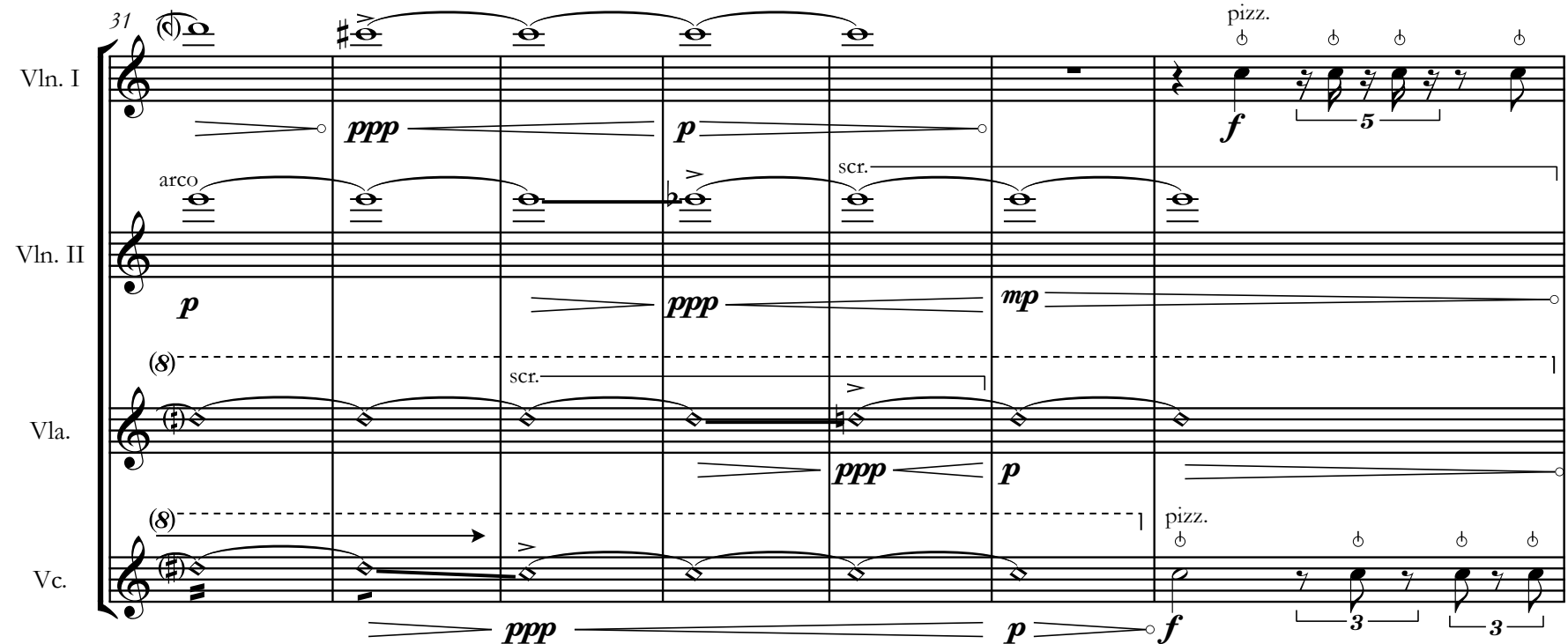

C

Vln. I

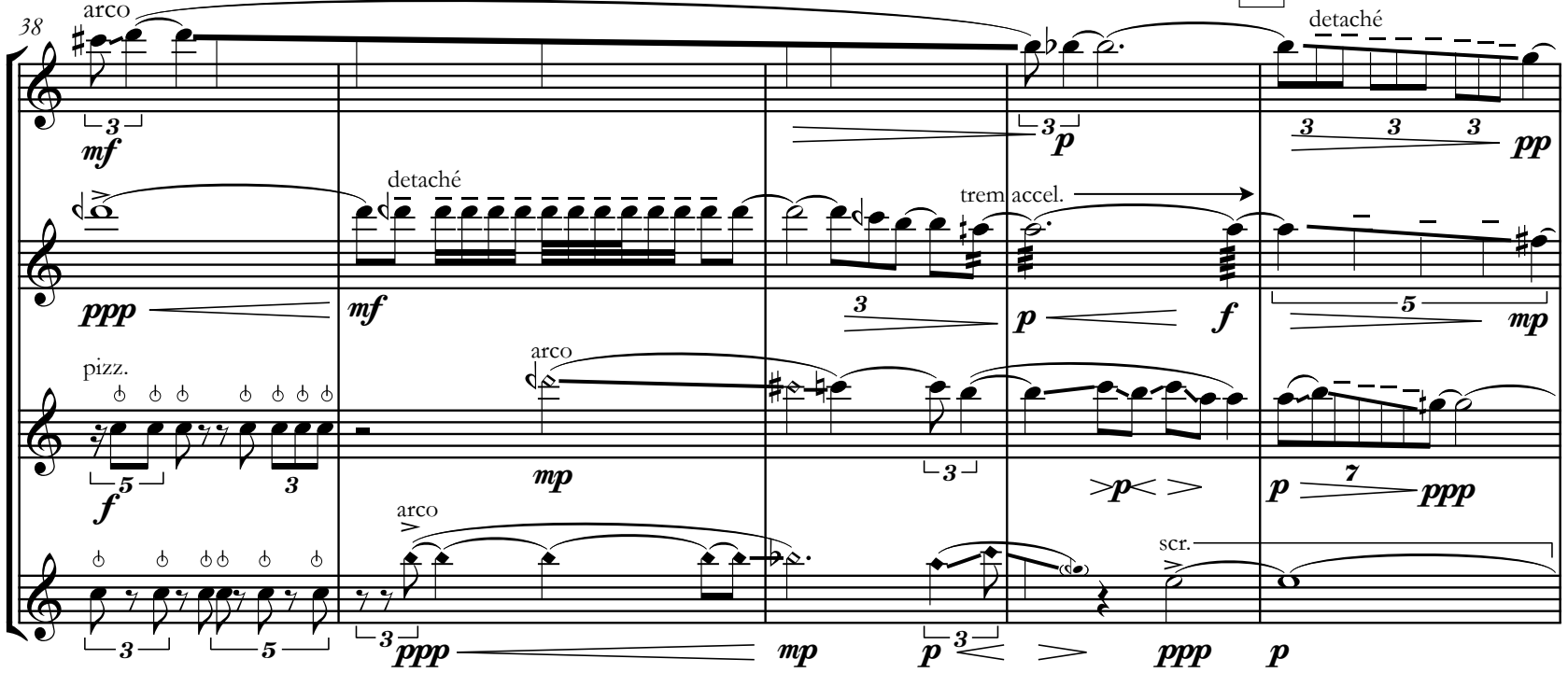

ccel. . . . . . $d=60$

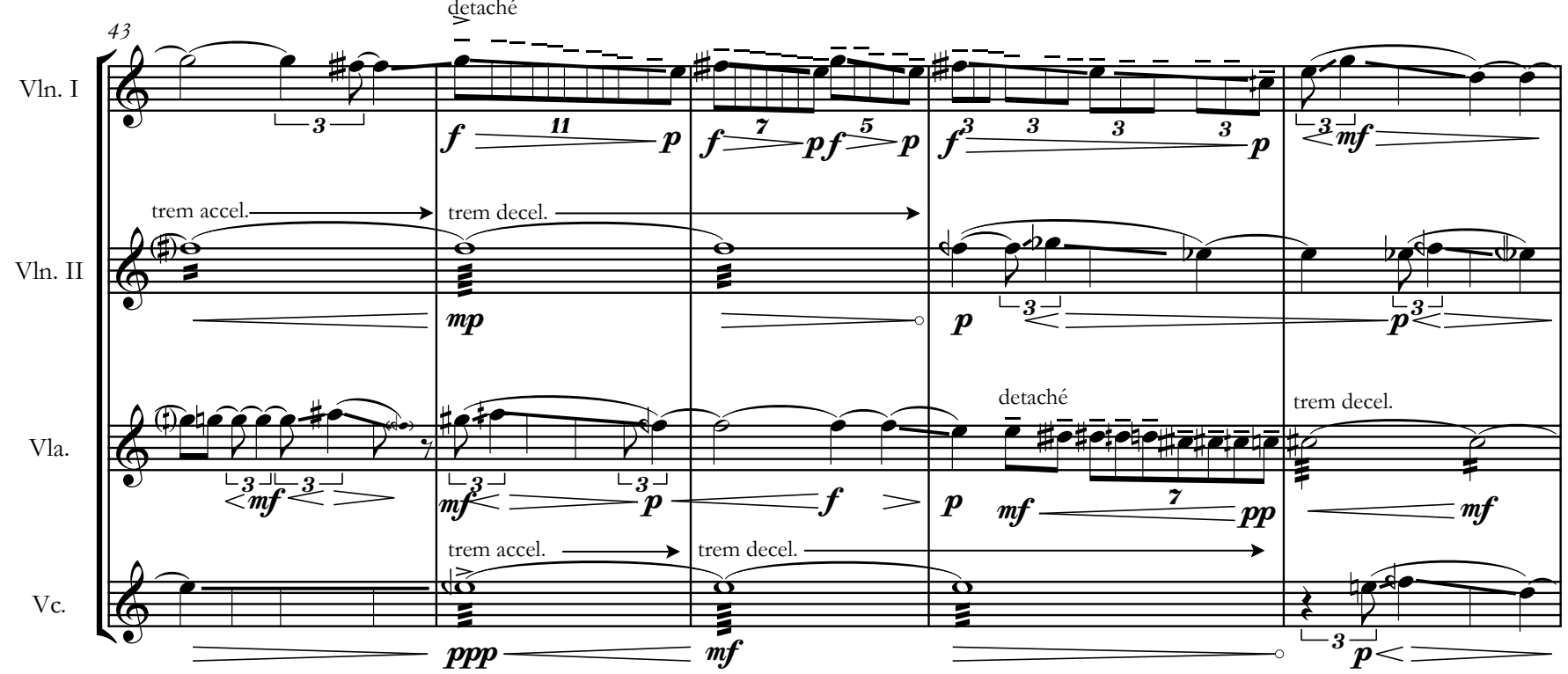


D

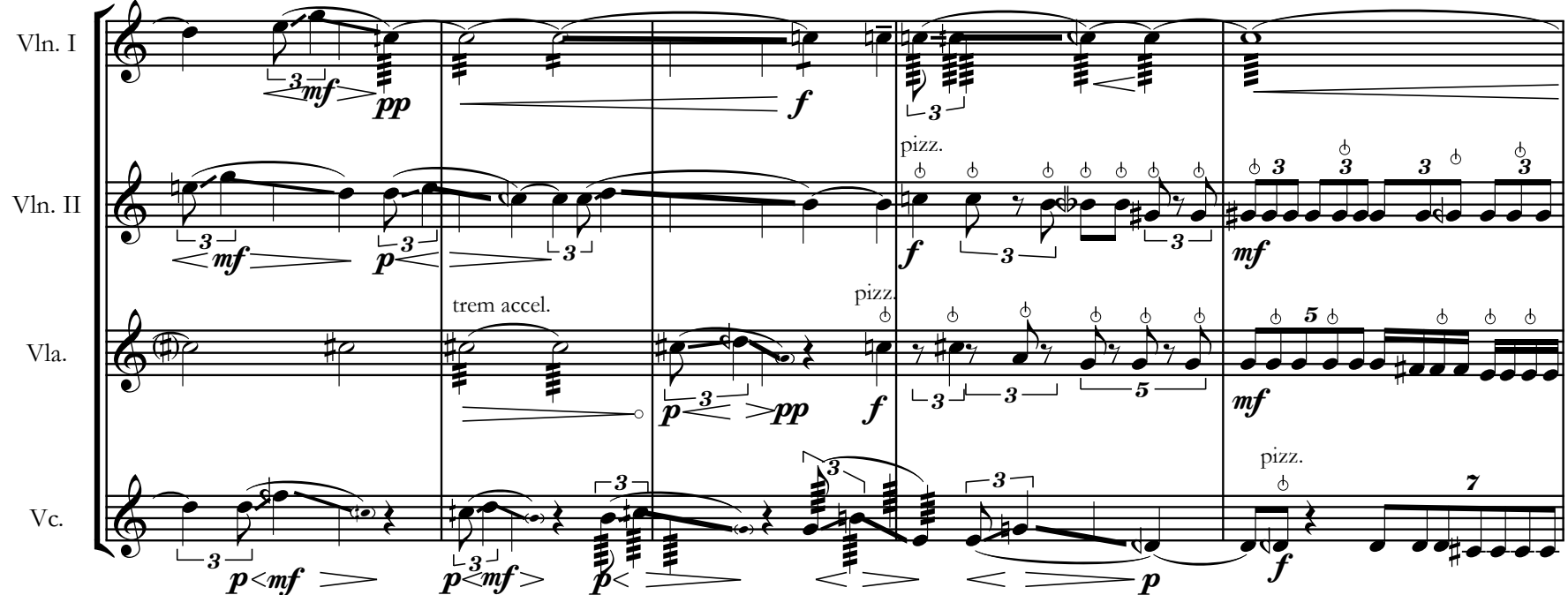

Vln. I

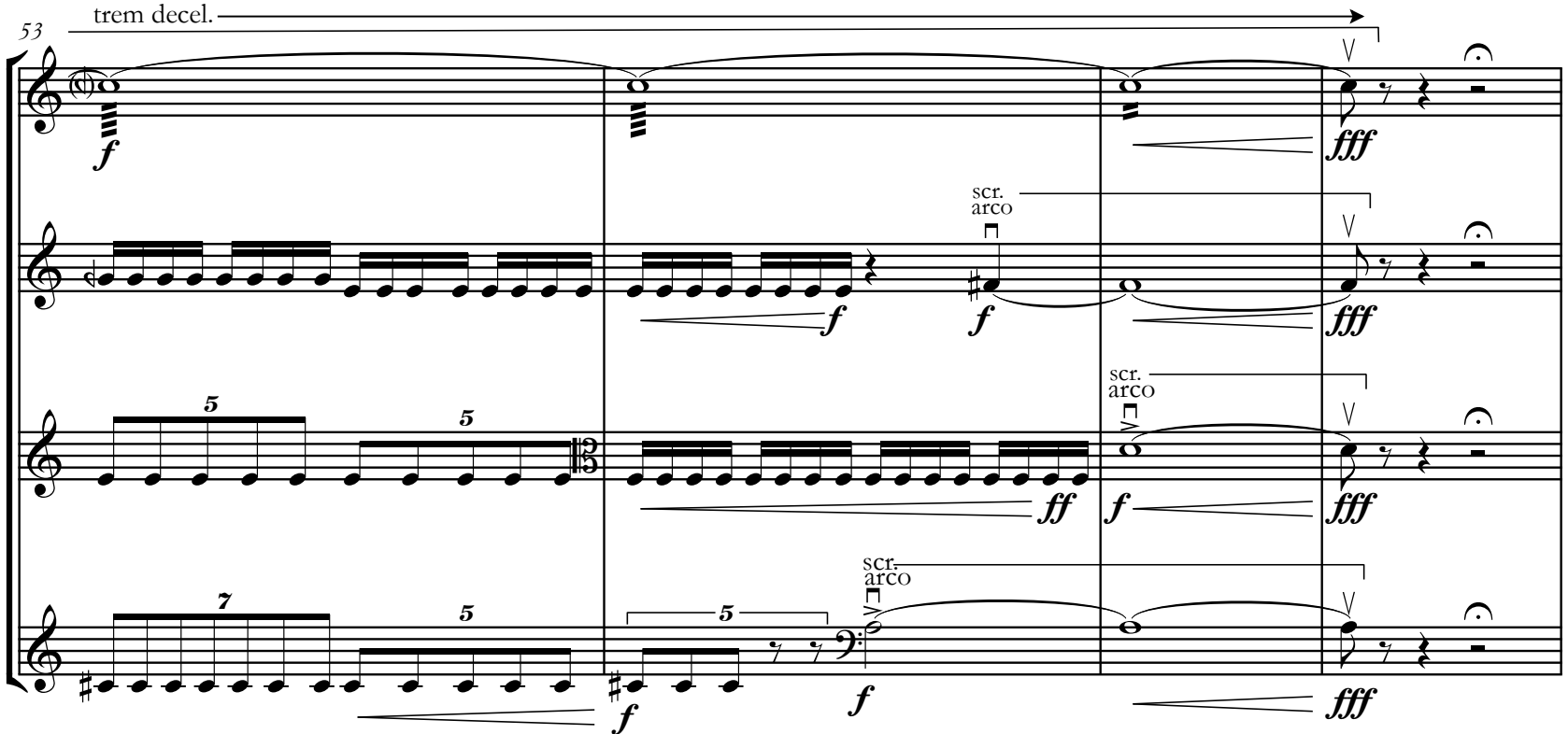

E

Vln. I

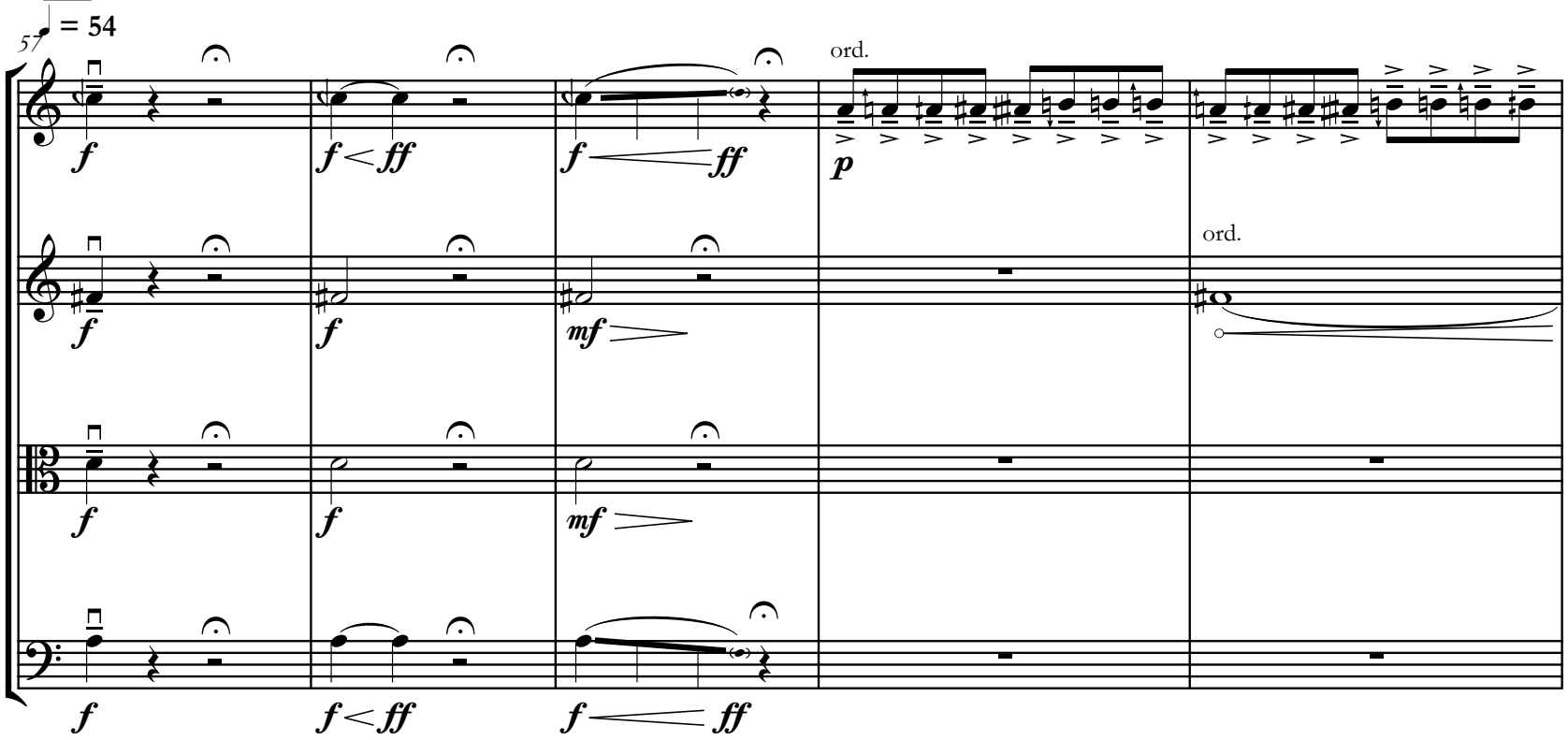



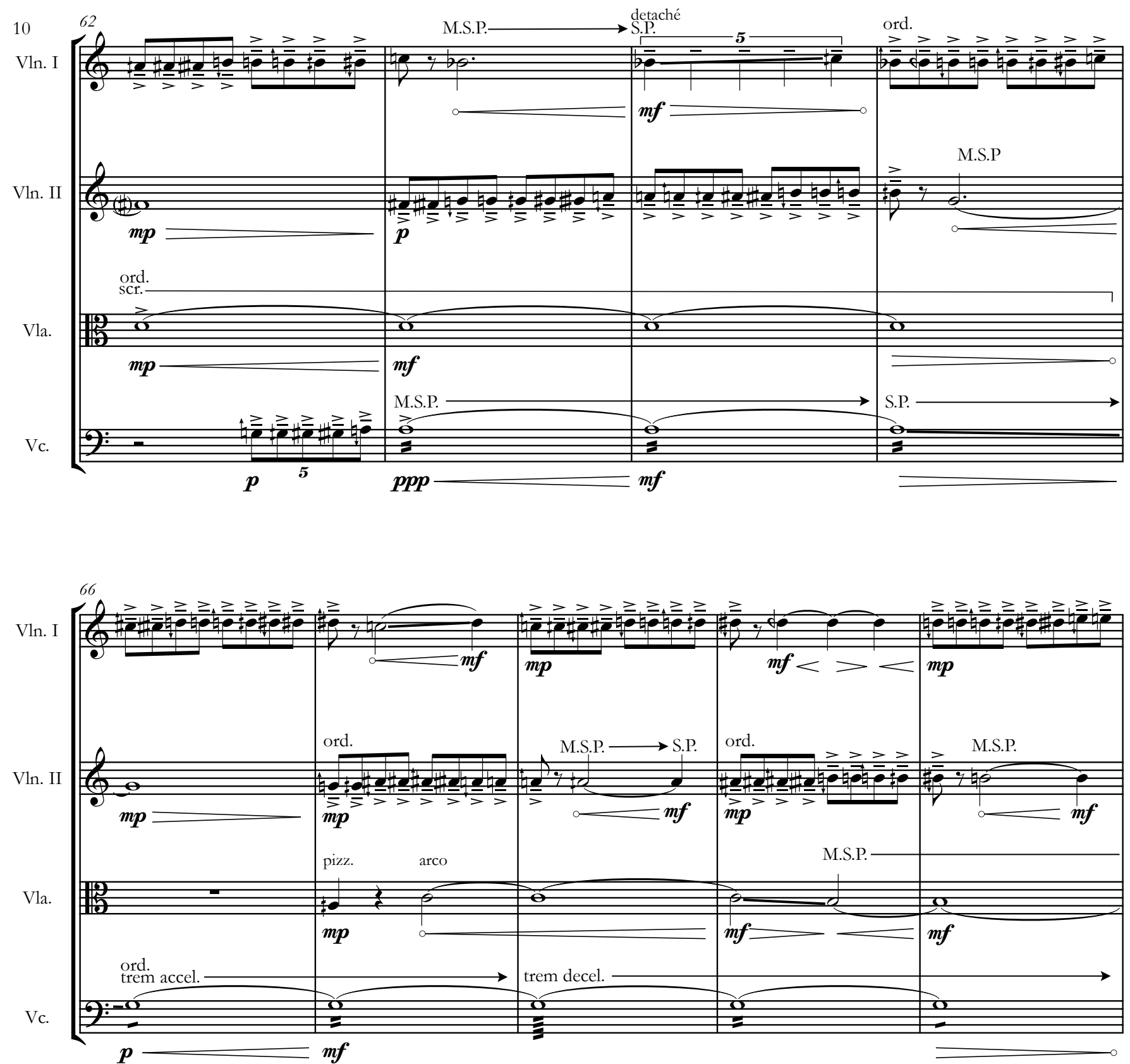

$\mathbf{F}$

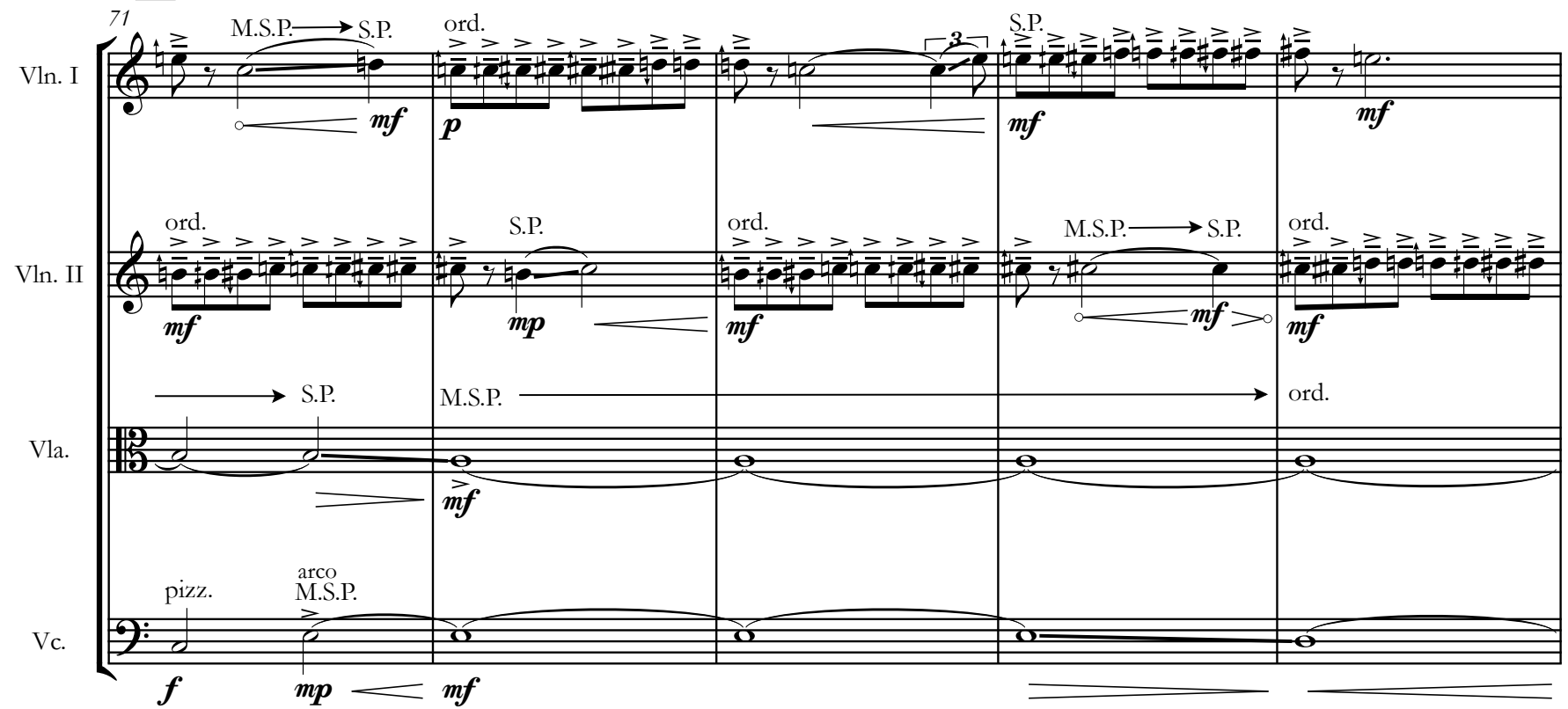




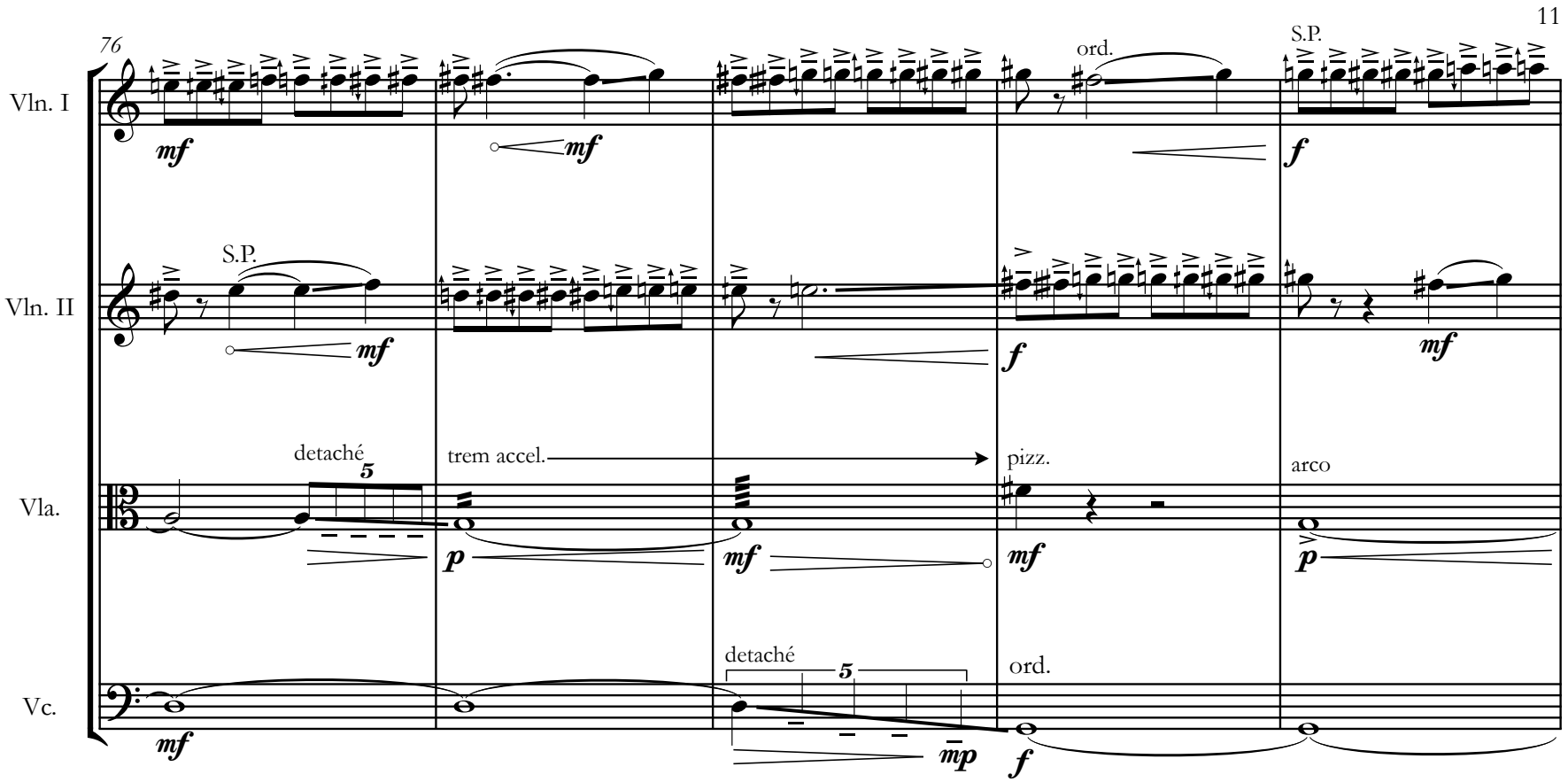

G
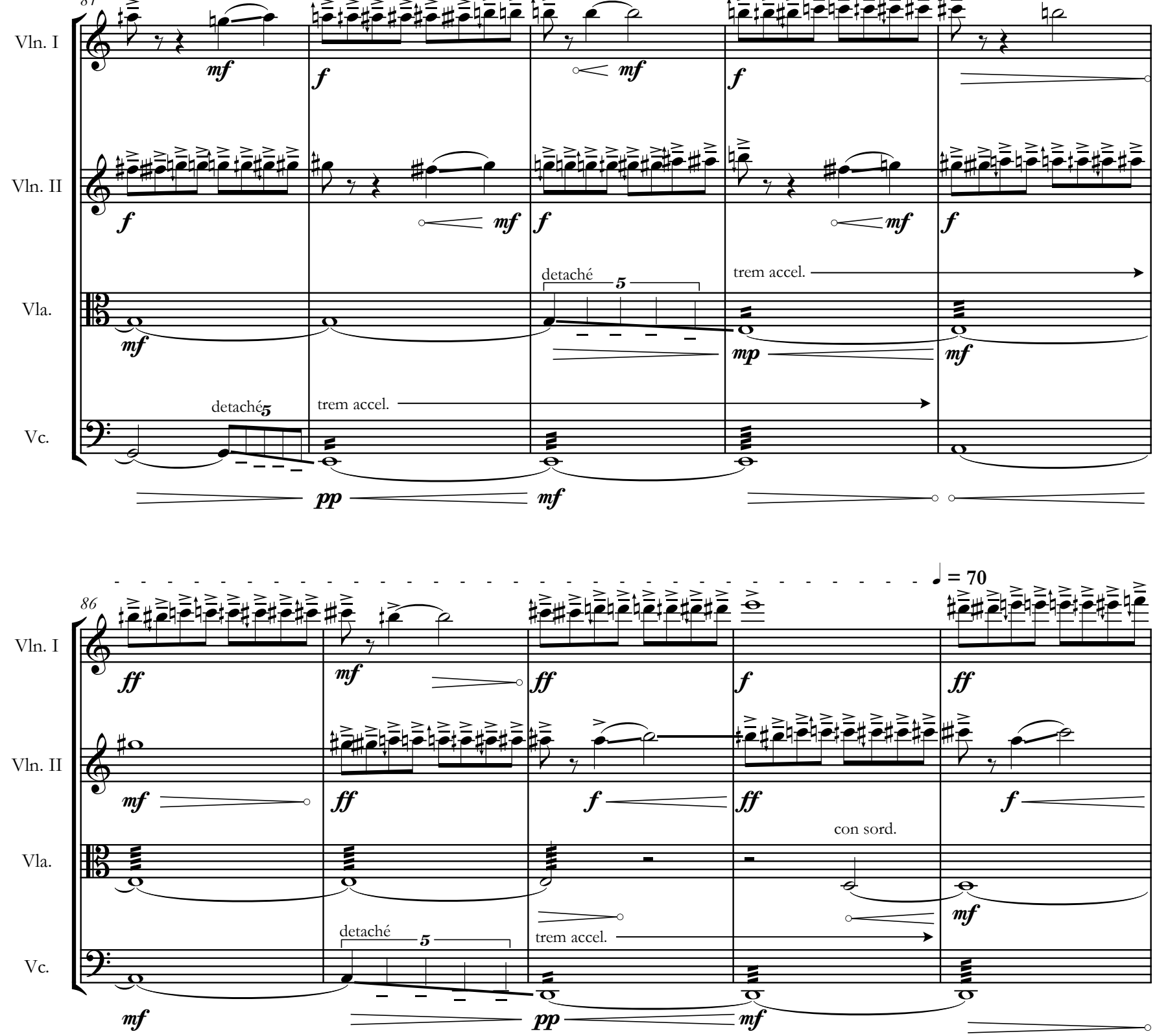


\section{H}
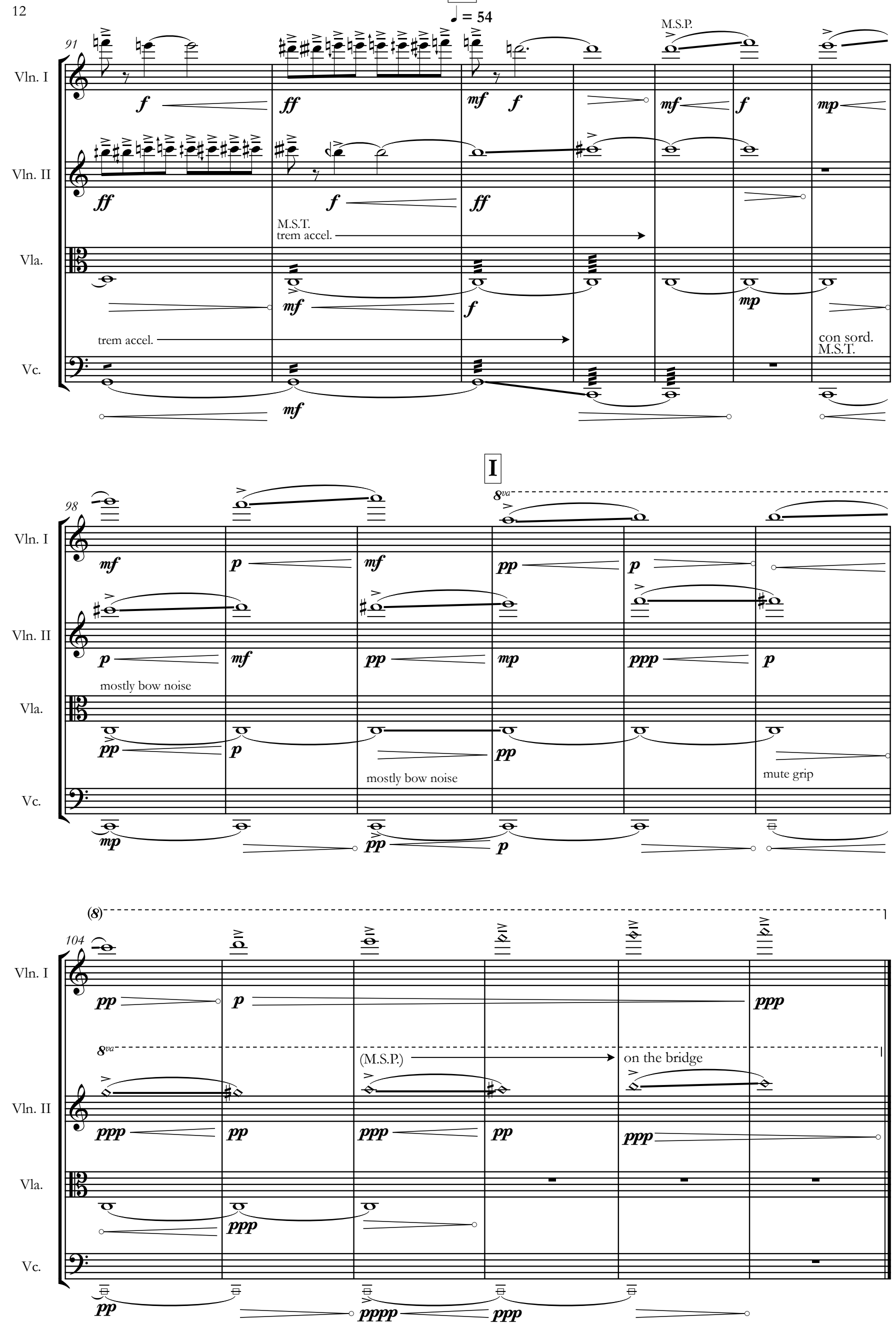


$$
\text { J A S O N P O S T }
$$

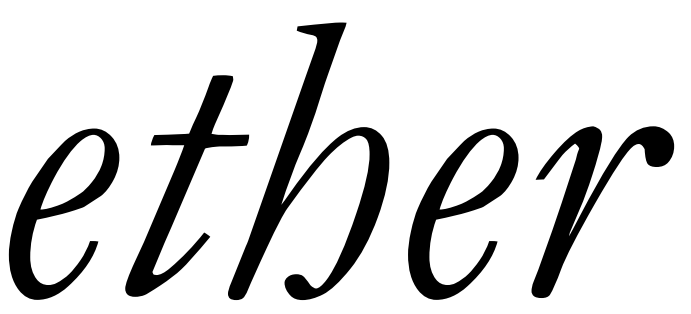

F O R O R G A N

A N D L IVE E L E C T R O N I C S

2014 


\section{Programme Notes}

The title Ether has a paradoxical relationship to the sound world of the work. While the organ sound is constantly surrounded by a thick drone texture, the gestural power of the work in is the recording and referencing of the live organ sound across the spatial arrangement of the live electronics. As these gestures are explored, the texture surrounding the organ struggles to incorporate them, caricaturing the live instrumental sound. This piece was written specifically for the organ in the Adam Concert Room at the New Zealand School of Music. This organ can produce interesting timbres by manipulating the stops.

\section{Duration: c.10 minutes}

www.jasonpost.info

jason.w.post@gmail.com

\section{Performance Notes}

The score is written in box notation with an extremely aleatoric aspect.

Times should be followed approximately and phrases can be interrupted to move onto the next box.

In the 'increase chromatic density' section on the $3^{\text {rd }}$ page of the score, it is up to the performer to choose notes gradually towards forming the chord in the next box.

It would be wise to have a separate performer operate the stops while the organist plays the manuals and pedals. 

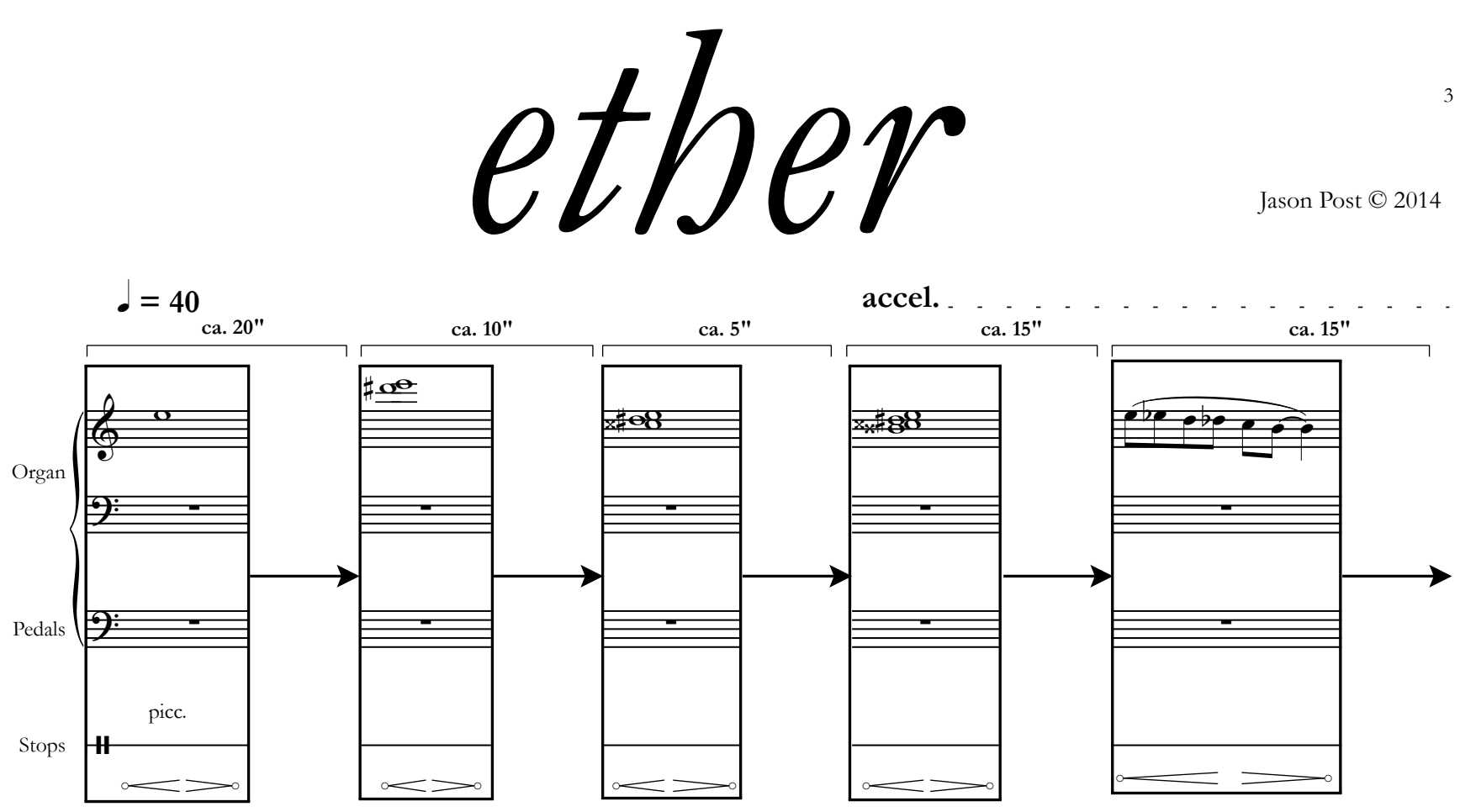

ca. $30^{-}$

ca. $30^{-}$

ca. $30^{\prime \prime}$

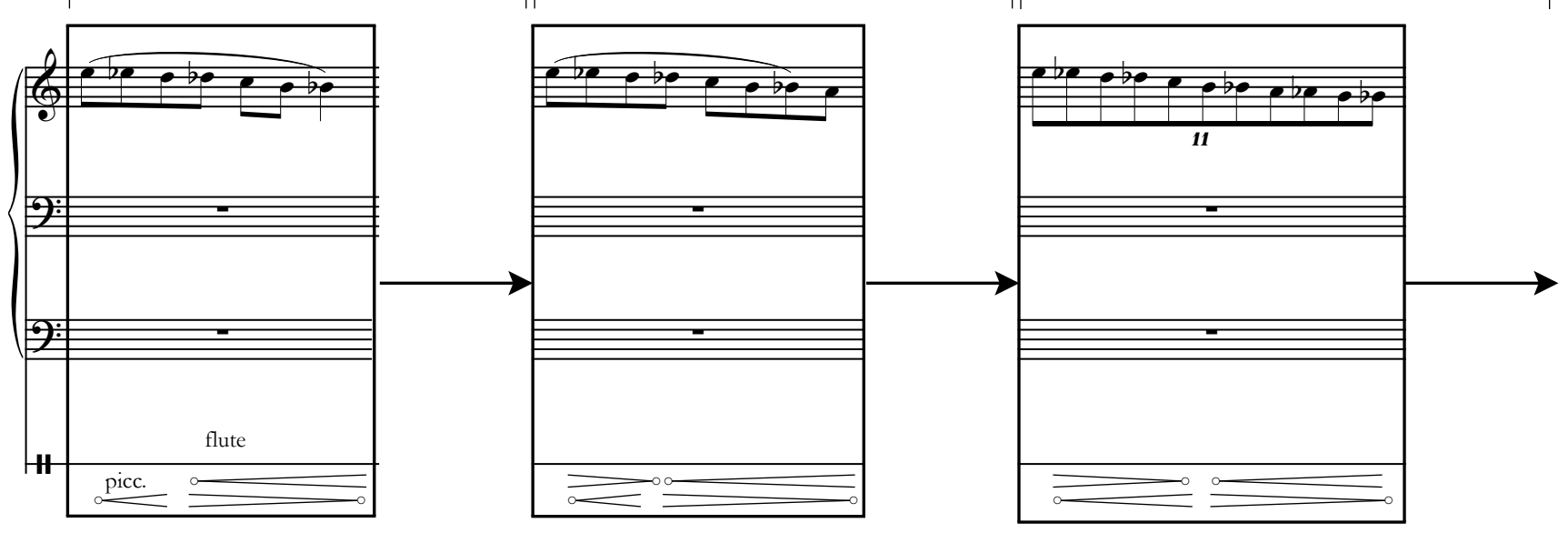

.$=70$ rit.

ca. $20 "$

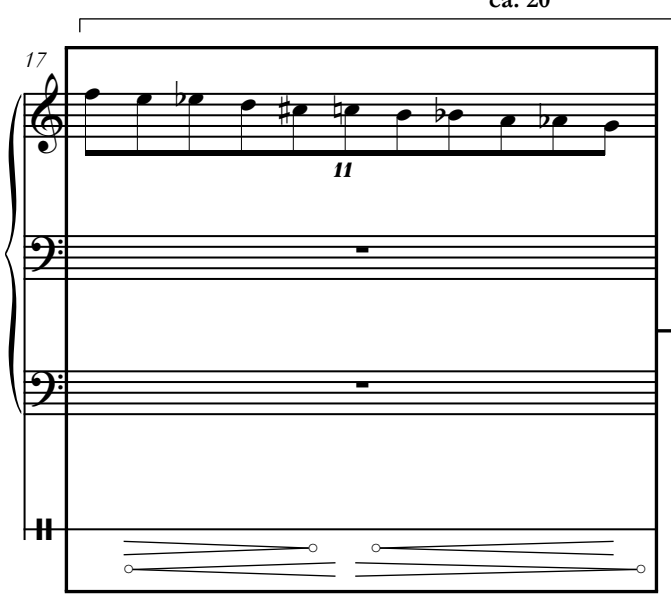

ca. $10^{\prime \prime}$

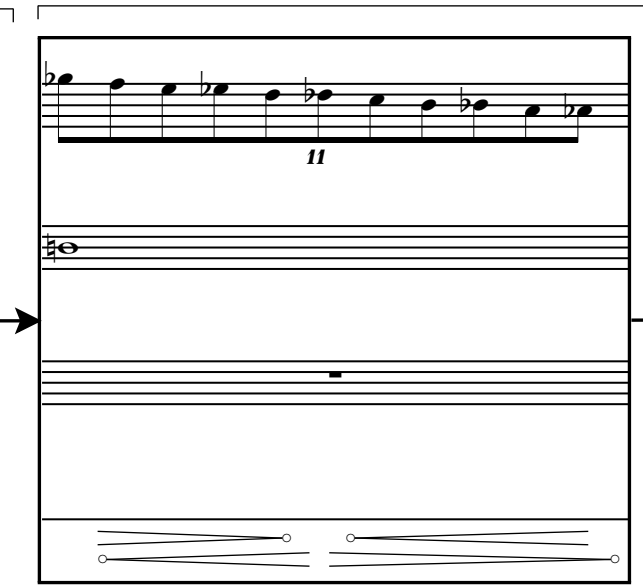


4

$\therefore \ldots+\ldots=50$

ca. 20"

ca. 20"

ca. 20"

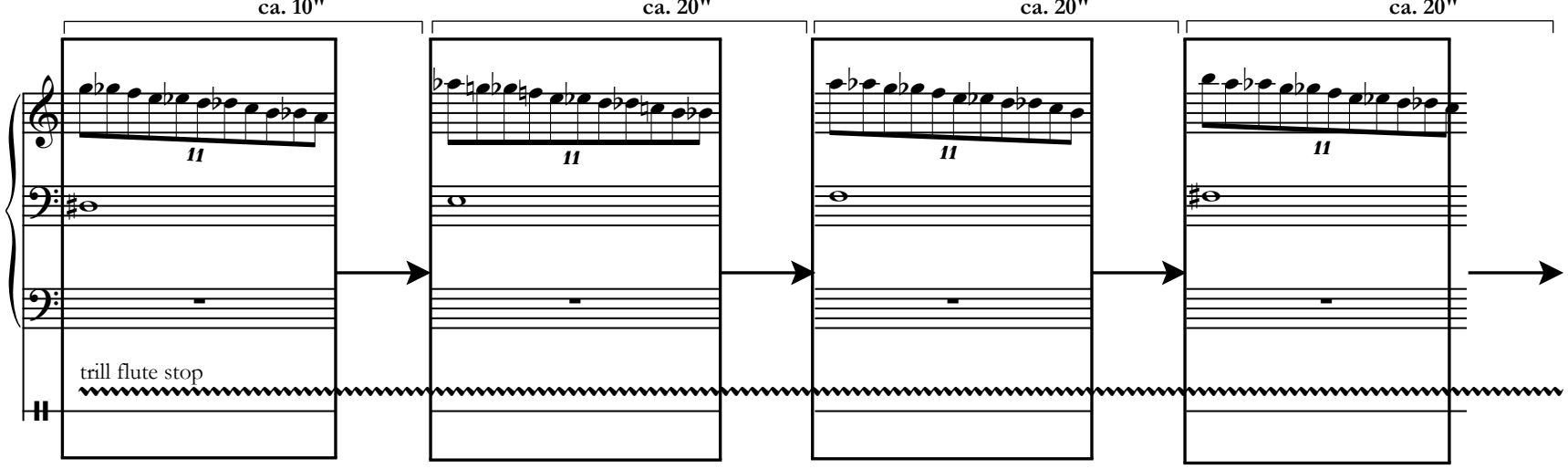

ca. 16"

ca. 12"

ca. 10"

ca. 8"

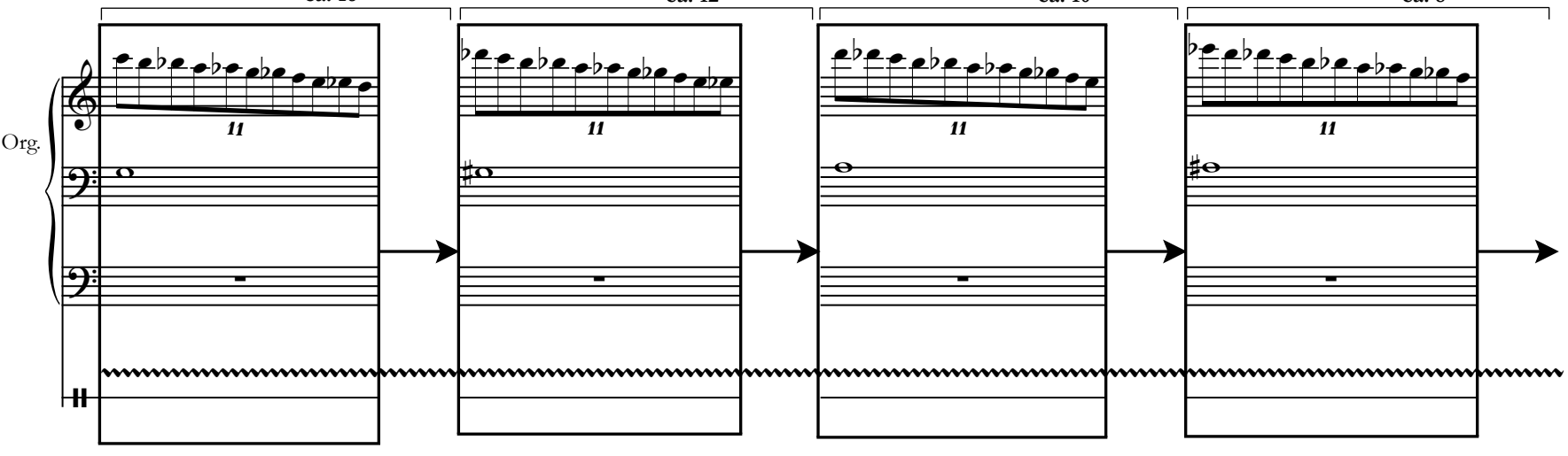

ca. 30"

ca. 20"

ca. $10 "$

ca. 20"

ca. 20"

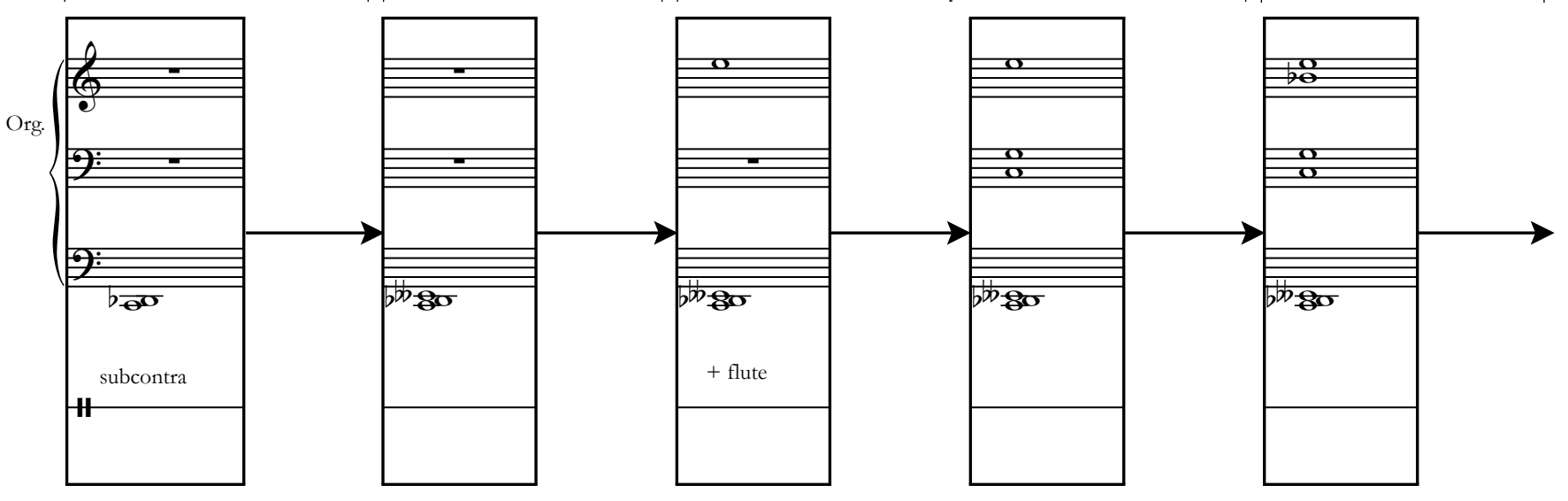

ca. $10 "$

ca. 10"

ca. 10"

ca. 10"

ca. 10"

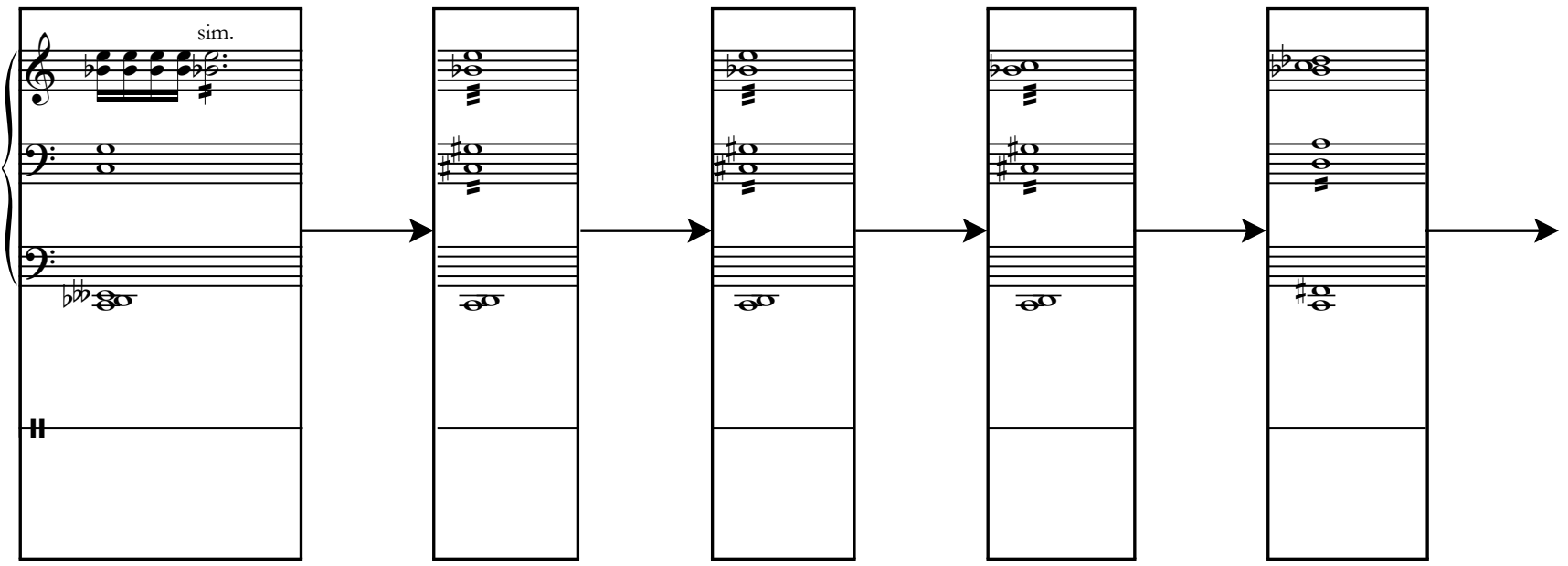




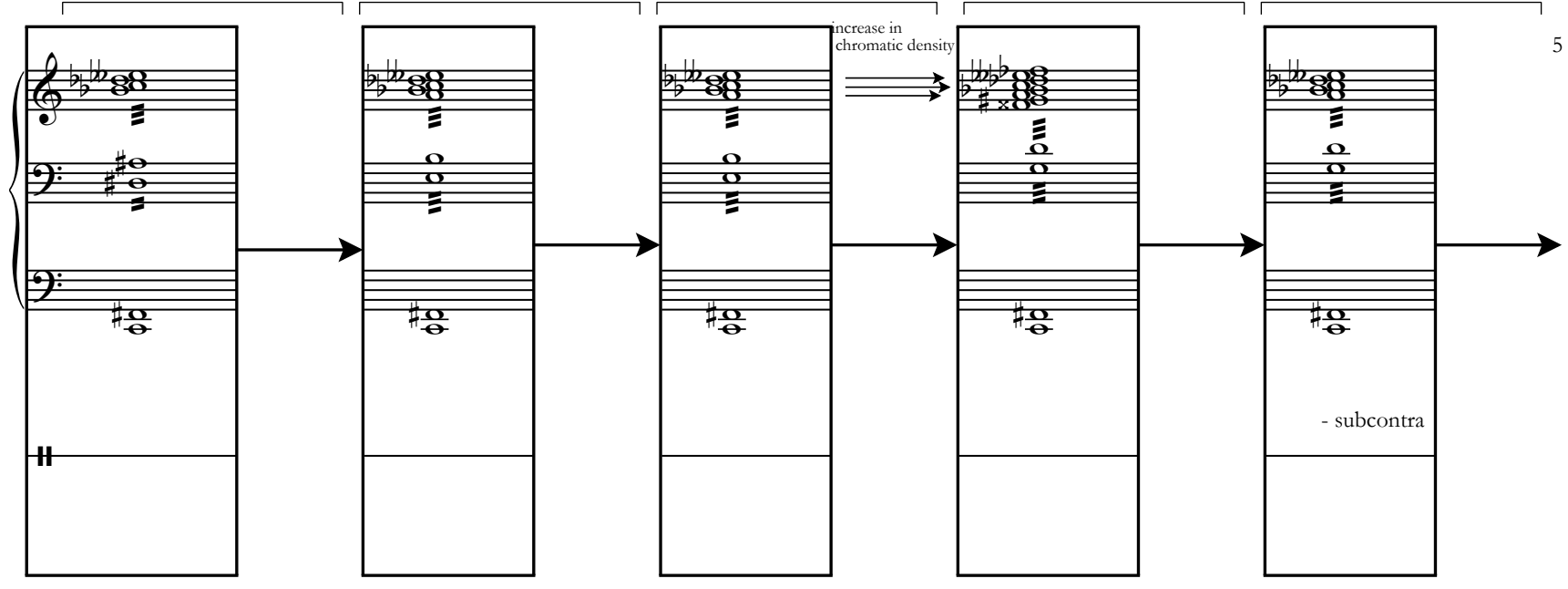

ca. $15 "$

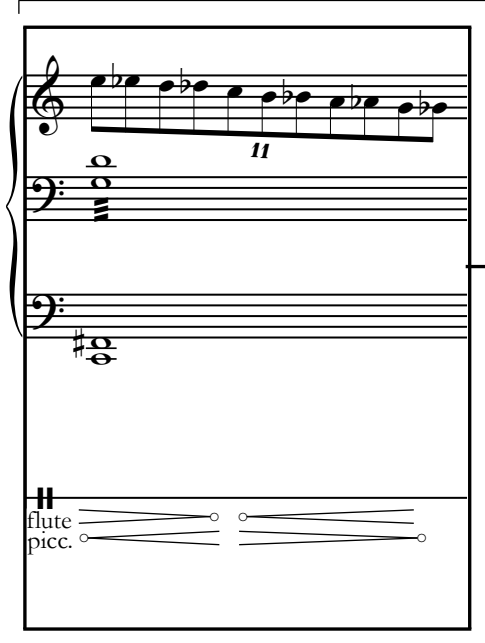

ca. $15 "$

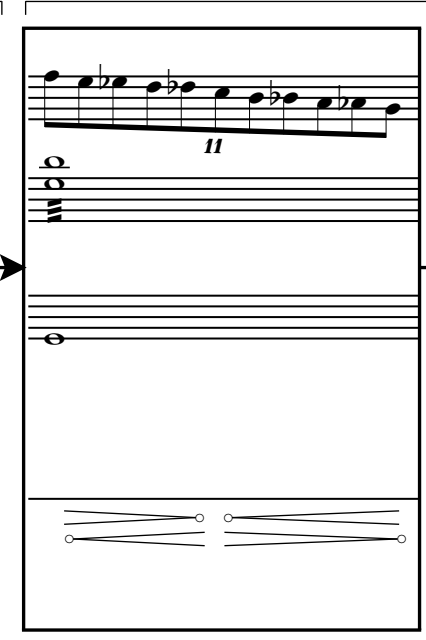

ca. $15^{\prime \prime}$

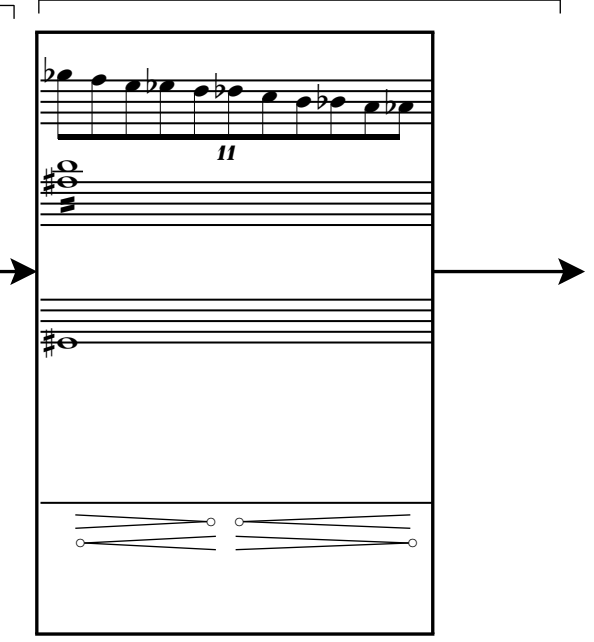

ca. $10 "$

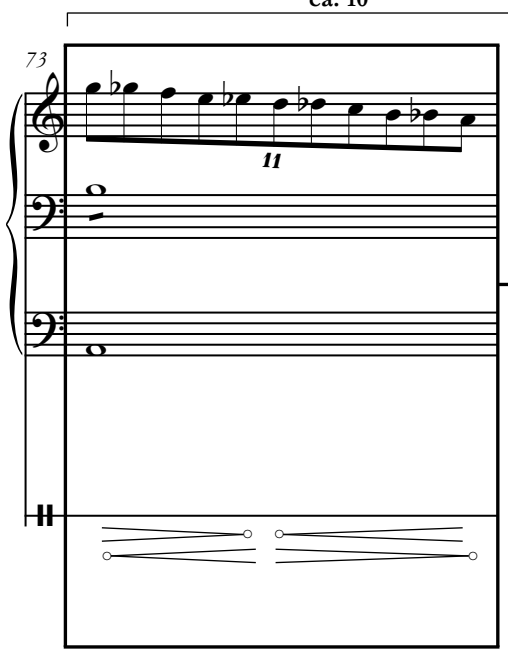

ca. $10^{\prime \prime}$

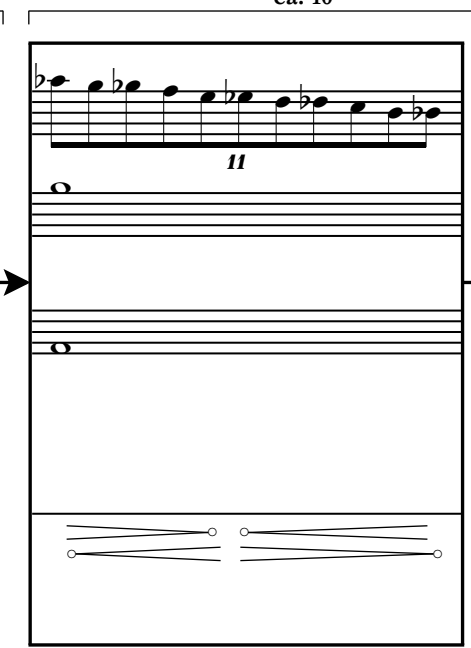

ca. 10"

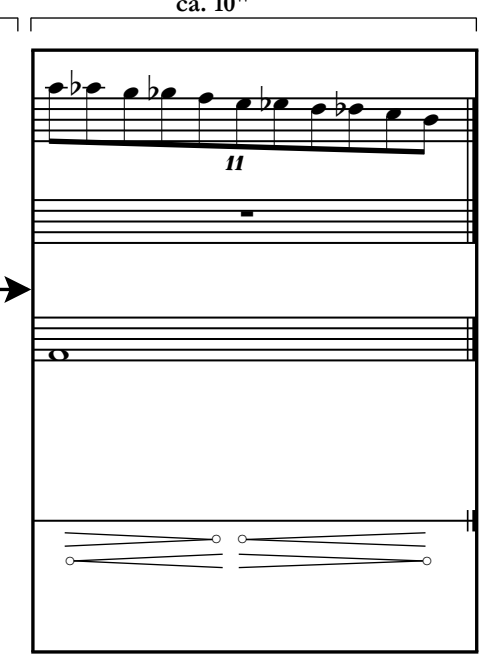




\section{Explanation of the Live Electronics in Ether}

This work consists of a live organ performer and a live electronics patch. While the notated score has elements of aleatoricism and a lot is left to the performer to interpret, the live electronics is substantial and extremely prescriptive. While the acoustic performance will always vary, the electronics treat the material is much the same way in time. This allows for subtle variation that affects the performance in a very direct way.

The live electronics set up of Ether consists of:

Two microphones in a coincident pair to accurately represent a stereo field. This can be set up behind the performing, pointing towards the pipes above.

Audio interface with eight channel capabilities

Computer running MaxMSP, with live electronics patch

Eight loudspeakers in a classic European arrangement

The following diagram demonstrates how the MaxMSP patch functions:

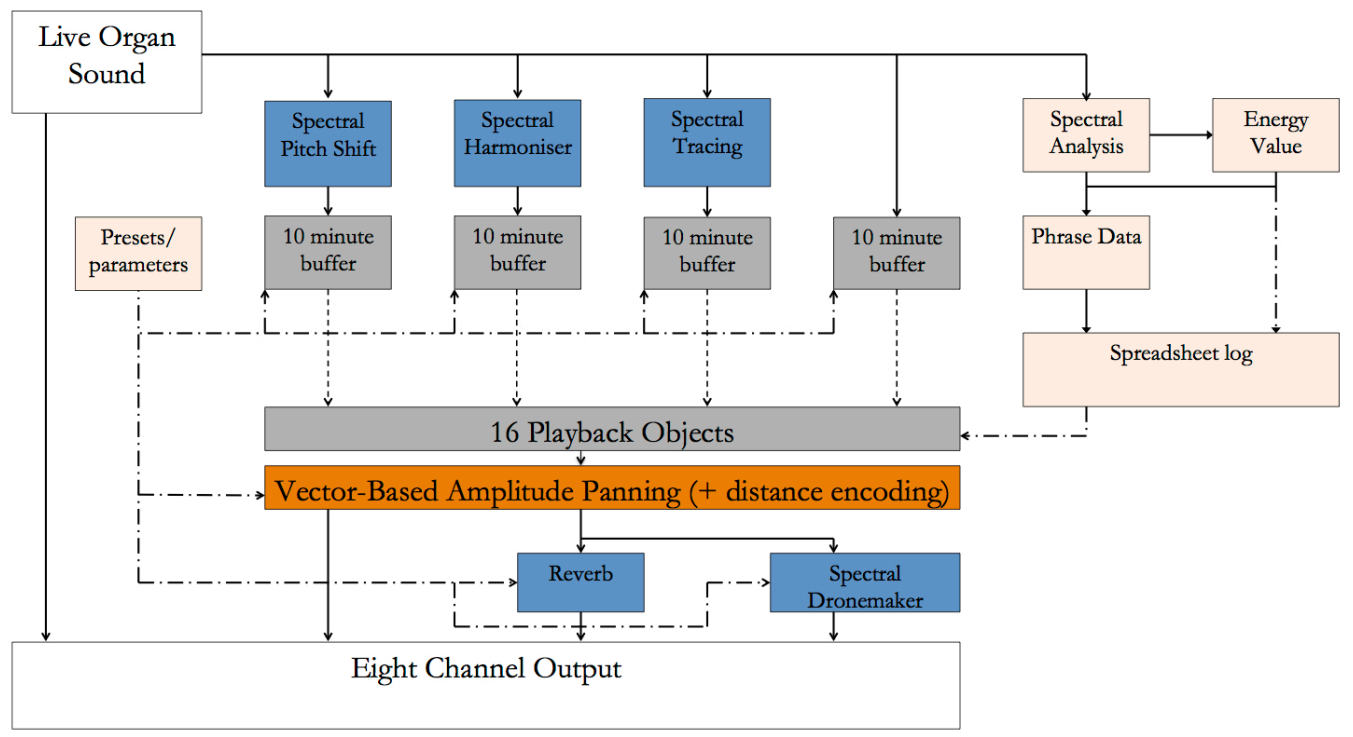


The peach coloured boxes represented data control functions, the blue represents audio processing, grey represents audio storage/playback, orange signifies spatial processing, and the white denotes acoustic sound. The dotted lines refer to the use data to control some other functionality. Michael Norris's Soundmagic Spectral plugins are required to run the patch, along with his 'spreadsheet' object, Karlheinz Essl's RTC object library, and the CICM spatialisation tools library. Soundmagic spectral and the spreadsheet object are available from the composer, while the object libraries can all be found on maxobjects.com

The patch recognizes phrases by analyzing the incoming sound envelope for an attack and release. This information is then stored as points to later reference so the playback objects can locate the correct time codes of the phrases in the audio buffers. Along side the time codes, an energy value is calculated, which acts as a referencing point. As the performer continues to play, these sounds are then referenced through the current energy level of the performer to play and complement the real time playing of phrases.

Presets are defined before the work begins. The live electronics engineer decides how long the work will last for, and variations in spatial processing. The reverb and spectral dronemaker wet/dry mix is also defined at the beginning of the work. From this point, the engineer's role is limited. They only need to make slight adjustments to the overall volume to prevent feedback if it becomes a problem. However this is unlikely considering very little live sound is directly amplified.

The spatialisation uses Vector Based Amplitude Panning (VBAP) to produce a virtual moving acoustic image. The presets are designed so the moving source slowly makes its way around the audience, thus giving the impression of enveloping the audience by extending the spatial presence of the organ itself.

Please note that the recording that accompanies this portfolio is a stereo down mix from the eight-channel version. 